NASA/TP-2005-213467

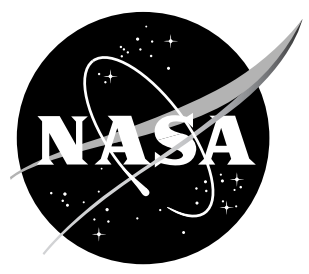

\title{
NASA Heavy Lift Rotorcraft Systems Investigation
}

Wayne Johnson and Gloria K. Yamauchi

Ames Research Center, Moffett Field, California

Michael E. Watts

Langley Research Center, Hampton, Virginia 
Since its founding, NASA has been dedicated to the advancement of aeronautics and space science. The NASA Scientific and Technical Information (STI) Program Office plays a key part in helping NASA maintain this important role.

The NASA STI Program Office is operated by Langley Research Center, the Lead Center for NASA's scientific and technical information. The NASA STI Program Office provides access to the NASA STI Database, the largest collection of aeronautical and space science STI in the world. The Program Office is also NASA's institutional mechanism for disseminating the results of its research and development activities. These results are published by NASA in the NASA STI Report Series, which includes the following report types:

- TECHNICAL PUBLICATION. Reports of completed research or a major significant phase of research that present the results of NASA programs and include extensive data or theoretical analysis. Includes compilations of significant scientific and technical data and information deemed to be of continuing reference value. NASA's counterpart of peer-reviewed formal professional papers but has less stringent limitations on manuscript length and extent of graphic presentations.

- TECHNICAL MEMORANDUM. Scientific and technical findings that are preliminary or of specialized interest, e.g., quick release reports, working papers, and bibliographies that contain minimal annotation. Does not contain extensive analysis.

- CONTRACTOR REPORT. Scientific and technical findings by NASA-sponsored contractors and grantees.
- CONFERENCE PUBLICATION. Collected papers from scientific and technical conferences, symposia, seminars, or other meetings sponsored or cosponsored by NASA.

- SPECIAL PUBLICATION. Scientific, technical, or historical information from NASA programs, projects, and missions, often concerned with subjects having substantial public interest.

- TECHNICAL TRANSLATION. Englishlanguage translations of foreign scientific and technical material pertinent to NASA's mission.

Specialized services that complement the STI Program Office's diverse offerings include creating custom thesauri, building customized databases, organizing and publishing research results ... even providing videos.

For more information about the NASA STI Program Office, see the following:

- Access the NASA STI Program Home Page at http://www.sti.nasa.gov

- E-mail your question via the Internet to help@sti.nasa.gov

- Fax your question to the NASA Access Help Desk at (301) 621-0134

- Telephone the NASA Access Help Desk at (301) 621-0390

- Write to: NASA Access Help Desk NASA Center for AeroSpace Information 7121 Standard Drive Hanover, MD 21076-1320 
NASA/TP-2005-213467

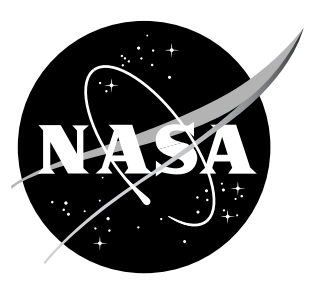

NASA Heavy Lift Rotorcraft Systems Investigation

Wayne Johnson and Gloria K. Yamauchi

Ames Research Center, Moffett Field, California

Michael E. Watts

Langley Research Center, Hampton, Virginia

National Aeronautics and

Space Administration

Ames Research Center

Moffett Field, California 94035-1000 


\section{Acknowledgments}

The NASA Heavy Lift Rotorcraft Systems Investigation was a community effort. The participation by Bell Helicopter, Boeing, and Sikorsky Aircraft is gratefully acknowledged. Contributions by Pennsylvania State University, University of Maryland, and Georgia Institute of Technology are also much appreciated. The individuals who contributed to the investigation are too numerous to list here, but the authors wish to recognize the following dedicated individuals on the government analysis team: C. W. Acree, John Coy, William A. Decker, Robert M. Kufeld, Ethan A. Romander, Johannes M. van Aken (NASA Ames); D. Douglas Boyd, Casey L. Burley (NASA Langley); Preston B. Martin, Richard J. Peyran, John R. Preston, Jeffrey D. Sinsay, Hyeonsoo Yeo (U. S. Army Aeroflightdynamics Directorate); Robert F. Handschuh, T. Kevin O'Brien (U. S. Army-Army Research Laboratory). Finally, the guidance provided by Charles C. Crawford, Troy F. Gaffey, Franklin D. Harris, Robert G. Loewy, and Kenneth M. Rosen during the course of this investigation is very much appreciated.

Available from:

NASA Center for AeroSpace Information 7121 Standard Drive

Hanover, MD 21076-1320

(301) 621-0390
National Technical Information Service 5285 Port Royal Road Springfield, VA 22161

(703) 487-4650 


\section{TABLE OF CONTENTS}

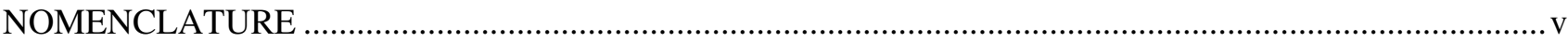

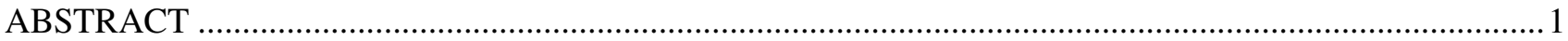

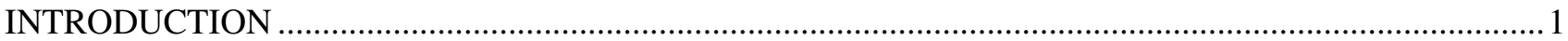

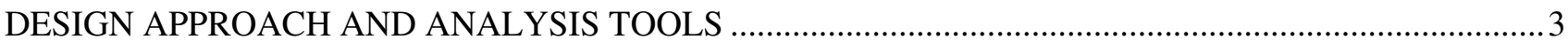

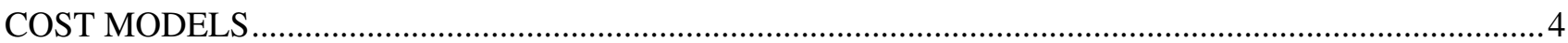

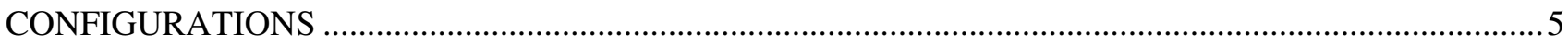

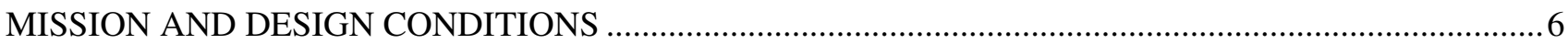

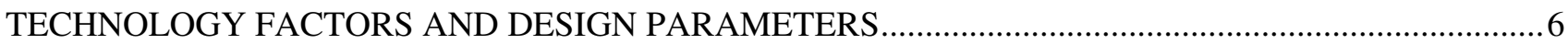

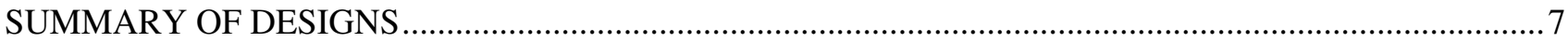

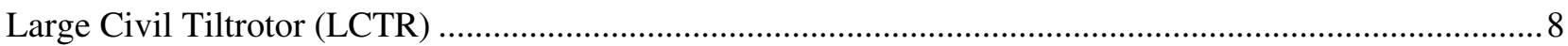

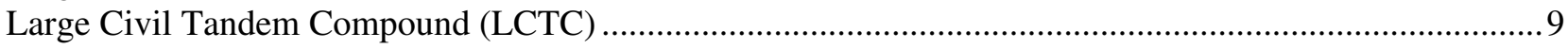

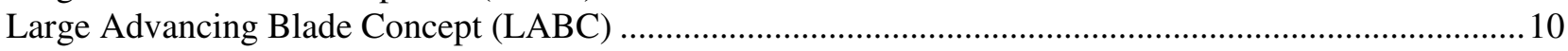

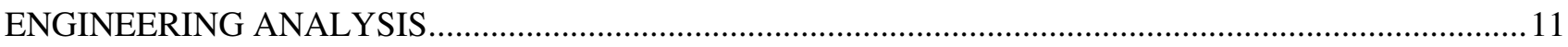

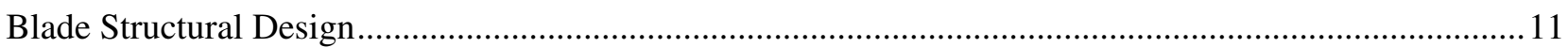

Airframe Structure

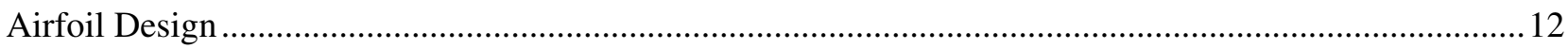

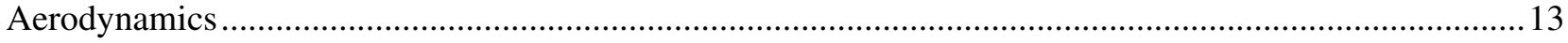

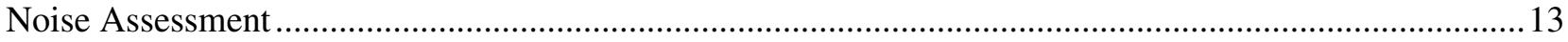

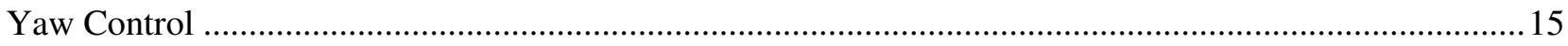

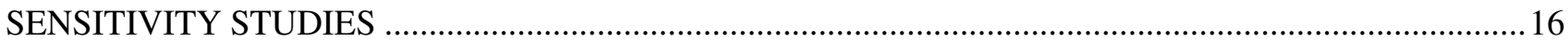

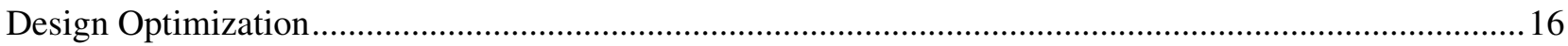

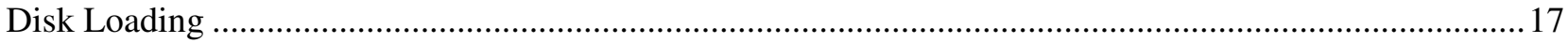

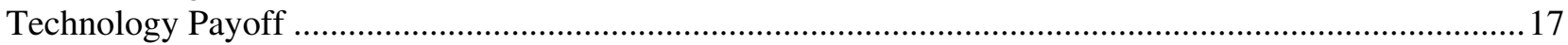

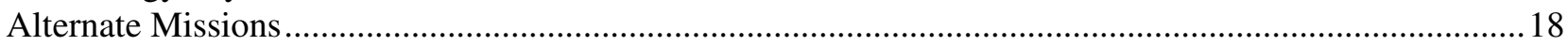

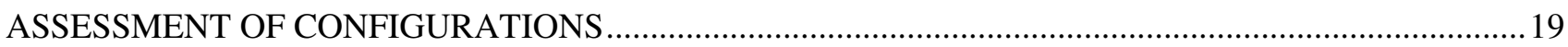

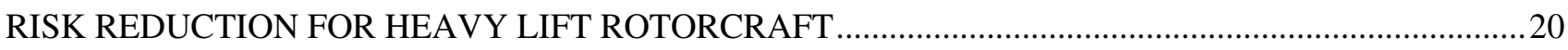

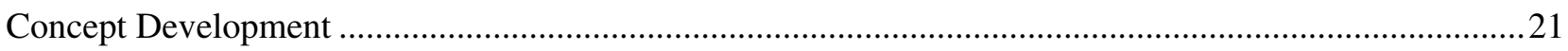

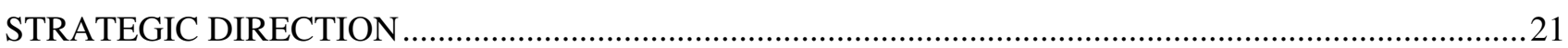

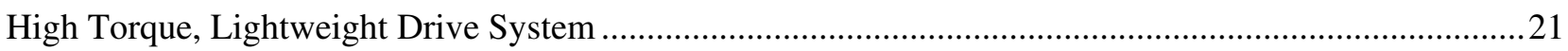

High Performance, Structurally Efficient Rotor/Wing System................................................................22

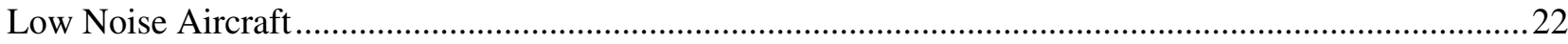

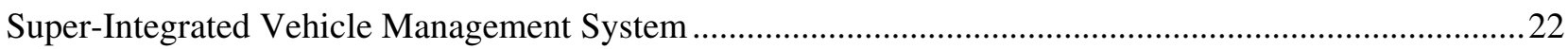

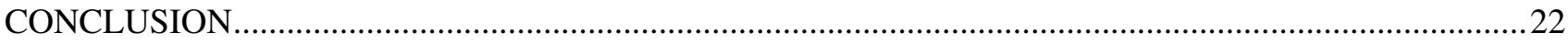

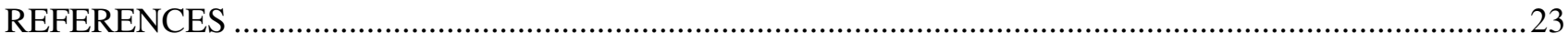

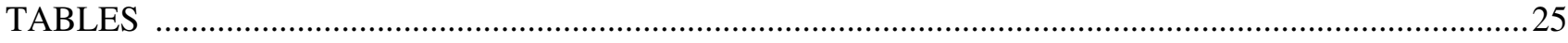

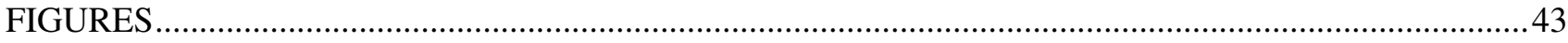

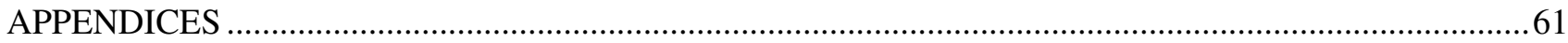




\section{NOMENCLATURE}

A rotor disk area

$\mathrm{c}_{\mathrm{do}} \quad$ mean drag coefficient for profile power

$\mathrm{C}_{\mathrm{T}} \quad$ rotor thrust coefficient, $\mathrm{T} /\left(\rho \mathrm{AV}_{\text {tip }}^{2}\right)$

$\mathrm{C}_{\mathrm{W}} \quad$ rotor weight coefficient, $\mathrm{W} /\left(\rho \mathrm{AV}^{2}{ }_{\text {tip }}\right)$

D/q airframe drag divided by dynamic pressure

L/D aircraft effective lift-to-drag ratio, W/VP (based on cruise power)

$\mathrm{L} / \mathrm{D}_{\mathrm{e}} \quad$ rotor lift-to-drag ratio, $\mathrm{LV} /(\mathrm{P}+\mathrm{VX})$

M Mach number

$\mathrm{M}_{\mathrm{at}} \quad$ advancing tip Mach number

P aircraft power

$\mathrm{R} \quad$ rotor radius

$\mathrm{T} \quad$ rotor thrust

V flight speed

$\mathrm{V}_{\mathrm{br}} \quad$ best range flight speed

$\mathrm{V}_{\text {tip }} \quad$ rotor tip speed

W gross weight

$\mathrm{W}_{\mathrm{E}} \quad$ empty weight

W/A disk loading

$\mathrm{X}$ rotor wind-axis drag force

$\kappa_{\text {ind }} \quad$ induced power factor $\left(\mathrm{P}_{\text {induced }} / \mathrm{P}_{\text {ideal }}\right)$

$\rho \quad$ air density

$\sigma \quad$ rotor solidity (ratio blade area to disk area)

ASM available seat miles

CTOL conventional takeoff and landing

DOC direct operating cost

DOC+I direct operating cost plus interest

ISA international standard atmosphere

LABC Large Advancing Blade Concept

LCTC Large Civil Tandem Compound

LCTR Large Civil Tilt Rotor
MCP maximum continuous power

MRP maximum rated power

OEI one-engine inoperative

RIA runway independent aircraft

SFC specific fuel consumption

SHP shaft power

SLS sea level standard

SOA state of the art

VTOL vertical takeoff and landing 


\title{
NASA HEAVY LIFT ROTORCRAFT SYSTEMS INVESTIGATION
}

\author{
Wayne Johnson, Gloria K. Yamauchi, and Michael E. Watts ${ }^{1}$ \\ Ames Research Center
}

\begin{abstract}
The NASA Heavy Lift Rotorcraft Systems Investigation examined in depth several rotorcraft configurations for large civil transport, designed to meet the technology goals of the NASA Vehicle Systems Program. The investigation identified the Large Civil Tiltrotor as the configuration with the best potential to meet the technology goals. The design presented was economically competitive, with the potential for substantial impact on the air transportation system. The keys to achieving a competitive aircraft were low drag airframe and low disk loading rotors; structural weight reduction, for both airframe and rotors; drive system weight reduction; improved engine efficiency; low maintenance design; and manufacturing cost comparable to fixed-wing aircraft. Risk reduction plans were developed to provide the strategic direction to support a heavy-lift rotorcraft development. The following high risk areas were identified for heavy lift rotorcraft: high torque, lightweight drive system; high performance, structurally efficient rotor/wing system; low noise aircraft; and super-integrated vehicle management system.
\end{abstract}

\section{INTRODUCTION}

The Rotorcraft (RC) Sector was established in January 2004 as one of six vehicle sectors within the Vehicle Systems Program (VSP) of the NASA Aeronautics Research Mission Directorate. The principal aim of the RC Sector is to improve public mobility and access to air transportation. The technology goals of the Sector originated from industry studies and workshops during 2001-2004 that focused on a new class of vehicles known as Runway Independent Aircraft (RIA). References 1-2 showed that RIA can relieve runway and terminal area congestion by replacing small aircraft and short-haul flights that use primary runways. The primary runways would then be used exclusively for larger aircraft and medium/long-haul flights. RIA would operate from stub runways and/or helicopter landing pads. This operational concept would increase the capacity of the air transportation system. The increased capacity could then be used to increase throughput or reduce delay throughout the system. Reference 1 conservatively estimates $10.2 \%$ of flights in 2017 as candidates for RIA. By removing $10 \%$ of the flights from the primary runways, reference 1 projects $79 \%$ less delay in 2017 , roughly equivalent to a cost avoidance of \$181B per year. Alternatively, replacing the removed short-haul flights with medium- and longhaul flights would increase system capacity by 152 billion revenue passenger miles, which translates into added services to the public in addition to substantial revenue for the airlines. Reference 3 describes three RIA configurations analyzed by the rotorcraft industry: the quad tiltrotor (Bell Helicopter), the reverse velocity rotor concept (Sikorsky), and the tiltrotor (Boeing). Figure 1 illustrates these industry concepts. The studies identified the benefits of advanced technology and the resulting effects on operating cost. In summary, references 1-3 provide justification for the overwhelming positive impact that RIA can have on the national air space.

Using the RIA studies as motivation, the RC Sector is focusing on enabling technology for a notional civil VTOL transport capable of carrying 120

\footnotetext{
${ }^{1}$ NASA Langley Research Center, Aero Performing Center Management Office, Hampton, VA 23681-2199.
} 
passengers at a cruise speed of 350 knots at $30,000 \mathrm{ft}$ altitude with a range of $1200 \mathrm{~nm}$ (without refueling). This heavy-lift transport will be "neighborly" quiet when operating near communities, economically competitive with a Boeing 737 aircraft, and will exploit available airspace and ground space (excluding primary runways). Specific 15-year technology goals for the notional transport are shown in table 1. These extreme mission and technology goals were established by the RC Sector to push the state-ofthe-art in rotorcraft technology. For comparison, the Mi-26, the largest helicopter in the world today, has a maximum speed of 160 knots with a service ceiling of approximately 15,000 ft and a range of $435 \mathrm{~nm}$. For each of the technology goals listed in table 1, objectives, technical challenges, and approaches were defined (table 2). The NASA Heavy Lift Rotorcraft Systems Investigation, the focus of this paper, is the first step toward attaining the RC Sector goals.

The objective of the investigation was to select a heavy lift rotorcraft system that has the best chance of meeting the goals of table 1 while being economically competitive. The first four goals of table 1 were given highest priority; table 2 lists the objectives, technical challenges, and approaches for these four goals. The deliverables of the investigation were a candidate configuration for a large civil VTOL transport, and a description of the research and development required for risk reduction. A NASA-led team of rotorcraft technologists analyzed three notional vehicle configurations suggested by the rotorcraft industry: a tiltrotor, a tandem-rotor compound, and an advancing blade concept configuration. These configurations were deemed, as a first cut, to be technically promising. In contrast to the RIA configuration study of reference 3 , the present investigation assessed all the candidate configurations against the same RC Sector mission and technology goals and provided detailed analysis in multiple technology areas. In approximately 12 months, the team performed extensive engineering analysis including aircraft design, performance optimization, blade and rotor aerodynamics, airframe aerodynamics, loads and stability analysis, blade structural design, external noise, one-engine inoperative requirements, handling qualities, and cost drivers. The team was divided into subgroups representing aeromechanics, acoustics, propulsion, structures, handling qualities, and cost. This approach was highly successful in attacking this complex design problem.

Team members included Ames Research Center (primary responsibility for developing concepts), Glenn Research Center (engine and propulsion), and Langley Research Center (acoustics and structures). The Advanced Design Team of the U. S. Army Aeroflightdynamics Directorate assisted with system design. The U. S. Army provided additional assistance in aeromechanics (RDECOM/AFDD), engine and propulsion (ARL), structures and materials (ARL/VTD, AMCOM/AATD). Contracts were established with Bell Helicopter, Boeing, and Sikorsky Aircraft to provide feedback on the NASA designs and risk reduction plans in addition to conducting limited sizing, design, and analysis of some of the concepts being investigated. Bell and Sikorsky prepared expositions on autorotation and one-engine-inoperative requirements for heavy lift. Also under contract were Pennsylvania State University (blade and wing structural design, airfoil design), and University of Maryland and Georgia Institute of Technology (assessments of slowedrotor compound configurations, including reaction drive). An independent review group, comprised of five non-government senior rotorcraft technologists with extensive design experience in the rotorcraft industry, U. S. Army, and academia, provided feedback on the process and content of the investigation.

This paper presents the results of the NASA Heavy Lift Rotorcraft Systems Investigation. It describes the approach used for developing the designs for the tiltrotor, the tandem-rotor compound, and the advancing blade concept configurations. The completed designs are summarized, together with the supporting engineering analyses. Trade studies quantifying the impact of technology and examining alternate missions are also discussed. The configurations are then ranked in terms of ability to meet the Rotorcraft Sector mission and goals. Finally, high risk areas for the selected configuration are identified and plans to mitigate the risks are presented. 


\section{DESIGN APPROACH AND ANALYSIS TOOLS}

The approach taken was to design large VTOL transports that are economically competitive with today's regional jet airliners and meet the RC Sector mission and goals. The principal cost drivers are weight and power. Advances in structural efficiency, aerodynamic efficiency, control concepts, propulsion concepts, dynamics solutions, and prediction capability should allow substantial reductions in empty weight, power, and fuel. Low power is ensured by low rotor disk loading and low aircraft drag. Lightweight at large size requires advanced technology. The heavy lift rotorcraft designs required tasks covering aircraft design, performance optimization, aerodynamics analysis (airfoil, blade, airframe, rotor, aircraft), structural design (airframe, wing, blade), rotor loads and stability analysis, assessment of propulsion, noise, and handling qualities, one-engine inoperative review, and cost estimation. The intent of the investigation team was to perform these analysis tasks in as much detail and as much depth as possible during the 12-month period, in order to inform and support the recommendations for risk reduction activities.

Figure 2 illustrates the design iterations and influences. Design is fundamentally an iterative process, and rotorcraft behavior is inherently multidisciplinary. The simplified representation of the influence of the factors in the right column of the figure reflects the limitations in time and resources of the present work.

The code RC performed the sizing of the rotorcraft, and the comprehensive analysis CAMRAD II was used for performance optimization, and loads and stability calculations. The sizing code incorporated significant weight savings (relative to current technology scaled to large size) as a result of structure, drive train, and engine technology. Cost models were developed and used to estimate the purchase price and direct operating cost of the heavy lift rotorcraft designs. The sizing code was used to perform sensitivity analyses, first to optimize the aircraft (variations including disk loading, tip speed, and number of engines); and then to quantify the influence of advanced technology.

The code RC (ref. 4) was the principal rotorcraft sizing and performance analysis tool for this investigation. $\mathrm{RC}$ was developed by the Advanced Design Team of the U. S. Army Aeroflightdynamics Directorate, RDECOM. Designer inputs to RC include design strategy (engine sizing, rotor sizing, etc.), rotorcraft parameters (drag coefficients, tail volume ratio, etc.), and requirements and constraints (take-off, payload, range, etc.). RC finds the aircraft that satisfies the designer inputs, produces the rotorcraft description, and conducts the performance analysis. Figure 3 illustrates the conceptual design process.

Technology in the sizing code is introduced in terms of technology factors and performance models. Weights (at the group weight level of detail) are estimated from statistical equations. These equations are calibrated to current technology level by comparing with existing aircraft. Technology factors are then applied to represent the impact of advanced technology. In this approach, technology is a change from the statistical equation, attributed to a new configuration or concept, new materials, new design methods, new operating procedures, etc. There are technology factors for blade and hub weight, vibration treatment, drive system weight, and fuselage, wing, and tail weight. Technology also influences performance, in particular, rotor hover and cruise efficiency, hub drag, and the engine weight and performance.

CAMRAD II is an aeromechanical analysis of helicopters and rotorcraft that incorporates a combination of advanced technologies, including multibody dynamics, nonlinear finite elements, and rotorcraft aerodynamics (ref. 5). The trim task finds the equilibrium solution (constant or periodic) for a steady state operating condition, and produces the solution for performance, loads, and vibration. The flutter task linearizes the equations about the trim solution, and produces the stability results. The aerodynamic model includes a wake analysis to calculate the rotor nonuniform induced-velocities, using rigid, prescribed or free wake geometry. CAMRAD II has undergone extensive correlation with performance and loads measurements on 
helicopters, tiltrotors, and other rotorcraft configurations. Complete aeroelastic models were developed for each of the configurations considered in this investigation.

An assessment of engine and drive train technology was made in order to define and substantiate the sizing code models. The engine model represented what could be obtained from (or required of) modern technology engines. Drive train concepts were developed for the heavy lift rotorcraft designs.

Blade structural load calculations were used to design rotor blade sections, and the resulting blade structural and inertial properties were used to repeat the loads and stability calculations. The blade design cycle was repeated as necessary to achieve a stable, low-weight solution. This structural design process required an assessment of advanced materials and application of innovative design and optimization techniques, in order to achieve a low weight at large size. A similar approach was used for the structural design of the wing sections. The resulting wing structural and inertial properties were used to develop NASTRAN finite element models of the airframe. The NASTRAN modes were used in CAMRAD II to calculate stability (particularly tiltrotor whirl flutter), linearized matrices for handling qualities analysis, and vibration.

The handling qualities of the aircraft were assessed, and the results used to guide the choice of configuration parameters for the sizing code. Expositions on autorotation and one-engine inoperative requirements for heavy lift rotorcraft were developed independently by Bell Helicopter and Sikorsky Aircraft, considering requirements and design implications. One-engine inoperative requirements were defined for use in the sizing code.

The rotor performance model in the RC sizing code was calibrated using the performance calculated by CAMRAD II, and the sizing task was repeated. An estimate of the drag of the airframe was used to define the aerodynamic model for the sizing code and the comprehensive analysis. Based on aerodynamic environment calculations from CAMRAD II, rotor blade airfoils were designed using the code MSES (ref. 6). Airfoil decks were constructed for the new airfoils, and used in the performance calculations. The contours of these airfoils were used in the blade structural design. A similar approach was used for aerodynamic design of wing airfoils. The three-dimensional NavierStokes analysis OVERFLOW-D was used to calculate the flow about the tiltrotor proprotor and pylon/nacelle. In addition, low fidelity CFD calculations using the Rot3DC code (ref. 7) were performed for the entire tiltrotor flow field, including cruise drag and hover download calculations.

Making use of the comprehensive analysis model, the aircraft noise was assessed using the CARMA system (ref. 8), and the results were used to guide the choice of configuration parameters for the sizing code. An assessment was made of the relative contributions of aircraft configuration parameters, rotor active control, and flight procedures towards the acoustics goals.

The result of this process was three heavy lift rotorcraft designs supported by substantial in-depth engineering analyses, and guidance and focus for the development of the risk reduction plans.

\section{COST MODELS}

Cost models were developed for VTOL and CTOL aircraft, based on statistical information for current operations. The cost metrics considered were flyaway cost (purchase price, in 2005 U.S. dollars) and direct operating cost plus interest, DOC+I (in 2005 U.S. cents/ASM). The components of DOC $+\mathrm{I}$ were maintenance (airframe, engine, rotor and drive), flight crew, fuel and oil, depreciation, insurance, and finance cost.

A principal source for the cost models was references 9 and 10 and its unpublished extensions. The parametric estimate of flyaway cost was based on data for 120 helicopters and 2 tiltrotors, with the U.S. multi-engine turbine helicopters covering a weight range from the Bell 206LT to the $\mathrm{CH}-53 \mathrm{E}$. The parametric equation gave flyaway cost from empty weight and installed power (\$/lb nearly just a function of $\left.\mathrm{W}_{\mathrm{E}} / \mathrm{P}\right)$, and the number of rotors and 
number of blades. The parametric estimate of maintenance cost was based on civil operations; the result was a function of weight empty and installed power. Flight crew costs were proportional to block hours. Depreciation, insurance, and finance cost were all proportional to flyaway cost.

The CTOL cost model was based on the economics of U. S. airline operations.

In order to compare VTOL and CTOL costs, the two cost models were applied to a Boeing 737-700 at a stage length of 500 miles. For the 737 in the VTOL cost model, the minimum complexity was used (one rotor and one blade), and an installed power trend was used to get an equivalent turboshaft power. Table 3 shows the results for flyaway cost and DOC+I. The costs are substantially higher with the VTOL model. With these results it is possible to establish cost technology factors:

Maintenance tech factor $=0.9 / 9.8=0.092$

Flyaway price tech factor $=48.0 / 83.6=0.57$

Insurance, depreciation, and finance costs are driven by flyaway price. Baseline cost estimates for the heavy lift rotorcraft designs were obtained using the above cost technology factors. A significant part of the differences between VTOL and CTOL costs must be the very different operations that produced the cost data used to develop the models. The remaining differences in cost must be attacked by advanced technology. Note in particular the importance of maintenance costs.

For the same mission, a VTOL aircraft will have higher gross weight and higher installed power than a CTOL aircraft. In addition, there are complexity factors in the VTOL model, including number of rotors and number of blades. Thus there is still a cost of VTOL capability in the cost model, even when the maintenance and flyaway price technology factors are used.

\section{CONFIGURATIONS}

Three aircraft configurations were the primary subject of the Heavy Lift Rotorcraft Systems Investigation:

1) Large Civil Tiltrotor (LCTR)

2) Large Civil Tandem Compound (LCTC)

3) Large Advancing Blade Concept (LABC)

These configurations were selected by industry as the most promising candidates for the civil mission. The conventional two-rotor tiltrotor configuration was considered, since a quad tiltrotor would not present as much of a challenge in terms of rotor size. A low rotor speed was used for the tiltrotor in cruise, to improve the proprotor propulsive efficiency. The LCTC and LABC use edgewise rotors in cruise, hence the rotor rotation must be slowed as the flight speed increases, to keep the advancing tip Mach number reasonable. The LCTC is a slowed-rotor compound: it has a wing and auxiliary propulsion for cruise, so the rotors are operated in an unloaded condition. The LABC uses stiff coaxial main rotors capable of carrying significant roll moment, hence generating lift on the rotor advancing side in forward flight. The LABC requires auxiliary propulsion at high speeds, but has no wing.

The LCTC slowed-rotor compound had shaft-driven tandem main rotors. Single main rotor and coaxial main rotors are alternate configurations. The number and arrangement of the main rotors affects performance through rotor/rotor and rotor/wing interference, and affects the aircraft size because of antitorque and transmission layout issues. An alternative to shaft drive is a reaction drive configuration, typically using jets at the blade tips. The reaction drive is used in hover; in cruise the rotor is operated in autorotation. With reaction drive the transmission weight is greatly reduced, but the rotor cruise performance is compromised by the need for thick blades, and the hover performance is poor because of high energy losses entailed in delivering the air to the blade tips. 
A major objective of the Rotorcraft Sector programs is to examine the potential of active control as an enabling technology for heavy lift, based on weight reduction and/or solution of dynamic or aerodynamic problems. In particular, attention is being given to on-blade control, including trailing edge flaps, leading edge droop, active twist, and active flow control. The present investigations contributed to identifying what problems (loads, vibration, stability, noise, gust response, etc.) must be attacked using active control.

\section{MISSION AND DESIGN CONDITIONS}

Based on the Rotorcraft Sector notional vehicle capabilities and technology goals, a civil mission was defined. This investigation is not intended to specify the market, but rather to identify enabling technology for civil applications of heavy lift rotorcraft. Table 4 describes the mission, and table 5 describes the payload and fuselage. Note in particular the OEI requirement in table 4: at takeoff conditions $\left(5 \mathrm{k} \mathrm{ISA}+20^{\circ} \mathrm{C}\right)$ the contingency power of the remaining engines (133\% OEI MCP) must be greater than $90 \%$ of hover out-of-ground-effect power required (the factor of $90 \%$ accounting for non-zero speed and some altitude loss during the takeoff).

For maximum utilization, the aircraft must have a wide range of capabilities. Although the aircraft were designed to the mission defined in table 4hence with very little hover time-efficient hover and low speed capability is essential to the RIA operational concept. This is reflected in the requirement for essentially OEI hover capability. The resulting designs optimize at balanced cruise and OEI hover power, so the cruise speed of 350 knots can be viewed as a fallout of the OEI requirement. Reasonable downwash and outwash from the rotors hovering in ground effect is required for effective utilization. For example, a disk loading of $20 \mathrm{lb} / \mathrm{ft}^{2}$ would produce an outwash with a peak velocity of over 90 knots. As a result of these considerations, high disk loading aircraft (such as tiltwings) were not among the configurations considered here.
Critical design conditions appropriate for civil heavy lift rotorcraft operations were defined for calculation of performance, loads, and stability. Table 6 summarizes these aeromechanics analysis conditions.

\section{TECHNOLOGY FACTORS AND DESIGN PARAMETERS}

Meeting the technology goals of the NASA Rotorcraft Sector requires high speed, high altitude, and long range for productivity. The heavy lift rotorcraft must have low disk loading for good hover efficiency, and low drag for efficient cruise. The target for improvement in hover efficiency implies a disk loading on the order of W/A $=10$ $\mathrm{lb} / \mathrm{ft}^{2}$. The actual disk loadings of the designs were determined based on minimum aircraft weight, power, and cost. Figure 4 shows historical trends for aircraft drag. For this heavy lift rotorcraft investigation, the target airframe and wing drag was $\mathrm{D} / \mathrm{q}=1.6(\mathrm{~W} / 1000)^{2 / 3}$. This drag level is higher than current turboprop aircraft, although about 35\% lower than is customary in the helicopter industry. Good aerodynamic design practice should be sufficient to achieve the target for airframe drag. Figure 5 shows historical trends for rotor hub drag. For concepts with edgewise rotors in cruise, hub drag must be added to the airframe and wing drag of the aircraft. For this investigation, the target hub drag was $\mathrm{D} / \mathrm{q}=0.4(\mathrm{~W} / 1000)^{2 / 3}$, which is less than half of current hub drag levels. Achieving this hub drag level will require advanced technology, certainly fairings but possibly also active flow control.

The weight technology factors used for the three baseline rotorcraft designs are summarized in table 7. In the RC weight equations, the blade and hub weight technology were actually characterized by the blade flap frequency; the equivalent multiplicative factors are given in table 7 . The baseline technology for the present designs was hingeless rotors. Advanced technology rotors have light blades, hence the actual blade flap frequencies are high. Weight reduction obtained from technology was specified by a reduced equivalent flap frequency in the weight equations, reflecting 
new design concepts for the blades and hub. In these terms, the flap frequency was reduced by a factor of 0.91 relative to current technology, resulting in the multiplicative factors given in table 7 . In addition, the weight equations used had a factor of 1.18 for tiltrotor blades compared to helicopter blades, based on calibration with current technology. The drive system weights for the baseline aircraft were calculated using the technology factor given in table 7 , without any penalty for using a two-speed transmission design.

A scaled engine model was used by the sizing code. The current and advanced engine technology is characterized in table 8. This model and technology were defined for engines with SLS MCP greater than $5000 \mathrm{hp}$.

The definition of the technology level in the sizing code also involves performance and aerodynamics. For the rotor, the design blade loading $\mathrm{C}_{\mathrm{w}} / \sigma$ was prescribed based on an assessment of what advanced technology could provide. Rotor induced power and profile power in the sizing code were calibrated to the results of the comprehensive analysis calculations. Thus the sizing code performance represented a rotor with optimum twist, taper, cruise tip speed, etc. However, current technology airfoils were used in the comprehensive analysis optimization. Some further improvement in aircraft performance can therefore be expected from the use of advanced technology airfoils, especially if specifically designed for these aircraft. Airframe drag was specified as described above. Current technology values were used for hover download. Further improvement in aircraft performance might be obtained from download reduction.

The statistical weight equations used in the sizing code incorporate an influence of size, based on historical trends. For rotorcraft designed for fixed disk loading, tip speed, blade loading (solidity), and number of blades, these equations imply that rotor blade, rotor hub, and drive system weight scale with gross weight to the $1.26,1.39$, and 1.12 powers, respectively. So for an increase in gross weight by a factor of 2.0, the rotor blade, rotor hub, and drive system weight increase by factors of $2.4,2.6$, and 2.2; the aircraft structural and drive system weight therefore increases by about a factor of 2.2. In order to maintain aircraft empty weight fraction as size increases, the design approach must be changed, which conventionally has resulted in an increase in disk loading with size.

Basic parameters of the rotorcraft were chosen for the three heavy lift configurations based on an assessment of current and future technology (table 9). The rotor blade loading $\left(\mathrm{C}_{\mathrm{w}} / \sigma\right.$, based on gross weight and thrust-weighted solidity) was chosen considering low speed maneuverability requirements. The $\mathrm{C}_{\mathrm{w}} / \sigma$ values in table 9 correspond to about an $8 \%$ improvement in maximum lift capability, compared to current technology. A relatively low hover tip speed was used, reflecting the importance of the noise goal. The cruise tip speed was chosen to optimize the performance. To be conservative, hover download values consistent with current technology were used. A low wing loading was chosen, for good low speed maneuverability and wide conversion speed range. The same blade loading and wing loading design values were used for both tiltrotor and slowed-rotor compound configurations.

\section{SUMMARY OF DESIGNS}

The heavy lift rotorcraft designs are summarized in table 10. Three-views of the aircraft are shown in figures 6-8. Recall that for these designs the blade loading, hover tip speed, and wing loading were specified, based on assessments of the technology. Cruise tip speed was optimized based on cruise efficiency. The disk loading was optimized based on aircraft weight, power, and cost. The optimum disk loading produces a balance in power requirements between cruise and OEI hover. Cruise efficiency defines the power available, then the disk loading is chosen that uses that power in hover (a larger rotor would increase the rotor and blade weight, while a smaller rotor would require more power, hence more engine and fuel weight). Table 11 compares the component weights of the three designs. The empty weight fraction is about 65\%. Table 12 summarizes the fixed empty. The fixed weight is comparable to current commercial jet aircraft. Table 13 shows the cruise drag buildup. The drag of the LCTR is comparable to good turboprop 
aerodynamic design. The LCTC adds the drag of the hub (less than current technology levels), and the LABC does not have the drag of the wing. This LABC design was produced by the sizing code using a rotor cruise effective $L / D_{e}$ that was higher than that predicted by the comprehensive analysis.

The aircraft cruise $\mathrm{L} / \mathrm{D}=\mathrm{WV} / \mathrm{P}$ (based on cruise power, including losses, at design gross weight) was the principal efficiency metric. For the mission considered, the LCTR had the best cruise efficiency, hence the smallest design gross weight and the smallest installed power (table 10). Next in efficiency is the LCTC, and after that the LABC.

Figure 9 shows the flyaway cost and DOC+I for the three heavy lift rotorcraft configurations, and figure 10 presents the DOC+I breakdown for the $1200 \mathrm{~nm}$ design mission. These figures include the Boeing 737 costs for comparison. Table 14 gives the parameters used to calculate the cost. The block hours per year value were based on Southwest Airlines operations. The difference in dead time between the VTOL and 737 reflects the difference in operations. For the VTOL costs, the aircraft parameters (empty weight, installed power, number of rotors and number of blades) and the mission parameters (fuel weight, block time and block speed for a specified range) were obtained from the $\mathrm{RC}$ code.

The VTOL cost model is driven by gross weight and power, so the LCTR has the lowest cost, followed by the LCTC and then the LABC. At the design stage length, the LCTR cost is about $20 \%$ higher than that of a current 737. That is the cost of VTOL capability.

\section{Large Civil Tiltrotor (LCTR)}

The configuration of the LCTR is shown in figure 6. The aircraft had two tilting rotors at the wing tips, a low wing, non-tilting engines, and a horizontal tail. A quad tiltrotor (two wings and four rotors) would have smaller rotors, but increased complexity and increased aerodynamic interference. The conventional two-rotor tiltrotor configuration was considered here, which allowed more exploration of the implications of large size on the rotor system design. A low wing was adapted for better structural load paths between wing, airframe, and landing gear. The horizontal tail was sized by trim requirements rather than stability, because the rotors can be used for flight dynamics stabilization as well as control. A vertical tail is not shown (since the rotors can be used for yaw control), but could be added if needed for yaw trim.

Table 15 gives the aircraft characteristics. Performance, loads, and stability calculations were performed for the conditions defined in table 6 . For helicopter mode loads calculations, lateral flapping was trimmed to zero using lateral cyclic. Symmetric trim was used for cruise performance and helicopter mode loads calculations (trim aircraft lift, drag, and pitching moment). For cruise stability calculations, the rotor was trimmed to conditions known to simulate extremes of whirl flutter behavior: the rotor trimmed to zero power; or the rotor trimmed for aircraft drag equilibrium up to maximum power, and then trimmed to constant power.

A hingeless rotor hub was used. To reduce mean blade bending loads, the hub incorporated $6 \mathrm{deg}$ precone and $0.002 \mathrm{R}$ torque offset. For blade stability, the chordwise center of gravity offset was constrained to be no farther than 5\% chord aft of the quarter chord. Excessive coning can significantly reduce hover figure of merit. A tip mass of $1.5 \mathrm{slug}$ was placed on each blade at $95 \% \mathrm{R}$, in order to reduce coning and thereby improve hover performance (an increase in hover figure of merit of about $2 \%$ was produced). Figure 11 shows the calculated blade frequencies, at collective pitch angles representative of helicopter mode and cruise. At helicopter mode tip speeds, the lag frequency was above $2 / \mathrm{rev}$ and the torsion frequency above $12 /$ rev. With these dynamic characteristics, no stability issues were observed, either blade or whirl flutter.

The blade twist and taper were varied to optimize the rotor for hover and cruise performance. The hover condition was $5 \mathrm{k} \mathrm{ISA}+20^{\circ} \mathrm{C}, 650 \mathrm{ft} / \mathrm{sec}$ tip speed, $\mathrm{C}_{\mathrm{T}} / \sigma=0.1557$. The cruise condition was 350 knots, 30k ISA, $350 \mathrm{ft} / \mathrm{sec}$ tip speed, with the rotor thrust trimmed to balance the aircraft drag. The twist distribution had two linear segments, inboard $(0.0 \mathrm{R}$ to $0.5 \mathrm{R})$ and outboard $(0.5 \mathrm{R}$ to $1.0 \mathrm{R})$. The comprehensive analysis did not have a collocation 
point at $0.5 \mathrm{R}$, so a transition from inboard slope to outboard slope was not modelled. The taper model considered was constant thrust-weighted solidity (constant $75 \% \mathrm{R}$ chord). Figure 12 presents the results for twist optimization, showing the typical hover-cruise compromise. The result was an optimum twist of $-32 \mathrm{deg}$ inboard and $-30 \mathrm{deg}$ outboard, and an optimum taper of 0.8 (tip/root chord).

The rotor performance from the sizing code and the comprehensive analysis are compared in table 16. The RC model was adjusted to match the CAMRAD II performance at the design conditions. These results are for current technology rotor airfoils. Figures 13 and 14 show the hover and cruise performance of the main rotor.

\section{Large Civil Tandem Compound (LCTC)}

The configuration of the LCTC is shown in figure 7. The aircraft had two main rotors in tandem configuration, a high wing, pusher propellers for cruise propulsion, and a horizontal tail. The length of the fuselage follows from the specification of the payload, and the disk loading was optimized to balance the cruise and hover power. As a result there was no overlap of the rotors. The horizontal tail was sized by trim requirements rather than stability.

Table 15 gives the aircraft characteristics. Performance, loads, and stability calculations were performed for the conditions defined in table 6 . The comprehensive analysis modelled the auxiliary propulsion as forces applied to the airframe. Rotor/rotor and rotor/wing interference were accounted for using the vortex wake model.

In hover and low speed flight, standard tandem helicopter controls, plus aircraft pitch and roll attitude, could be used to trim this aircraft. At moderate speeds, the pitch angle could be fixed and the propeller thrust trimmed instead. Even at low speeds, the lateral stick would be connected to the ailerons, and the longitudinal stick to the elevator. For the 80 knot load factor sweep (to obtain blade loads), the mean propeller thrust was fixed at the aircraft drag value, and the pilot's controls plus aircraft pitch and roll attitude were used to trim the aircraft (with pilot's collective, longitudinal cyclic, lateral cyclic, and pedal connected to mean rotor collective, differential collective, ailerons, and differential propeller thrust respectively). In addition, flapping was trimmed to zero (for load control) using rotor cyclic pitch; thus there were 10 trim variables for the load factor sweep.

In cruise the aircraft was trimmed using lateral stick to the ailerons, longitudinal stick to the elevator, pedal to differential propeller thrust; plus propeller thrust, and aircraft pitch and roll angles. Front and rear rotor collective pitch angles were set to values optimized for cruise performance (optimized rotor thrust). In addition, rotor flapping was trimmed to zero (for load control) using rotor longitudinal and lateral cyclic; thus there were 10 trim variables for cruise.

A hingeless rotor hub was used. Figure 15 shows the calculated blade frequencies, at a collective pitch angle of $10 \mathrm{deg}$. At helicopter mode tip speeds, the lag frequency was above $6 / \mathrm{rev}$ and the torsion frequency about 7.5/rev. With these dynamic characteristics, no stability issues were observed, either in hover or in high advance ratio forward flight.

The blade twist and taper were varied to optimize the rotor for hover and cruise performance. The hover condition was $5 \mathrm{k}$ ISA $+20^{\circ} \mathrm{C}, 650 \mathrm{ft} / \mathrm{sec}$ tip speed, $\mathrm{C}_{\mathrm{T}} / \sigma=0.1491$. The cruise condition was 350 knots, 30k ISA, $205 \mathrm{ft} / \mathrm{sec}$ tip speed, $138764 \mathrm{lb}$ gross weight. The twist distribution had two linear segments, inboard $(0.0 \mathrm{R}$ to $0.5 \mathrm{R})$ and outboard ( $0.5 \mathrm{R}$ to $1.0 \mathrm{R})$. The taper model considered was constant thrust-weighted solidity (constant $75 \% \mathrm{R}$ chord). Figure 16 presents the results for twist optimization, showing the hover-cruise compromise. For each value of outboard twist, the inboard twist values are $3,0,-3$, and $-6 \mathrm{deg}$. The result was an optimum twist of 0 deg inboard and $-12 \mathrm{deg}$ outboard, with an optimum taper of 0.8 (tip/root chord).

Collective pitch of the front and rear rotors was varied to find the optimum rotor thrust for high speed cruise flight. For an untwisted rotor, the best aircraft performance would be obtained with zero collective (no lift, no induced power, and minimum 
profile power). With negative outboard twist, for improved hover performance, the optimum collective was $-2 \mathrm{deg}$, which resulted in the rotors carrying about $10 \%$ of the aircraft lift (the rotor thrust variation with collective was negative at this high advance ratio). This optimum occurred with a small, positive shaft power to the rotors. With the rotor in autorotation (achieved using an aft tilt of the rotor) the rotor thrust was large, hence the total rotor drag larger and the aircraft L/D somewhat smaller.

The rotor advancing tip Mach number was varied, and the optimum cruise performance was found at $M_{a t}=0.80$ (for the airfoils used). Further reductions in rotor rotational speed did not improve the aircraft L/D.

The rotor performances from the sizing code and from the comprehensive analysis are compared in table 17. The RC model was adjusted to match the CAMRAD II performance at the design conditions. These results are for current technology rotor airfoils. Figures 17 and 18 show respectively the hover performance of the main rotor and the aircraft cruise performance. The rotor performance in cruise is presented in terms of aircraft $\mathrm{L} / \mathrm{D}=\mathrm{WV} / \mathrm{P}$, calculated without accessory or other losses, and using a propeller efficiency of 0.86 (from the sizing code).

\section{Large Advancing Blade Concept (LABC)}

The configuration of the LABC is shown in figure 8 . The aircraft had two main rotors in coaxial configuration, pusher propellers for cruise propulsion, and horizontal and vertical tails for cruise trim. Ducted propellers on stub wings might be a better configuration for the auxiliary propulsion.

Table 15 gives the aircraft characteristics. Performance, loads, and stability calculations were performed for the conditions defined in table 6 . The comprehensive analysis modelled the auxiliary propulsion as forces applied to the airframe. Rotor/rotor interference was accounted for using the vortex wake model.

In hover and low speed flight, standard coaxial helicopter controls, plus aircraft pitch and roll attitude, were used to trim the aircraft. At moderate speeds, the pitch angle was fixed and the propeller thrust trimmed instead. Even at low speeds, the pedal was connected to the rudder, and the longitudinal stick to the elevator. In addition, differential hub moment was trimmed to zero (for load control) using differential cyclic; thus there were 8 trim variables for low speed flight.

In cruise the aircraft was trimmed using lateral stick to rotor lateral cyclic, longitudinal stick to the elevator, pedal to the rudder; plus propeller thrust, and aircraft pitch and roll angles. Lift offset (rotor differential roll moment) was trimmed to a specified value using differential lateral cyclic. Rotor collective pitch angles were set to values optimized for cruise performance (optimized rotor angle of attack). In addition, rotor pitch moment was trimmed to zero (for load control) using rotor longitudinal cyclic; thus there were 9 trim variables for cruise.

A hingeless rotor hub was used. Figure 19 shows the calculated blade frequencies at collective pitch angle of $0 \mathrm{deg}$. At helicopter mode tip speeds, the flap frequency was about $3 / \mathrm{rev}$, the lag frequency about $9 / \mathrm{rev}$, and the torsion frequency above $15 / \mathrm{rev}$. With these dynamic characteristics, no stability issues were observed, either in hover or in high advance ratio forward flight.

The blade twist was varied to optimize the rotor for hover and cruise performance. The hover condition was $5 \mathrm{k} \mathrm{ISA}+20^{\circ} \mathrm{C}, 650 \mathrm{ft} / \mathrm{sec}$ tip speed, $160636 \mathrm{lb}$ gross weight. The cruise condition was 350 knots, 30k ISA, $255 \mathrm{ft} / \mathrm{sec}$ tip speed, $160636 \mathrm{lb}$ gross weight. The twist distribution had two linear segments, inboard ( $0.0 \mathrm{R}$ to $0.5 \mathrm{R})$ and outboard ( $0.5 \mathrm{R}$ to $1.0 \mathrm{R})$. The result was an optimum twist of 0 deg inboard and -10 deg outboard.

Collective pitch of the rotors was varied to find the optimum rotor shaft angle for high speed cruise flight. With the twist used, the optimum collective was $0 \mathrm{deg}$.

Rotor lift offset (differential roll moment) was varied, and the best cruise performance was found for $0.2 \mathrm{R}$ offset (differential roll moment divided by gross weight and rotor radius). The rotor advancing 
tip Mach number was varied. The optimum cruise performance was found at $\mathrm{M}_{\mathrm{at}}=0.85$ (for the airfoils used).

The rotor performance from the sizing code and the comprehensive analysis are compared in table 18 . Figures 20 and 21 show respectively the hover performance of the main rotor and the aircraft cruise performance. These results are for current technology rotor airfoils. The rotor performance in cruise is presented in terms of aircraft $\mathrm{L} / \mathrm{D}=\mathrm{WV} / \mathrm{P}$, calculated without accessory or other losses, and using a propeller efficiency of 0.88 (from the sizing code). For the LABC (unlike the other two designs) the RC model was not adjusted to match the CAMRAD II performance at the design conditions, because in order to obtain a converged design from the sizing code, it was necessary to assume a rotor effective L/D substantially larger than that obtained from the comprehensive analysis. It is anticipated that significant improvements in the calculated L/D can be realized using specially designed airfoils and an optimized planform, thereby making the comprehensive analysis calculations closer to the performance on which the RC design was based.

\section{ENGINEERING ANALYSIS}

\section{Blade Structural Design}

Blade structural designs were developed for the LCTR, LCTC, and LABC rotors. Sections were designed at four radial stations. Composite materials were used for all blades. The material chosen was IM7/8552, because of its high modulus and high strength.

The composite blade section was modelled using Vlasov theory for closed sections. Using the classical laminated plate theory as a basis, Vlasov theory relates beam displacements and rotations to the beam forces, in order to find the section stiffnesses. The plate forces are related to section forces through the principle of virtual work. The plate strains and first order curvatures can be expressed in terms of the blade displacements and rotation through geometric considerations. The result is a relation between generalized section forces and generalized beam displacements and rotations. Thus beam properties can be determined from the laminate properties and the cross-section geometry.

The design procedure started by identifying the design variables: materials, skin and spar thickness (number of plies), web location, and ply orientation. Thickness of the skin and spar were changed by increasing or reducing the number of plies. The ply angle for the spar started at 0 and the ply angle for the skin started at $\pm 45 \mathrm{deg}$. The ply angles of skin and spar were varied to meet the stiffness and strength requirements. The design iteration continued until the blade cross section inertia and stiffness properties were within the targeted range, and the stresses or strains satisfied the failure criteria. Non-structural mass was not used in the section design, but could be added in the comprehensive analysis model.

The comprehensive analysis calculations supplied blade loads at critical flight conditions. For a given radial station, the largest value (positive or negative) of the load over all operating conditions was found for flap and lag bending moments, torsion moment, and axial force. For the structural design it was assumed that these largest individual loads all occurred at the same time. A factor of safety of 1.5 was used. However, blade design details such as the leading edge protection, the trailing edge block, and anti-icing, were not yet accounted for.

The Tsai-Wu strength failure criterion was applied in the strength analysis. This approach did not however address laminate failure modes, such as delamination. Carbon fiber design strains for aircraft structures are typically in the range of 3000-4500 microstrain, because that has been found to provide a conservative design for damaged structural laminates under cyclic loading. Current allowables for IM7/8552 are on the order of 4500 microstrain (compression) and 6000 microstrain (tension), but are typically reduced in practice. Here industry design practice of 3000 microstrain was used for allowable laminate strain.

Figure 22 shows the cross section strain analysis for the LCTR blade. The normal strains across the section were all within 3000 microstrain. Figure 23 
shows the corresponding cross section stress analysis. These results were obtained after 10 iterations between loads calculations, blade structural design, and the aircraft sizing.

This process produced the blade weight given in table 15. The results are somewhat smaller than the total blade weight from the sizing code (table 11), which confirms the technology factors being used (table 7).

\section{Airframe Structure}

Airframe structural models were required in order to assess whirl flutter stability of the tiltrotor, and to assess vibration and handling qualities of all three configurations. The tiltrotor model required a wing aerodynamic and structural design.

A $24 \%$ thick wing airfoil was designed to meet the requirement of low drag at the cruise operating condition (fig. 24). The wing structural design approach was similar to that for the blade structure. The structural design criteria used were (a) 2-g jump takeoff at the design gross weight (primarily for bending); and (b) 2-g symmetrical pullout with 75deg nacelle angle (for torsion). The initial section design was for minimum weight, with no requirements for flutter or frequency placement. The material used was IM7/8552, with the Tsai-Wu strength criteria and a 1.5 factor of safety. A buckling criterion has not yet been applied. Nonstructural weight for fuel tanks and other items was added based on the sizing code weight estimates.

The LCTR configuration had a low wing. The benefits of the low wing were lighter, simpler structure carrying the landing gear loads to the wing; no sponsons needed for the landing gear, hence lower drag; and reduction in download because of the absence of the fountain over the fuselage. The constraints were the requirement for fixed engines and tilting shafts; and the need for hingeless rotors for adequate pitch control. The consequences for the airframe design were lower sweep and larger dihedral than existing tiltrotors, and different design loads for torsion.

The wing design was used with the geometry and weights from the sizing code to develop a
NASTRAN model. At this stage in a design the airframe structural dynamics model must be very simple, but such simple models are adequate to obtain the low frequency modes that are important for whirl flutter and handling qualities.

Figure 25 illustrates the NASTRAN model for the LCTR. The model had 10 wing spar elements, rigid pylons, and 9 fuselage elements. Structural and nonstructural masses were separately modelled. The fuselage model was based on a conventional fixed wing design. Figure 11 showed the uncoupled airframe frequencies. The lowest frequency mode is symmetric wing beam bending, at $2.64 \mathrm{~Hz}$. Symmetric and antisymmetric wing beam bending, chord bending, and torsion, account for the first six modes. The lowest frequency fuselage mode is lateral bending, at $5.64 \mathrm{~Hz}$. For this large transport, the high fuselage inertia and integral center wing structure resulted in several mode pairs (symmetric and antisymmetric) with nearly the same frequencies (less than $0.1 \mathrm{~Hz}$ separation). Note also that traditional tiltrotor frequency criteria are not useful: at the low cruise rpm of the LCTR, the 2-g strength criterion places the lowest wing/nacelle mode above $2 /$ rev.

With these designs for the airframe and the hingeless rotor, the LCTR met the criterion for whirl flutter (table 6). Hence loads, rather than whirl flutter, were the design drivers for both rotor blades and wing. The airframe structural dynamics model used the weights from the sizing code.

Figure 26 illustrates the NASTRAN model for the LCTC: 12 wing spar elements, 11 fuselage elements with rigid pylons and tail. Figure 27 illustrates the NASTRAN model for the LABC: 10 fuselage elements, with rigid pylons and tail. Figures 15 and 19 show the frequencies of the uncoupled airframe modes. These structural dynamic models were used to generate linearized models of the aircraft, in order to assess the handling qualities including the influence of airframe elastic modes.

\section{Airfoil Design}

A multipoint airfoil design approach was developed, and applied to the heavy lift rotorcraft configurations. The comprehensive analysis 
CAMRAD II was used to define the rotor blade section operating conditions (lift coefficient, Mach number, and Reynolds number) for hover, cruise, and maneuver points. The Eppler incompressible airfoil code was used to obtain initial contours, given the airfoil geometric constraints and flow physics issues. Then the MSES transonic airfoil code (Euler solver plus boundary layer analysis, ref. 6) was used with an optimization routine to produce airfoil contours that satisfied the constraints. A basic philosophy of the design approach was to relax pitching moment constraints for individual sections, and instead design for small integrated torsion moment over the entire blade.

Figure 28 shows the airfoils designed for the LCTR blade: inboard, mid-span, and tip sections. The objective was to reduce the section drag relative to current technology airfoils at hover and cruise conditions, while maintaining or increasing maximum lift capability for maneuver conditions. Figure 29 shows the envelope (for variations of twist) of cruise propulsive efficiency and hover figure of merit with the current technology (SOA) and LCTR airfoils. The state-of-the-art curve corresponds to the envelope of figure 12. The airfoils designed specifically for the LCTR produce improvements of about $2 \%$ in cruise and $1 \%$ in hover.

All of the performance calculations from the comprehensive analysis, to which the sizing code performance analysis was calibrated, were performed using current technology airfoils (with Reynolds number corrections implemented in CAMRAD II). Figure 29 therefore illustrates the performance improvements that can be expected by introducing specially designed airfoils.

\section{Aerodynamics}

The Navier-Stokes flow solver OVERFLOW-D was used to analyze the transonic flow about the tiltrotor and spinner in cruise flight, with the objective of optimizing rotor performance and minimizing interference drag. Figure 30 shows the grid system. Overset, body fitted, curvilinear grids were nested inside a series of Cartesian background grids. Approximately 8 million grid points were used (to model one blade and one-quarter of the centerbody, since the axial flow environment is periodic). The collective was varied to trim the rotor to a specified thrust, but bending and torsion deflections of the blade were ignored.

The OVERFLOW-D calculations were used to determine the maximum allowable thickness of the proprotor blades. Structural considerations imply a large thickness ratio, while minimizing compressibility power losses implies small thickness ratio. Using current technology airfoils scaled in thickness, it was determined that a tip thickness ratio of $8 \%$ or less is needed, in order to avoid excessive wave drag. With an $8 \%$ thick tip, a range of root thicknesses from 20 to $26 \%$ gave nearly the same propulsive efficiency.

The LCTR airfoils were designed for maximum performance at the hover and cruise operating conditions. The LCTR tip airfoil is $9.0 \%$ thick. When the LCTR airfoils were used in the OVERFLOW-D calculations, there were no shocks at the tip. However, shocks did form at the root, extending out to $0.14 \mathrm{R}$ with a peak Mach number of 1.10 (fig. 31(a)). This shock corresponded to the point of maximum Mach number on the spinner. Hence the spinner diameter was reduced in the vicinity of the rotor plane, which reduced the peak Mach number to 1.01 (fig. 31(b)). The result was a $2 \%$ improvement in propulsive efficiency.

The ROT3DC Navier-Stokes flow solver was used to calculate the LCTR airframe aerodynamics, in particular the hover download. ROT3DC solves incompressible Navier-Stokes equations on a Cartesian grid, with the rotors modelled by timeaveraged momentum source disks. Figure 32 shows the wing and body pressures from a download calculation for high wing and low wing LCTR configurations. The download with the low wing was about $8 \%$, compared to $10 \%$ for the high wing; half of the reduction comes from the loading on the wing and half from the loading on the fuselage.

\section{Noise Assessment}

The NASA technology goal is to reduce the aircraft noise by $80 \%$, hence a $14 \mathrm{EPNdB}$ reduction below the SOA level. Achieving this goal will require a combination of design for low noise, active control 
for noise source reduction, and flight operational procedures to reduce the noise impact on the community.

An initial acoustic assessment of the heavy lift vehicles was performed. This investigation involved examination of each concept vehicle; identification of potentially important interior and exterior noise sources; assessment of the possible impact of these sources on the community and passengers; assessment of proposed heavy lift concepts using a state-of-the-art prediction capability called the Comprehensive Analytical Rotorcraft Model for Acoustics (CARMA); and development of risk reduction plans to define and prioritize key research efforts required to accomplish the Rotorcraft Sector noise goals.

For noise certification, the Federal Aviation Administration (FAA) specifies a descent condition, a level flight condition, and a take-off condition at which certain maximum noise criteria must be met. Although FAA Noise Certification is not part of the NASA Rotorcraft Sector goals, eventually any commercial heavy lift vehicle will have to meet these requirements. Some of the issues that will arise are associated with the sheer size of the vehicle. To clarify this, consider that the level flight condition for the FAA Noise Certification requires an over-flight at an altitude of $120 \mathrm{~m}$, regardless of the size of the vehicle. Certification of a hypothetical heavy lift vehicle, with rotors twice the size of a conventional vehicle, would be equivalent to requiring a conventional vehicle to be certified at an altitude of $60 \mathrm{~m}$ (i.e., half the altitude). Because of the size difference, spherical spreading alone suggests that the noise would be approximately $6 \mathrm{~dB}$ higher for the heavy lift vehicle.

Another issue is that the heavy lift rotorcraft under consideration are expected to have high levels of noise at low frequencies. The present heavy lift rotorcraft designs have fundamental blade passage frequencies in the range of 9 to $12 \mathrm{~Hz}$. FAA Certification noise limits and the NASA Rotorcraft Sector goals both are cast in terms of the Effective Perceived Noise Level (EPNL) noise metric. The EPNL metric is computed using one-third octave bands, with the lowest band considered having a center frequency of $50 \mathrm{~Hz}$; this lowest band spans frequencies from 45 to $56 \mathrm{~Hz}$. Therefore, any noise below $45 \mathrm{~Hz}$ is ignored by the EPNL metric. These represent difficult issues to resolve and may require the FAA to reassess, and possibly change, certification requirements for heavy lift rotorcraft.

The Rotorcraft Sector community noise goals are based on the EPNL metric and on the microphone locations used in FAA Noise Certification. However, there are two important differences between the FAA Certification noise limits and the Rotorcraft Sector goals. First, the Rotorcraft Sector community noise goal does not require use of the FAA flight profiles; low noise flight profiles can be developed and used. Second, the FAA Certification requirements are based on noise limits at specific microphones, whereas the Sector goals are based on EPNL averaged across microphones and flight conditions. The noise reduction goal can be achieved by any combination of the low noise flight operations and vehicle/rotor/engine design. Since the goal is based on the EPNL metric, only noise in the audible range is considered. The goal metric was chosen prior to knowledge of low frequency noise characteristics of the current heavy lift designs. The current heavy lift rotor designs all have blade passage frequencies below the lower limit of the audible range (which is approximately $20 \mathrm{~Hz}$ ), and much lower than typically found on most helicopters. There are likely to be additional noise issues at these low frequencies that will need to be addressed. In addition, the appropriateness of the NASA goal metrics must be reassessed.

Infrasonic and very low frequency noise can induce vibrations in structures. Community acceptance of noises that rattle windows and dishes tends to be low. This low acceptance will impact the operations of aircraft by airport operators. Low frequency noises at very high levels can also have negative physiological and psychological (psycho-acoustic) effects on humans (refs. 11 and 12). These effects will most likely be transient in nature for communities as vehicles pass nearby. Nonetheless, these effects will have an influence on community acceptance of the vehicles. Psycho-acoustic effects will be more prominent for passengers and crew because of long exposure times; these effects must be quantified further. 
Under the same atmospheric conditions, low frequency noise propagates over longer distances than higher frequency noise because of different rates of atmospheric attenuation for different frequencies. Therefore it is expected that heavy lift vehicles will be heard or felt from much longer distances.

The primary noise prediction tool applied to quantify the external noise during the assessment task has been CARMA (ref. 8). CARMA is a collection of stand-alone analyses that are linked by interface codes that facilitate information transfer. The CARMA system currently accomplishes a sequence of tasks that includes (1) comprehensive analysis of a rotorcraft vehicle, including high resolution analysis of the rotor blade motion and aerodynamics; (2) noise prediction on a hemisphere near the vehicle (excluding atmospheric effects); and (3) propagation of the noise from all hemispheres on a vehicle to distant observers (including atmospheric effects).

CARMA was used to show how a heavy lift rotorcraft can be examined in the context of the FAA Noise Certification requirements and in the context of the NASA Rotorcraft Sector goals. For this sample assessment, three flight conditions are considered: level flight at 63 knots, descent at 80 knots on a 6 deg glide slope, and take-off at 80 knots in a 6 deg climb. Microphones and flightpaths used were as specified in the FAA Noise Certification guidelines. The certification requirement is applied to the maximum level seen at any of the three microphones.

Figure 33(a) shows the LCTR results compared to the FAA Noise Certification requirements. The solid lines are the FAA noise limits. The LCTR level flight noise is higher than the FAA limit, but the descent and take-off conditions are lower than the limits. These calculations were restricted to $1 / 3$ octave bands (predicted tone noise converted to $1 / 3$ octave), and broadband and other noise sources (such as engine and airframe) were not included; and EPNdB effectively filters out information below the $50 \mathrm{~Hz} 1 / 3$-octave band. Figure 33(b) shows the same information as in figure 33(a), but it was processed to match the NASA Rotorcraft Sector goal metrics. The NASA goal metrics are computed by averaging the levels at the three microphones for a given condition, then averaging these three new values directly over the three flight conditions. The NASA Rotorcraft sector goal is to reduce the aircraft noise by $80 \%$, hence a 14 EPNdB reduction below the SOA level. Achieving this community goal will require a combination of design for low noise, active control for noise source reduction, and flight operational procedures.

The infrasonic range is typically defined as sound at frequencies below approximately $20 \mathrm{~Hz}$; this is below the normal human audible range. High levels of infrasonic noise at frequencies of around 8 to 12 $\mathrm{Hz}$ create acoustic resonances in certain human body cavities and can vibrate internal organs. This noise is felt rather than heard until the levels become very high. At levels of approximately 130 $\mathrm{dB}$, the infrasonic noise reaches audible levels and approaches the threshold of pain. To avoid the acoustic range where the noise is felt, energy in frequencies less than approximately $20 \mathrm{~Hz}$ should be avoided. This places a constraint on the rotor design.

This investigation has identified the importance of the effects of low frequency, high amplitude noise on humans and structures. This is a sensitive subject, economically, politically and legally. A lower limit in the design process on the blade passage frequency, at say $20 \mathrm{~Hz}$, may be necessary. The blade passage frequency is $9.3,10.8$, and 11.3 $\mathrm{Hz}$, for the current LCTR, LCTC, and LABC designs respectively (all with a $650 \mathrm{ft} / \mathrm{sec}$ hover tip speed). Increasing the hover tip speed would increase the noise levels, and so probably higher disk loading (smaller rotor diameter) and a larger number of blades will be required. New or revised metrics will likely be required for heavy lift rotorcraft noise assessment and certification. The NASA technology goal will also need to be revised to fully address environmental impact of the noise spectrum for heavy lift rotorcraft.

\section{Yaw Control}

Both the tiltrotor and the tandem compound utilize rotor inplane forces produced by cyclic pitch for low speed yaw control. The designs considered had hingeless rotors. Figure 34 shows the thrust vector 
tilt per degree of rotor cyclic as a function of blade flap frequency from $1 / \mathrm{rev}$ (zero effective hinge offset) to $4 / \mathrm{rev}$. The calculations were performed for a flapping rotor in hover, with a Lock number of 8.0 and solidity of 0.075 . Inflow gradients caused by hub moments, which can substantially change the behavior at low thrust, were also included. With gimballed or low-hinge-offset flapping blades, cyclic control tilts the tip-path plane, which in turn tilts the rotor thrust vector. Differential cyclic control on the two rotors produces opposing inplane hub forces, and hence a yaw moment on the aircraft. With a hingeless rotor, the flapping produced by cyclic pitch is reduced, but inplane hub forces are still produced by cyclic. For 1/rev flap frequency, the response is $1 \mathrm{deg}$ of thrust vector tilt per degree of cyclic (fig. 34), and as the flap frequency increases, the thrust vector tilt per cyclic is reduced. At high thrust (levels required for yaw control), the thrust vector tilt approaches $0.5 \mathrm{deg}$ per degree of cyclic.

Figure 35 shows the hub moment, which for large flap frequency approaches the value of the aerodynamic hub moment produced by cyclic. The variation of hub moment with collective (mean thrust) is a result of the influence of the wake (a lift deficiency function).

Hence yaw moment capability with hingeless rotors is reduced compared to a gimballed or low-hingeoffset articulated rotor, but at most by a factor of 2 . Yaw control requires a corresponding increase in cyclic control authority. With a hingeless rotor however, there is a substantial hub moment associated with this yaw control. A hovering turn might in fact be a critical case for the blade design. For a tiltrotor, introducing nacelle tilt may reduce these hub moments.

\section{SENSITIVITY STUDIES}

\section{Design Optimization}

Table 19 compares the baseline designs for the LCTR, LCTC, and LABC, in terms of the following metrics:

a) aircraft mission gross weight (lb)

b) installed engine power (hp) c) mission fuel (lb)

d) purchase price $(\$ M)$

e) direct operating cost DOC+I (cents/ASM)

The fuel weights in table 11 include the reserves. Sensitivity studies were conducted using the sizing code, to optimize the designs by examining variations in disk loading and number of blades. The influence of hover tip speed and cruise tip speed were also examined, considering in particular the noise requirements.

Figure 36 shows the influence of disk loading and number of blades on the LCTR design. The optimum disk loading is about $10 \mathrm{lb} / \mathrm{ft}^{2}$. Indicated on the figure is the disk loading above which the OEI requirement determines engine size, and below which cruise determines engine size. The optimum disk loading occurs where the OEI and cruise power requirements balance. The sizing code shows the metrics decreasing as the number of blades increases. However, with four blades the blade aspect ratio is already reasonably large, and there is some concern that deicing system weights might reverse the trend with blade number. Figure 37 shows the influence of hover tip speed and number of blades on the LCTR design. These design parameters are expected to be influenced by the noise criteria. Figure 38 shows the influence of the number of engines on the LCTR design. The increase in metrics with 2 or 3 engines reflects the influence of the OEI requirement.

Figure 39 shows the influence of cruise tip speed on the LCTR design. For the 1-speed transmission, the rotor-to-engine speed ratio is fixed, so as cruise tip speed is reduced so is the engine speed, with eventually a significant increase in SFC. This is the conventional approach for tiltrotor design, which leads to an optimum at a cruise tip speed of about $85 \%$ of hover tip speed, as found here. For the 2 -speed transmission results in figure 39 , the engine is operated at optimum speed, regardless of the rotor speed, and it is assumed here that there is no transmission weight or efficiency penalty from the 2-speed capability. Rotor propulsive efficiency increases as the cruise speed is decreased, hence the optimum is at a cruise tip speed of about $350 \mathrm{ft} / \mathrm{sec}$. 
Figure 40 addresses the question of a weight penalty for the 2-speed transmission. The results in figure 40 for no weight penalty are the same as the 2 -speed results in figure 39. Shown in figure 40 are the metrics for a $20 \%$ transmission weight penalty. Figure 40 also shows a break-even drive system weight, established by increasing the transmission weight until the operating cost equaled that for a cruise tip speed of $85 \%$ hover tip speed (the conventional approach). The difference between the two curves for drive system weight in figure 40 is the penalty that can exist with the 2-speed transmission remaining a cost-effective choice.

Figure 41 shows the influence of disk loading and number of blades on the LCTC design. The optimum disk loading is about $15 \mathrm{lb} / \mathrm{ft}^{2}$. As with the LCTR, the optimum disk loading occurs where the OEI and cruise power requirements balance. Figure 42 shows the influence of hover tip speed and number of blades on the LCTC design. These design parameters are expected to be influenced by the noise criteria. Figure 43 shows the influence of the number of engines on the LCTC design.

For the LABC, the sizing code models the rotor performance in terms of the rotor $\mathrm{L} / \mathrm{D}$, which is obtained from the comprehensive analysis calculations of performance. Disk loading for the LABC was therefore determined by iterating between RC and CAMRAD II, not by simply varying disk loading in $\mathrm{RC}$ as for the LCTR and LCTC (figs. 36 and 41).

\section{Disk Loading}

Assuming a balance of OEI and cruise power requirements for the design permits a simple estimate of the disk loading. The engine power available as a function of lapse rate, and the power required for $\mathrm{OEI}$ and cruise are:

$$
\begin{array}{ll}
\text { engine: } & \mathrm{P}=\mathrm{P}_{0} \delta \mathrm{L}(\theta) \\
\text { OEI: } & 1.33\left(\mathrm{~N}_{\mathrm{e}}-1\right) \mathrm{P}_{\mathrm{OEI}}=0.9 \mathrm{P}_{\mathrm{H}} \\
\text { hover: } & \mathrm{P}_{\mathrm{H}}=\mathrm{W}\left(\mathrm{DL} / 2 \rho_{\mathrm{OEI}}\right)^{1 / 2} / \mathrm{M} \\
\text { cruise: } & \mathrm{N}_{\mathrm{e}} \mathrm{P}_{\mathrm{CR}}=\mathrm{WV} / \mathrm{L} / \mathrm{D}
\end{array}
$$

where $\mathrm{M}$ is the aircraft (not isolated rotor) hover figure of merit, and L/D is the aircraft cruise lift-todrag ratio. In these equations, $\delta$ is the pressure ratio, $\theta$ the temperature ratio, $\mathrm{L}$ the engine lapse rate, and $\mathrm{N}_{\mathrm{e}}$ the number of engines. Then

$$
\begin{aligned}
& \mathrm{f}_{\text {eff }}=\mathrm{M} /(\mathrm{L} / \mathrm{D}) \\
& \mathrm{f}_{\text {OEI }}=\left(1.33\left(\mathrm{~N}_{\mathrm{e}}-1\right)\right) /\left(0.9 \mathrm{~N}_{\mathrm{e}}\right)=1.1083 \\
& \mathrm{f}_{\text {eng }}=\left(\delta_{\text {OEI }} \mathrm{L}\left(\theta_{\text {OEI }}\right) /\left(\delta_{\mathrm{CR}} \mathrm{L}\left(\theta_{\mathrm{CR}}\right)\right)=1.3414\right. \\
& \mathrm{W} / \mathrm{A}=2 \rho_{\text {OEI }} \mathrm{V}_{\text {CR }}^{2}\left[\mathrm{f}_{\text {eff }} \mathrm{f}_{\text {OEI }} \mathrm{f}_{\text {eng }}\right]^{2}=2948 \mathrm{f}_{\text {eff }}^{2}
\end{aligned}
$$

with numerical values given for the OEI and cruise conditions considered here. For example, $\mathrm{M}=0.64$ and $\mathrm{L} / \mathrm{D}=11.1$ (LCTR) gives a disk loading of $\mathrm{W} / \mathrm{A}=9.8 \mathrm{lb} / \mathrm{ft}^{2}$.

\section{Technology Payoff}

The impact and payoff of advanced technology were quantified using the sizing code. For this purpose, the technology factors were changed from values representing advanced technology to values representing current technology. The technology factors for weights are given in table 7 , and the engine model is described in table 8. Table 20 and figures 44-46 show the percentage increase (a negative value is good) in the five metrics, caused by removal of various aspects of the advanced technology from the design assumptions. Results are given for the LCTR and LCTC, but not for the LABC because of the level of maturity of the sizing code for that configuration. Figure 44(a) shows the impact of rotor blade and hub weight reduction, and figure 44(b) shows the impact of all structural weight reductions (blade, hub, fuselage, and wing). Individually the hub weight, fuselage weight, and wing weight had small influence; collectively they contribute the significant influence shown in figure 44(b). Figure 44(c) shows the impact drive system weight reduction. Figures 45(a) and 45(b) show the impact of drag reductions, and figure 45(c) shows the impact of all aerodynamics (drag, rotor figure of merit and cruise efficiency, and download). Individually the hover figure of merit, cruise efficiency (propulsive efficiency for LCTR, rotor drag for LCTC), and download had small influence; collectively they contribute the 
significant influence shown in figure 45(c). Figure 46(a) shows the major impact engine technology has on the designs. Increases in vibration treatment weight and acoustic treatment weight were also examined, and found to have a small impact on the metrics.

A conservative design approach, based on past aircraft design experience, would increase the estimated power required (and hence fuel burned) by $25 \%$, and increase the estimated empty weight by $15 \%$, for a fixed payload and performance requirement. The penalty for imposing these weight and power contingencies is shown in figure 46(b). Since the need for large contingencies is attributed to lack of accuracy of current design and analysis tools, figure 46(b) shows the economic payoff possible by improving these tools.

Figure 47 shows the costs for the LCTR with and without the cost technology factors, and figure 48 presents the corresponding DOC+I breakdown. These results emphasize and quantify the importance of controlling the maintenance costs for heavy lift rotorcraft.

\section{Alternate Missions}

The three configurations were also sized for an alternate mission, composed of three $400 \mathrm{~nm}$ segments (takeoff, climb, cruise at 30k, descent, and landing; with one reserve segment), instead of a single $1200 \mathrm{~nm}$ segment. Table 21 compares the aircraft designed for the baseline and alternate mission. The additional climb and descent time in the $3 \times 400$ mission resulted in heavier aircraft carrying more fuel. The relative efficiency of the three configurations remained unchanged.

To explore the influence of the design condition on the comparative performance of the heavy lift rotorcraft configurations, the performance optimization and aircraft sizing were performed for the following alternate design cruise conditions:
a) $30 \mathrm{k} / \mathrm{ISA}$ and 350 knots (baseline)
b) $20 \mathrm{k} / \mathrm{ISA}$ and 350 knots
c) $20 \mathrm{k} / \mathrm{ISA}$ and 250 knots
d) $10 \mathrm{k} / \mathrm{ISA}$ and 250 knots
e) $5 \mathrm{k} / \mathrm{ISA}+20^{\circ} \mathrm{C}$ and 250 knots

Designs were developed for the tiltrotor (LCTR), advancing blade concept (LABC), and slowed rotor compound with tandem main rotors (LCTC). In addition, a slowed rotor compound with a single main rotor was examined, for both shaft drive (LCSC) and reaction drive (LRDC).

The comprehensive analysis was used to optimize the rotor performance. Table 22 shows the aircraft characteristics assumed for the performance optimization, and the results of the optimization for the three primary configurations. All cases used current technology rotor airfoils with Reynolds number corrections for the drag (and stall delay for the tiltrotor). For the slowed-rotor compound configurations, rotor/rotor and rotor/wing interference were included in the comprehensive analysis model (otherwise the tandem and single main rotor configurations would have identical performance). The comprehensive analysis results were used to estimate aircraft $\mathrm{L} / \mathrm{D}=\mathrm{WV} / \mathrm{P}$ as a function of flight speed (fig. 49). The relative efficiency of the configurations was the same for all conditions. For the slowed rotor compound, the rotor/rotor interference resulted in a small reduction in aircraft $\mathrm{L} / \mathrm{D}$ for the tandem configuration compared to the single main rotor. The differences between powered (optimum thrust) and autorotating operation were also examined, with the latter giving slightly worse performance. Also note that the LABC efficiency improves as the altitude decreases (the higher density making it easier for the rotor to generate the required lift), while the efficiency improves as altitude increases for the other configurations (which use the fixed wing for lift in cruise). Significant improvements in the calculated L/D are possible using specially designed airfoils, particularly for the LABC, which will also benefit from further optimization of the planform.

Spreadsheets were developed to produce designs incorporating the comprehensive analysis performance (fig. 49), component weight calculations, and mission analysis. The results are given in tables 23 to 27. For the tiltrotor, advancing blade, and compound configurations respectively, the disk loading was 10,25 , and $15 \mathrm{lb} / \mathrm{ft}^{2}$; the drag was $\mathrm{D} / \mathrm{q} /(\mathrm{W} / 1000)^{2 / 3}=1.5,1.3,1.9$; the thrust-weighted $\mathrm{C}_{\mathrm{w}} / \sigma=0.14, \quad 0.10, \quad 0.14$. The performance calculations shown in figure 49 used a disk loading 
of $20 \mathrm{lb} / \mathrm{ft}^{2}$ for the LABC, but $25 \mathrm{lb} / \mathrm{ft}^{2}$ produced lower weight and cost. For all configurations the hover tip speed was $650 \mathrm{ft} / \mathrm{sec}$; wing loading was 80 $\mathrm{lb} / \mathrm{ft}^{2}$; power turbine efficiency was $83 \%$ (considered a conservative value); body weight was fixed at the values from the baseline designs (table 11); and fuel price for DOC+I calculations was $\$ 5.00 /$ gal. Note that the spreadsheet design process is not as sophisticated as the RC sizing code, so the results in table 23 are slightly different from those in tables 10 and 21.

For the LCTR, the hover figure of merit and cruise propulsive efficiency were set to the values from the comprehensive analysis, for $350 \mathrm{ft} / \mathrm{sec}$ tip speed and optimized twist (from table 22). The wing efficiency was estimated to be 1.00 . The transmission weight fraction was fixed at the value from the baseline design (table 11).

For the $\mathrm{LABC}$, the hover figure of merit and cruise rotor effective L/D were set to the values from the comprehensive analysis, for optimized $\mathrm{M}_{\mathrm{at}}$, collective, twist, and lift offset (table 22). The propeller propulsive efficiency was set to 0.90 . The transmission weight fraction was fixed at the value from the baseline design (table 11).

For the slowed-rotor compounds, the hover figure of merit and rotor drag D/qA were set to the values from the comprehensive analysis, for optimized $\mathrm{M}_{\mathrm{at}}$, collective, and twist (table 22). In addition, the wing induced efficiency and the fraction of weight carried by the wing were set to the values from the comprehensive analysis. The propeller propulsive efficiency was set to 0.90 . It was assumed that $40 \%$ of the tandem transmission weight was the propeller gearbox (which is the same for all the compound configurations); and that the rotor transmission weight for the single main rotor and reaction drive were respectively $67 \%$ and $20 \%$ of the tandem. Thus the transmission weight fraction for the tandem, single rotor, and for reaction drive cases was fixed at respectively $100 \%, 80 \%$, and $50 \%$ of the value from the baseline design (table 11). The reaction drive efficiency used for the hover performance was $50 \%$.

For all of the design operating conditions considered, the tiltrotor configuration had the best cost, efficiency, and productivity (tables 23-27). All of the configurations would benefit from improved airfoils. A detailed analysis of the reaction drive is needed for a more accurate estimate of the weight and power compared to shaft drive systems. A more accurate estimate of the LABC weight and power requires a better analysis of rotor and hub, specially designed airfoils, and further optimization of the planform.

\section{ASSESSMENT OF CONFIGURATIONS}

For the NASA civil mission, the LCTR had the best cruise efficiency, hence the lowest weight and lowest cost. The LCTR is the configuration with the most promise to meet the NASA technology goals.

The LCTC had good cruise efficiency, but less than the tiltrotor, and higher development risk than the tiltrotor. Single main rotor and tandem rotor configurations were comparable in efficiency and risk. Even if reaction drive produced the smallest slowed-rotor compound rotorcraft, the high installed power compromises efficiency, and the reaction drive system has higher noise and substantially increased risk.

The LABC had lower cruise efficiency than the tiltrotor for the NASA civil mission, and higher development risk than the tiltrotor.

The LCTR design presented was economically competitive with comparable fixed wing aircraft, with the potential for substantial impact on the air transportation system. The keys to achieving a competitive aircraft are: low drag airframe and low disk loading rotors; structural weight reduction, for both airframe and rotors; drive system weight reduction; improved engine efficiency; low maintenance design; and manufacturing cost comparable to CTOL aircraft.

Thus the LCTR design demonstrated the potential for achieving the Rotorcraft Sector goals of tables 1 and 2 . With a disk loading of $10 \mathrm{lb} / \mathrm{ft}^{2}$ compared to the state-of-the-art value of $20 \mathrm{lb} / \mathrm{ft}^{2}$, the $40 \%$ increase in hover efficiency was attained. Considering the OEI hover power (power from 3 out 
of 4 engines), the power loading was $\mathrm{W} / \mathrm{P}=6.0$. At the cruise conditions, the aircraft lift-to-drag ratio was $\mathrm{L} / \mathrm{D}=14.5$ (table 16), exceeding the $44 \%$ improvement goal. The airframe drag was estimated to be $\mathrm{D} / \mathrm{q}=1.5 /(\mathrm{W} / 1000)^{2 / 3}$ (table 13). The weight technology factors (table 7) led to about $22 \%$ reduction in gross weight (table 20), from a 30\% reduction in empty weight, which was consistent with the goal of a $25 \%$ reduction in empty weight excluding engines. The design had an empty weight fraction of 0.65 (table 11), or 0.62 excluding engines, so technology countered the growth in empty weight fraction with aircraft size and speed. The calculated noise was 9.3 EPNdB below certification requirements (fig. 33), compared to the goal of $14 \mathrm{EPNdB}$, with active control and flight operations available to obtain the full reduction as well as deal with low frequency noise.

\section{RISK REDUCTION FOR HEAVY LIFT ROTORCRAFT}

The NASA Heavy Lift Rotorcraft Systems Investigation was a focused and coordinated analytical effort to select the best configuration for meeting the Rotorcraft Sector vehicle technology goals. During the course of the investigation, high risk areas were identified. The definition of high risk is one or both of the following: capability or attribute unavailable today, so it is necessary to assume advanced technology will be available in the future in order for the aircraft to achieve the technology goals; or cost prevents the vehicle from being economically competitive, so the payoff of advanced technology is essential to achieving the goals. The following were identified as high risk areas for heavy lift rotorcraft:
a) High torque, lightweight drive system.
b) High performance, structurally efficient rotor/ wing system.
c) Low noise aircraft.
d) Super-integrated vehicle management system.

Plans were then developed to mitigate the above risks. The risk reduction plans provide the strategic direction to support a heavy-lift rotorcraft development.
The risk reduction plans parallel a prototype development program, and feed design solutions at high technology readiness levels (TRL) to the prototype program. Although a prototype is not part of the NASA plan, it serves to provide schedule pull for the required tasks. The risk reduction program elements are technology readiness level benchmarks, program tasks, and strategic direction. Technology readiness level benchmarks are major milestones demonstrating significant increases in TRL, principally by integrated tests of hardware. There are two primary thrusts: early technology leads to advanced technology and supports a possible year 7 prototype; advanced technology leads to a year 10 prototype.

Tasks were identified for each of the four risk areas. The tasks were organized by discipline (propulsion, structures, aeromechanics, acoustics, and handling qualities) although all elements are connected because of the interdisciplinary nature of rotorcraft problems. Detailed task descriptions have been developed, including schedules showing ground test, wind tunnel test, flight test, and decision milestones, together with connections to the TRL benchmarks. The tasks constitute the work required to achieve the TRL benchmarks. The strategic direction provides guidance for selecting highest priority activities, aimed at the highest risk areas of heavy lift rotorcraft development.

The risk reduction plan has the following TRL benchmarks.

a) Full-scale propulsion system ground test: complete transmission and engine arrangement; metrics are weight, cost, and noise.

b) Full-scale structure ground test: rotor blade and hub, airframe components, wing components; metrics are weight, cost, and interior noise.

c) Large-scale rotor system wind tunnel test: dynamically scaled rotor and hub; metrics are performance, loads, vibration, control, and noise.

d) Flight simulation test: including elastic airframe and load control system; metrics are handling qualities, control, and noise. 
e) Noise and control flight test: existing aircraft, with rotor active control and low-noise operations; metrics are noise, vibration, control, handling qualities.

f) Integrated large-scale wind tunnel test: utilize propulsion, structure, rotor systems from earlier benchmarks; metrics are system integration.

\section{Concept Development}

The first year of the risk reduction program is also devoted to further refinement of the rotorcraft concept. Decisions must be made to narrow the focus of the program elements, since parallel research lines cannot be afforded. It is essential to focus the work on areas of high payoff for heavy lift rotorcraft. This concept development should be conducted by several companies, for the selected heavy lift rotorcraft configuration (which for the NASA mission is the LCTR). The first phase would be completed within 12 months. A second phase would be completed in year 5 , for the advanced technology thrust. A number of LCTR configuration features require decisions: the wing (high or low), nacelle (engine tilt or not), tail, and number of engines.

For the propulsion system, it is first necessary to establish what engine technology is available from the engine manufacturer, in particular the possibility for maintaining good SFC over a wide engine rpm range (by design point, or variable geometry, or a multi-speed output shaft gearbox). The required engine development must be defined. Then the transmission requirements can be defined, including the system configuration.

Structural design concepts must be identified for lightweight, heavy lift rotorcraft, specifically for the blade and hub, for the airframe, and for the wing. A blade and hub concept must be identified that first is a solution to the stability issues (whirl flutter for the LCTR), then is a solution for the strength and weight requirements. The requirement for active control of loads must be established, and the approach defined (flight condition limiting, active load control, others). The requirement for control of noise, vibration, gust, and performance must be established, and the control method selected (IBC, or on-blade, or airframe).

Design guidelines for noise must be established (such as minimum blade-passage frequency), based on physiological and psychological effects on human response. Low noise concepts and approaches must be identified (design features, active control, flight operations). Certification and community noise impact requirements must be defined. The requirements and certification approach for handling qualities must be established, including one-engine inoperative.

The technology contributions to reduction of purchase price and maintenance cost must be identified. A public benefit model and reality-based cost model should be developed.

\section{STRATEGIC DIRECTION}

The strategic direction provides guidance for selecting highest priority activities, aimed at the four highest risk areas of heavy lift rotorcraft development. Note that there are some important and difficult tasks that are not high risk, including rotor aerodynamic design and optimization, rotor and wing airfoil design, airframe aerodynamics, and airframe structures.

\section{High Torque, Lightweight Drive System}

Innovative design is required for low drive system weight. Large size implies high torque and high weight fraction, hence drive system weight reduction is essential for an efficient and economical aircraft. The focus must be on design concept, advanced-technology components, and materials.

Low maintenance is required for low operating cost. Low maintenance must be a primary design requirement, even ahead of weight and performance.

High flight speed requires, or at least benefits from, a variable speed propulsion system design. First it is necessary to establish the speed range available 
from advanced engine technology, and to define the engine required for the heavy lift rotorcraft concept.

\section{High Performance, Structurally Efficient Rotor/Wing System}

Innovative rotor and wing design is required, probably with unconventional dynamics. Large size implies high weight fraction, high speed introduces stability issues, and good rotor system performance is essential for an efficient and economical aircraft. The focus must be on integrated rotor/wing performance and dynamic behavior.

Structural efficiency is required for low rotor and hub and wing weight. The focus must be on design concepts for durability and damage tolerance.

Low maintenance is required for low operating cost. Low maintenance must be a primary design requirement, even ahead of weight and performance.

\section{Low Noise Aircraft}

New approaches are required to meet the challenge of low noise. Large size implies low frequency noise and expanded acoustic footprint. An understanding of heavy lift vehicle acoustic phenomena (low frequency and relative distance to community) is required, including psychoacoustics for low frequency. New rotor design guidelines and annoyance metrics must be developed. The focus must be on a combination of rotor design, active control, and flight operations.

\section{Super-Integrated Vehicle Management System}

Broad spectrum active control is required for an effective heavy lift rotorcraft. Large size implies a significant influence of low frequency airframe elastic modes on flight dynamics. Active control is required to achieve the goals of low rotor-induced vibration and noise. Safe operation in one-engine inoperative conditions is essential for civil rotorcraft. Rotor load limiting and active control are needed for full utilization of the structural capability in the rotor and airframe. Hence an expanded integration of the vehicle management system is required: a flight control system for good handling qualities and gust response, active control of vibration and noise, and rotor load limiting and active control. The focus must be on load limiting and system integration.

\section{CONCLUSION}

The NASA Heavy Lift Rotorcraft Systems Investigation examined in depth several rotorcraft configurations for large civil transport, designed to meet the technology goals of the NASA Vehicle Systems Program. Design and analysis tools were applied to define three configurations: Large Civil Tiltrotor (LCTR), Large Civil Tandem Compound (LCTC), and Large Advancing Blade Concept (LABC).

For the NASA civil mission, the Large Civil Tiltrotor had the best cruise efficiency, hence the lowest weight and lowest cost. Thus the LCTR is the configuration with the best potential to meet the NASA technology goals. The design presented was economically competitive, with the potential for substantial impact on the air transportation system. While fixed wing aircraft for this mission exist, the investigation showed only the potential for a high speed, heavy lift rotorcraft. The keys to achieving a competitive aircraft were low drag airframe and low disk loading rotors; structural weight reduction, for both airframe and rotors; drive system weight reduction; improved engine efficiency; low maintenance design; and manufacturing cost comparable to fixed-wing aircraft.

Risk reduction plans were developed to provide the strategic direction to support a heavy-lift rotorcraft development. The following high risk areas were identified for heavy lift rotorcraft: high torque, lightweight drive system; high performance, structurally efficient rotor/wing system; low noise aircraft; and super-integrated vehicle management system. 


\section{REFERENCES}

1. Johnson, J.; Stouffer, V.; Long, D.; and Gribko, J.: Evaluation of the National Throughput Benefits of the Civil Tiltrotor. NASA/CR2001-211055, September 2001.

2. Stouffer, V.; Johnson, J.; and Gribko, J.: Civil Tiltrotor Feasibility Study for the New York and Washington Terminal Areas. NASA/CR-2001-210659, January 2001.

3. Smith, D. E.; Wilkerson, J.; Montoro, G. J.; Coy, J.; and Zuk, J.: Technology Development for Runway Independent Aircraft. Proceedings of the American Helicopter Society 59th Annual Forum, Phoenix, AZ, May 2003.

4. Preston, J.; and Peyran, R.: Linking a SolidModeling Capability with a Conceptual Rotorcraft Sizing Code. American Helicopter Society Vertical Lift Aircraft Design Conference, San Francisco, CA, January 2000.

5. Johnson, W.: Rotorcraft Aeromechanics Applications of a Comprehensive Analysis. HeliJapan 98: AHS International Meeting on Advanced Rotorcraft Technology and Disaster Relief, Gifu, Japan, April 1998.

6. Drela, M.: Newton Solution of Coupled Viscous/Inviscid Multielement Airfoil Flows. AIAA Paper No. 90-1470, 21st Fluid Dynamics, Plasma Dynamics, and Lasers Conference, Seattle, WA, June 1990.

7. Rajagopalan, R. G.: A Procedure for Rotor Performance Flowfield and Interference: A Perspective. AIAA Paper No. 2000-0116, 38th Aerospace Sciences Meeting, Reno, NV, January 2000.

8. Boyd, Jr., D. D.; Burley, C. L.; and Conner, D. A.: Acoustic Predictions of Manned and Unmanned Rotorcraft Using the Comprehensive Analytical Rotorcraft Model for Acoustics (CARMA) Code System. AHS International Specialists' Meeting on Unmanned Rotorcraft Design, Control, and Testing, Chandler, AZ, January 2005.
9. Harris, F. D.; and Scully, M. P.: Rotorcraft Cost Too Much. Journal of the American Helicopter Society, Vol. 43, No. 1, January 1998.

10. Harris, F. D.: An Econonic Model of U.S. Airline Operating Expenses. NASA/CR2005-213476, December 2005.

11. Kryter, K. D: The Effects of Noise on Man. (Second Edition), Academic Press, Inc., New York, NY, 1985.

12. Burns, W.: Noise and Man (Second Edition), J. B. Lippincott Company, 1973. 
TABLE 1. ROTORCRAFT SECTOR CAPABILITY SET AND TECHNOLOGY GOALS.

\begin{tabular}{|ll|}
\hline \multicolumn{2}{|c|}{ ROTORCRAFT NOTIONAL VEHICLE 15-YEAR CAPABILITIES } \\
\hline Payload & 120 passengers \\
Cruise speed & $\mathrm{M}=0.60(350 \mathrm{knots})$ at $30000 \mathrm{ft}$ \\
Cruise altitude & at or above $22000 \mathrm{ft}$ (icing) \\
Range & $1200 \mathrm{~nm}$ \\
\hline \multicolumn{1}{|c|}{ ROTORCRAFT SECTOR 15-YR TECHNOLOGY GOALS } \\
\hline Hover efficiency, W/P & 6 \\
Efficient Cruise, L/D & 12 \\
Empty Weight Fraction & 0.41 (excluding engines) \\
Community Noise & SOA-14 EPNdb \\
Flight Control & Automated single-pilot CAT IIIC SNI for heavy lift \\
Advanced Engine Performance & SFC = SOA*0.9, SHP/W = SOA*1.2 \\
Cabin Noise and Vibration & $77 \mathrm{dBA} \& 0.05 \mathrm{~g}$ \\
\hline
\end{tabular}

TABLE 2. ROTORCRAFT SECTOR GOALS, OBJECTIVES, TECHNICAL CHALLENGES, AND APPROACH.

\begin{tabular}{|c|c|c|c|}
\hline GOALS & OBJECTIVES & TECHNICAL CHALLENGES & APPROACHES \\
\hline $\begin{array}{l}\text { Hover Efficiency } \\
(\mathrm{W} / \mathrm{P}=6, \mathrm{SOA}=4.3)\end{array}$ & $\begin{array}{l}\text { Increase overall hover } \\
\text { efficiency by } 40 \% \text { for large } \\
\text { rotorcraft }\end{array}$ & $\begin{array}{l}\text { Reduce rotor power with } \\
\text { minimal weight impact and } \\
\text { acceptable rotor dynamics }\end{array}$ & $\begin{array}{l}\text { Design large, lightweight } \\
\text { aeroelastically stable rotor } \\
\text { systems }\end{array}$ \\
\hline $\begin{array}{l}\text { Efficient Cruise } \\
(\mathrm{L} / \mathrm{D}=12, \mathrm{SOA}=6.5)\end{array}$ & $\begin{array}{l}\text { Reduce drag by } 44 \% \text { at a } \\
\text { cruise Mach of } 0.60\end{array}$ & $\begin{array}{l}\text { Reduce drag without adversely } \\
\text { affecting performance, noise, and } \\
\text { vibration }\end{array}$ & $\begin{array}{l}\text { Investigate novel rotor } \\
\text { configurations enabling } \\
\text { high-lift and high-speed } \\
\text { cruise w/low noise and } \\
\text { vibration } \\
\text { Optimize airframe } \\
\text { propulsion integration to } \\
\text { reduce interference drag }\end{array}$ \\
\hline $\begin{array}{l}\text { Empty Weight Fraction } \\
\text { (excluding engines, } \\
\mathrm{We} / \mathrm{W}=0.41, \mathrm{SOA}=0.55 \text { ) }\end{array}$ & $\begin{array}{l}\text { Reduce rotor weight by } 25 \% \\
\text { Reduce subsystem by } 25 \% \\
\text { (drive system, high-lift, etc.) } \\
\text { Reduce airframe structural } \\
\text { weight by } 25 \%\end{array}$ & $\begin{array}{l}\text { Reduce rotor weight fraction as } \\
\text { vehicle size doubles } \\
\text { Reduce subsystem empty weight } \\
\text { fraction as vehicle size doubles }\end{array}$ & $\begin{array}{l}\text { Develop lightweight drive } \\
\text { systems and transmission } \\
\text { concepts }\end{array}$ \\
\hline $\begin{array}{l}\text { Reduce Community Noise } \\
(\mathrm{SOA}-14 \mathrm{EPN} \mathrm{dB})\end{array}$ & $\begin{array}{l}\text { Reduce rotorcraft system } \\
\text { noise by } 80 \%\end{array}$ & $\begin{array}{l}\text { Reduce RC systems source noise } \\
\text { without degrading performance } \\
\text { Reduce noise through flight } \\
\text { capabilities and operational } \\
\text { procedures that are safe \& } \\
\text { certifiable with acceptable } \\
\text { community impact }\end{array}$ & $\begin{array}{l}\text { Develop and validate source } \\
\text { noise prediction and } \\
\text { propagation capabilities } \\
\text { Develop and validate system } \\
\text { noise prediction capabilities } \\
\text { Develop and demonstrate } \\
\text { low noise operations and } \\
\text { capabilities with acceptable } \\
\text { handling qualities }\end{array}$ \\
\hline
\end{tabular}


TABLE 3. COMPARISON OF CTOL AND VTOL COST MODEL RESULTS (BOTH FOR BOEING 737 AIRCRAFT).

\begin{tabular}{|lll|}
\hline 737-700 run using & CTOL cost model & VTOL cost model \\
\hline Flyaway Cost, \$ (US1999) & $\$ 48.0 \mathrm{M}$ & $\$ 83.6 \mathrm{M}$ \\
\hline $\begin{array}{l}\text { Total Direct Operating Cost + Interest } \\
\text { (Cents/ASM, US 1999) }\end{array}$ & 6.8 & 18.9 \\
\hline Maintenance & 0.9 & \\
$\quad$ Airframe & 0.6 & 9.8 \\
Engine & 0.3 & 4.9 \\
Rotor \& Drive System & $\mathrm{n} / \mathrm{a}$ & 2.9 \\
Flight Crew Salary \& Expense & 0.9 & 2.0 \\
Fuel \& Oil & 0.9 & 0.9 \\
Depreciation & 2.4 & 0.9 \\
Insurance Cost & 0.2 & 4.1 \\
Finance Cost & 1.6 & 0.3 \\
\hline
\end{tabular}

TABLE 4. CIVIL DESIGN MISSION.

$1200 \mathrm{~nm}$ range, 120 passengers

Cruise at 350 knots and $30000 \mathrm{ft}$ (min $22000 \mathrm{ft}$, for icing)

Design mission

Idle $5 \mathrm{~min}$

Takeoff +1 min Hover OGE $\quad 5 \mathrm{k}$ ISA $+20^{\circ} \mathrm{C}$

[convert]

Climb at V best range (0k ISA to 30k ISA, distance part of range)

Cruise at 350 knots, for $1200 \mathrm{~nm}$ range $30 \mathrm{k}$ ISA

Reserve: $30 \mathrm{~min}+30 \mathrm{~nm}$ at $\mathrm{V}_{\mathrm{br}} \quad$ 30k ISA

Descend at $\mathrm{V}_{\mathrm{br}}$ (no range credit)

[convert]

1 min Hover OGE + Landing 5k ISA $+20^{\circ} \mathrm{C}$

Idle $5 \mathrm{~min}$

Design power

Hover: $95 \%$ MRP, $5 \mathrm{k}$ ISA $+20^{\circ} \mathrm{C}$

Cruise: $100 \%$ MCP, 30k ISA

One engine inoperative (OEI):

at $5 \mathrm{k} \mathrm{ISA}+20^{\circ} \mathrm{C}, 133 \%$ (OEI MCP) greater than $90 \%$ (HOGE $\mathrm{P}_{\text {req }}$ )

at $22 \mathrm{k}$ ISA, (OEI MCP) greater than $\left(\mathrm{P}_{\text {req }}\right.$ at $\left.\mathrm{V}_{\mathrm{br}}\right)$

4 engines 
TABLE 5. PAYLOAD AND FUSELAGE.

Payload: 120 passengers $=26400 \mathrm{lb}$

Passengers: 120 at $220 \mathrm{lb}$ each

$(190+30$ baggage $)$

Flight crew: 2 at $240 \mathrm{lb}$ each

Cabin crew: 3 at $210 \mathrm{lb}$ each

Fuselage size and layout

12 first class $(4 \times 3,38$ in pitch)

pitch)

108 economy class $(6 \times 18,32$ in

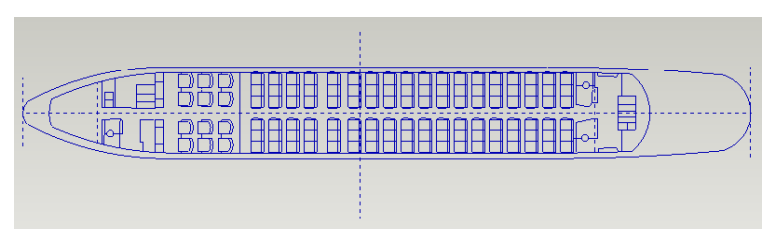

Length $=109.61 \mathrm{ft}$, width $=12.25 \mathrm{ft}$

TABLE 6. CRITICAL DESIGN CONDITIONS FOR AEROMECHANICS ANALYSIS.

Blade stability

Thrust sweep in hover (SLS), to rotor stall

Level flight speed sweep (30k ISA), to maximum power

Aircraft and rotor stability

Up to 350 knots at SLS, 500 knots at 30k ISA

flutter speed $1.2 \mathrm{~V}_{\text {dive }}=1.2\left(1.25 \mathrm{~V}_{\text {cruise }}\right)=1.50 \mathrm{~V}_{\text {cruise }}=525$ knots (FAR)

flutter speed $\mathrm{V}_{\mathrm{L}}=1.15\left(1.2 \mathrm{~V}_{\text {cruise }}\right)=1.38 \mathrm{~V}_{\text {cruise }}=480$ knots $($ MIL-A-8870)

Tiltrotor high speed forward flight

Zero and max power; sea level, 30k; symmetric and antisymmetric modes, with drive train

Ground resonance and air resonance for soft-inplane rotors

Performance

Thrust sweep in hover $\left(5 \mathrm{k} \mathrm{ISA}+20^{\circ} \mathrm{C}\right)$, for power and figure of merit

Speed sweep in high speed forward flight (30k ISA) for power and efficiency

Loads (blade, hub, control), deflection, and vibration

Load factor sweep at 80 knots (SLS), to $1.5 \mathrm{~g}$

Level flight speed sweep $\left(5 \mathrm{k}\right.$ ISA $+20^{\circ} \mathrm{C}$ ), to maximum power

Nacelle angles of 80, $60 \mathrm{deg}$ for tiltrotor

TABLE 7. WEIGHT TECHNOLOGY FACTORS USED FOR AIRCRAFT SIZING.

\begin{tabular}{|l|l|}
\hline Rotor blade weight & 0.79 \\
\hline Rotor hub weight & 0.96 \\
\hline Drive system weight & 0.67 \\
\hline Fuselage weight & 0.88 \\
\hline Wing primary structure weight & 0.88 \\
\hline Empennage weight & 0.90 \\
\hline
\end{tabular}


TABLE 8. ENGINE TECHNOLOGY USED FOR AIRCRAFT SIZING.

\begin{tabular}{|llll|}
\hline & & $\begin{array}{l}\text { Current } \\
\text { technology }\end{array}$ & $\begin{array}{l}\text { Advanced } \\
\text { technology }\end{array}$ \\
\hline SFC (SLS MCP) & lb/shp-hr & 0.4260 & 0.3243 \\
specific power (MCP) & hp/lb/sec & 140.8 & 290.0 \\
power/weight & shp/lb & 6.49 & 7.48 \\
\hline Relative SLS MRP & & & \\
MRP at 5k ISA+20 ${ }^{\circ} \mathrm{C}$ & ratio shp & 0.769 & 0.769 \\
MCP at 30k ISA & ratio $\mathrm{shp}$ & 0.348 & 0.348 \\
Fuel flow at 5k ISA+20 ${ }^{\circ} \mathrm{C}$ & ratio $\mathrm{lb} / \mathrm{hr}$ & 0.781 & 0.781 \\
Fuel flow at 30k ISA & ratio lb/hr & 0.334 & 0.334 \\
\hline
\end{tabular}

TABLE 9. ADVANCED TECHNOLOGY ESTIMATES.

\begin{tabular}{|c|c|c|c|c|}
\hline & & LCTR & LCTC & LABC \\
\hline & & Tiltrotor & $\begin{array}{l}\text { Tandem } \\
\text { compound }\end{array}$ & $\begin{array}{l}\text { Advancing blade } \\
\text { concept }\end{array}$ \\
\hline \multicolumn{5}{|l|}{ Specified } \\
\hline Hover $\mathrm{C}_{\mathrm{w}} / \sigma,\left(5 \mathrm{k}\right.$ ISA $\left.+20^{\circ} \mathrm{C}\right)$ & & 0.141 & 0.141 & 0.100 \\
\hline Hover $\mathrm{C}_{\mathrm{W}} / \sigma,\left(4 \mathrm{k} / 95^{\circ} \mathrm{F}\right)$ & & 0.140 & 0.140 & 0.100 \\
\hline Hover download & & $9.7 \%$ & $5.7 \%$ & $5.5 \%$ \\
\hline Tip speed, hover & $\mathrm{ft} / \mathrm{sec}$ & 650 & 650 & 650 \\
\hline Tip speed, cruise & $\mathrm{ft} / \mathrm{sec}$ & 350 & 205 & 255 \\
\hline Cruise speed, 30k & knots & 350 & 350 & 350 \\
\hline Drag, D/q / (W/1000) & $\mathrm{ft}^{2}$ & 1.5 & 1.9 & 1.3 \\
\hline Wing loading & $\mathrm{lb} / \mathrm{ft}^{2}$ & 80 & 80 & - \\
\hline \multicolumn{5}{|l|}{ Optimum } \\
\hline Disk loading, W/A & $\mathrm{lb} / \mathrm{ft}^{2}$ & 10 & 15 & 25 \\
\hline Maximum $\mathrm{M}_{\mathrm{at}}$ & & 0.70 & 0.80 & 0.85 \\
\hline Cruise tip speed & $\mathrm{ft} / \mathrm{sec}$ & 350 & 205 & 255 \\
\hline
\end{tabular}


TABLE 10. HEAVY LIFT ROTORCRAFT DESIGNS.

\begin{tabular}{|c|c|c|c|}
\hline & LCTR & LCTC & LABC \\
\hline & Tiltrotor & Tandem compound & Advancing blade \\
\hline Mission gross weight (lb) & 123562 & 138764 & 160636 \\
\hline Engines (hp) & $4 \times 6914$ & $4 \times 9684$ & $4 \times 14267$ \\
\hline Rotor diameter (ft) & 88.7 & 76.7 & 90.5 \\
\hline Disk loading W/A (lb/ft $\left.{ }^{2}\right)$ & 10 & 15 & 25 \\
\hline $\mathrm{C}_{\mathrm{w}} / \sigma\left(\right.$ geom, $5 \mathrm{k}$ ISA $\left.+20^{\circ} \mathrm{C}\right)$ & 0.133 & 0.133 & 0.0675 \\
\hline $\mathrm{C}_{\mathrm{w}} / \sigma\left(\mathrm{T}-\mathrm{wt}, 5 \mathrm{k} \mathrm{ISA}+20^{\circ} \mathrm{C}\right)$ & 0.141 & 0.141 & 0.090 \\
\hline Hover tip speed (ft/sec) & 650 & 650 & 650 \\
\hline Cruise tip speed (ft/sec) & 350 & 205 & 255 \\
\hline maximum $\mathrm{M}_{\mathrm{at}}$ & 0.70 & 0.80 & 0.85 \\
\hline Solidity & 0.0881 & 0.1321 & 0.1721 \\
\hline Number blades per rotor & 4 & 4 & 5 \\
\hline chord (75\%R, ft) & 3.06 & 3.98 & 4.89 \\
\hline aspect ratio & 14.5 & 9.6 & 9.2 \\
\hline taper ratio & 0.8 & 0.8 & 0.33 \\
\hline Drag D/q $\left(\mathrm{ft}^{2}\right)$ & 37.3 & 50.3 & 38.1 \\
\hline$(\mathrm{D} / \mathrm{q}) /(\mathrm{W} / 1000)^{2 / 3}$ & 1.5 & 1.9 & 1.3 \\
\hline Wing loading $\left(\mathrm{lb} / \mathrm{ft}^{2}\right)$ & 80 & 80 & - \\
\hline area $\left(\mathrm{ft}^{2}\right)$ & 1545 & 1735 & - \\
\hline $\operatorname{span}(\mathrm{ft})$ & 105 & 144 & - \\
\hline aspect ratio & 7.1 & 12.0 & - \\
\hline Mission, payload & 120 pass & 120 pass & 120 pass \\
\hline range $(\mathrm{nm})$ & 1200 & 1200 & 1200 \\
\hline cruise altitude (ft) & 30000 & 30000 & 30000 \\
\hline cruise speed (kt) & 350 & 350 & 350 \\
\hline Cruise power (hp) & 11904 & 15956 & 25068 \\
\hline Cruise $\mathrm{L} / \mathrm{D}=\mathrm{WV} / \mathrm{P}$ & 11.1 & 9.3 & 6.9 \\
\hline
\end{tabular}


TABLE 11. CONCEPT WEIGHT COMPARISON.

\begin{tabular}{|c|c|c|c|}
\hline & LCTR & LCTC & LABC \\
\hline GROSS WEIGHT & 123562 & 138762 & 160636 \\
\hline Weight empty fraction & $65.3 \%$ & $65.6 \%$ & $64.7 \%$ \\
\hline WEIGHT EMPTY & 80701 & 91079 & 103991 \\
\hline FIXED WEIGHT & 13583 & 13583 & 13583 \\
\hline SCALED WEIGHT & 67119 & 77497 & 90408 \\
\hline Structure & 36104 & 41668 & 47529 \\
\hline Wing Group & 8804 & 11998 & 0 \\
\hline Primary Structure & 5545 & 9206 & 0 \\
\hline Fairings & 1111 & 1442 & 0 \\
\hline Fittings & 1349 & 1349 & 0 \\
\hline Surface Controls & 797 & 0 & 0 \\
\hline Primary Thruster & 13714 & 11494 & 24572 \\
\hline Blades & 6968 & 5863 & 11204 \\
\hline Hub \& Hinge & 6498 & 5631 & 13369 \\
\hline Fairing / Spinner & 248 & 0 & 0 \\
\hline Tail / Aux Thrust & 594 & 2870 & 4135 \\
\hline Body Group & 7072 & 10194 & 11596 \\
\hline Landing Gear Group & 3228 & 3625 & 4197 \\
\hline Nacelle & 2422 & 1091 & 2411 \\
\hline Nacelle (Engine Support) & 495 & 678 & 1055 \\
\hline External Cowling & 296 & 413 & 1355 \\
\hline Pylon Support Structure & 1631 & 0 & 0 \\
\hline Air Induction & 270 & 397 & 617 \\
\hline Propulsion & 18373 & 24928 & 29021 \\
\hline Engine installation & 4540 & 6446 & 9284 \\
\hline Engine & 3698 & 5179 & 7630 \\
\hline Exhaust System & 683 & 956 & 1409 \\
\hline Accessories & 160 & 311 & 245 \\
\hline Fuel System & 556 & 957 & 887 \\
\hline Drive System & 13277 & 17525 & 18850 \\
\hline Gearbox \& Rotor Shaft & 11880 & 16602 & 18397 \\
\hline Gearboxes & 10336 & 14444 & 16340 \\
\hline Rotor Shaft(s) & 1544 & 2158 & 2058 \\
\hline Flight Controls & 4927 & 4628 & 5238 \\
\hline Rotary Wing Controls & 1211 & 3242 & 3805 \\
\hline Non-Boosted & 144 & 234 & 215 \\
\hline Boost Mechanism & 452 & 398 & 478 \\
\hline Boosted & 614 & 2609 & 3112 \\
\hline Other Scaled Weight & 7716 & 6273 & 8621 \\
\hline USEFUL LOAD & 42860 & 47684 & 56645 \\
\hline Crew & 1110 & 1110 & 1110 \\
\hline Fixed Useful Load & 100 & 100 & 100 \\
\hline Fluids & 240 & 240 & 240 \\
\hline Fuel & 15010 & 19834 & 28795 \\
\hline
\end{tabular}


TABLE 12. FIXED EMPTY WEIGHT SUMMARY (SAME FOR ALL CONFIGURATIONS).

\begin{tabular}{|c|c|c|c|}
\hline FIXED WEIGHT & 13583 & & \\
\hline $\begin{array}{l}\text { Flight Controls } \\
\text { Cockpit Controls } \\
\text { Electronics and Sensors }\end{array}$ & & 210 & $\begin{array}{r}75 \\
135\end{array}$ \\
\hline $\begin{array}{l}\text { Equipment } \\
\text { Aux Power Unit (APU) } \\
\text { Instruments } \\
\text { Utility Hyd \& Pneumatics } \\
\text { Electrical System } \\
\text { Avionics (MEP) } \\
\text { Furnishings \& Equipment } \\
\text { Air Conditioning } \\
\text { Ice Protection (fixed) } \\
\text { Aircraft Handling } \\
\text { Load Handling } \\
\end{array}$ & & 13373 & $\begin{array}{r}600 \\
150 \\
150 \\
1500 \\
800 \\
8,588 \\
1,200 \\
100 \\
100 \\
185 \\
\end{array}$ \\
\hline Furnishings \& Equipment & 8588 & & \\
\hline $\begin{array}{l}\text { Seats (crew and passenger) } \\
\text { Galleys } \\
\text { Lavatory (3) } \\
\text { Floor Covering } \\
\text { Panels, Doors, Partitions } \\
\text { Emergency Equipment } \\
\quad \text { Portable Oxygen } \\
\text { Fire Extinguishers } \\
\text { Escape Provisions }\end{array}$ & & $\begin{array}{r}2656 \\
515 \\
495 \\
375 \\
3872 \\
674\end{array}$ & $\begin{array}{l}174 \\
375 \\
125\end{array}$ \\
\hline
\end{tabular}


TABLE 13. CRUISE DRAG BUILDUP.

\begin{tabular}{|lccc|}
\hline & LCTR & LCTC & LABC \\
\hline Wing D/q & 14.10 & 15.84 & - \\
area & 1545 & 1735 & \\
$\mathrm{C}_{\mathrm{D}}$ & .0091 & .0091 & 12.38 \\
Body D/q & 11.88 & 12.42 & 4290 \\
$\mathrm{~S}_{\text {wet }}$ & 3650 & 3650 & .0021 \\
$\mathrm{C}_{\mathrm{f}}$ & .0021 & .0021 & 3.50 \\
interference & 4.32 & 4.86 & 1.37 \\
Horizontal Tail D/q & 1.33 & 1.91 & 186 \\
area & 180 & 217 & 1.33 \\
Vertical Tail D/q & & 9.39 & 9.45 \\
Pylon D/q & 10.02 & 10.72 & 13.45 \\
Hub D/q & & 0.40 & 0.45 \\
\hline hub D/q / (W/1000) & & 50.28 & 38.06 \\
\hline Total D/q & 37.33 & 1.88 & 1.29 \\
D/q / (W/1000) & 1.50 & 138764 & 160636 \\
\hline Gross Weight & 123562 & $5.7 \%$ & $5.5 \%$ \\
Hover Download (\%T) & $9.7 \%$ & & \\
\hline
\end{tabular}

TABLE 14. COST PARAMETERS.

\begin{tabular}{|llll|}
\hline & & VTOL & CTOL (B737) \\
\hline Block hour per year & hr & 3750 & 3750 \\
Non-flight time per trip & min & 12 & 45 \\
Flight speed & knots & 350 & 460 \\
Number of seats & & 120 & 137 \\
Fuel price & \$/gal & 5.00 & 5.00 \\
\hline
\end{tabular}


TABLE 15. HEAVY LIFT ROTORCRAFT CHARACTERISTICS.

\begin{tabular}{|c|c|c|c|}
\hline & LCTR & LCTC & LABC \\
\hline Design gross weight (lb) & 123562 & 138764 & 160636 \\
\hline Total cruise drag, D/q $\left(\mathrm{ft}^{2}\right)$ & 37.3 & 50.3 & 38.1 \\
\hline Disk loading, W/A (lb/ft $\left.{ }^{2}\right)$ & 10 & 15 & 25 \\
\hline Hover $\mathrm{C}_{\mathrm{w}} / \sigma\left(\mathrm{T}-\mathrm{wt}, 5 \mathrm{k}\right.$ ISA $\left.+20^{\circ} \mathrm{C}\right)$ & 0.141 & 0.141 & 0.090 \\
\hline Hover download & $9.7 \%$ & $5.7 \%$ & $5.5 \%$ \\
\hline Rotor radius ( $\mathrm{ft}$ ) & 44.35 & 38.37 & 45.22 \\
\hline Number of blades per rotor & 4 & 4 & 5 \\
\hline Solidity (thrust weighted) & 0.0881 & 0.1321 & 0.1721 \\
\hline Chord $(75 \% \mathrm{R} \mathrm{ft})$ & 3.07 & 3.98 & 4.89 \\
\hline Maximum $\mathrm{M}_{\mathrm{at}}$ & 0.70 & 0.80 & 0.85 \\
\hline Tip speed (ft/sec), hover & 650 & 650 & 650 \\
\hline Tip speed (ft/sec), cruise & 350 & 205 & 255 \\
\hline Rotor speed (rpm), hover & 140 & 162 & 137 \\
\hline Rotor speed (rpm), cruise & 75 & 51 & 54 \\
\hline Blade taper & 0.8 & 0.8 & 0.333 \\
\hline Blade twist (deg), inboard of $50 \% \mathrm{R}$ & -32 & 0 & 0 \\
\hline Blade twist (deg), outboard of $50 \% \mathrm{R}$ & -30 & -12 & -10 \\
\hline Lock number & 12.1 & 13.0 & 19.1 \\
\hline Single blade weight (lb), from blade structural design & 745 & 646 & 1080 \\
\hline Total blade weight $(\mathrm{lb})$, all rotors & 5960 & 5168 & 10800 \\
\hline Data source and identification & & & \\
\hline Size, airframe aerodynamics: from RC code & $5 / 13 / 05$ & $4 / 22 / 05$ & $5 / 12 / 05$ \\
\hline Blade stiffness, inertia: from structural design & $6 / 17 / 05$ & $5 / 13 / 05$ & $7 / 18 / 05$ \\
\hline Airframe structural dynamics: from NASTRAN model & $5 / 05$ & $5 / 05$ & $5 / 05$ \\
\hline Rotor airfoils & \multicolumn{3}{|c|}{$\begin{array}{l}\text { Current technology airfoils, with Reynolds } \\
\text { number correction of drag, and with stall } \\
\text { delay for LCTR }\end{array}$} \\
\hline
\end{tabular}


TABLE 16. COMPARISON OF LCTR ROTOR PERFORMANCE FROM RC (SIZING) AND CAMRADII (COMPREHENSIVE ANALYSIS).

\begin{tabular}{|c|c|c|c|c|}
\hline & \multicolumn{2}{|c|}{$\begin{array}{l}\text { HOVER } \\
5 \mathrm{k} \text { ISA }+20^{\circ} \mathrm{C}, 650 \mathrm{ft} / \mathrm{sec}\end{array}$} & \multicolumn{2}{|c|}{$\begin{array}{l}\text { CRUISE } \\
350 \text { knots, } 30 \mathrm{k} \text { ISA, } 350 \mathrm{ft} / \mathrm{sec} \\
\mathrm{V} / \mathrm{V}_{\text {tip }}=1.688, \mathrm{M}_{\mathrm{at}}=0.70\end{array}$} \\
\hline & $\mathrm{RC}$ & CAMRADII & $\mathrm{RC}$ & CAMRADII \\
\hline Thrust & 136836 & 136751 & 8531 & 8538 \\
\hline $\mathrm{C}_{\mathrm{T}} / \sigma$ & 0.1557 & 0.1556 & 0.0720 & 0.0720 \\
\hline Power & 17061 & 17155 & 11283 & 11296 \\
\hline Parasite power & & & 9163 & 9170 \\
\hline Induced power & 15879 & 15967 & 248 & 256 \\
\hline Profile power & 1182 & 1186 & 1875 & 1869 \\
\hline$\kappa_{\text {ind }}$ & 1.186 & 1.193 & 24.323 & 25.125 \\
\hline $\mathrm{c}_{\mathrm{do}}$ & 0.0091 & 0.0091 & 0.0087 & 0.0087 \\
\hline Figure of merit & 0.785 & 0.780 & & \\
\hline Propulsive efficiency & & & 0.812 & 0.812 \\
\hline $\mathrm{L} / \mathrm{D}=\mathrm{WV} / \mathrm{P}$ & & & 11.76 & 11.75 \\
\hline
\end{tabular}

TABLE 17. COMPARISON OF LCTC ROTOR PERFORMANCE FROM RC (SIZING) AND CAMRADII (COMPREHENSIVE ANALYSIS).

\begin{tabular}{|c|c|c|c|c|}
\hline & \multicolumn{2}{|c|}{$\begin{array}{l}\text { HOVER } \\
5 \mathrm{k} \mathrm{ISA}+20^{\circ} \mathrm{C}, 650 \mathrm{ft} / \mathrm{sec}\end{array}$} & \multicolumn{2}{|c|}{$\begin{array}{l}\text { CRUISE } \\
350 \text { knots, 30k ISA, } 205 \mathrm{ft} / \mathrm{sec} \\
\mathrm{V} / \mathrm{V}_{\text {tip }}=2.882, \mathrm{M}_{\mathrm{at}}=0.80\end{array}$} \\
\hline & $\mathrm{RC}$ & CAMRADII & $\mathrm{RC}$ & CAMRADII \\
\hline Thrust & 147102 & 146914 & 13608 & 12812 \\
\hline $\mathrm{C}_{\mathrm{T}} / \sigma$ & 0.1491 & 0.1489 & 0.2981 & 0.2806 \\
\hline Power & 23803 & 23513 & 0 & 16 \\
\hline Induced power & 22520 & 22237 & 462 & 442 \\
\hline Profile power & 1283 & 1276 & 2280 & 2348 \\
\hline$\kappa_{\text {ind }}$ & 1.305 & 1.291 & 13.332 & 14.389 \\
\hline $\mathrm{c}_{\mathrm{do}}$ & 0.0088 & 0.0088 & 0.0101 & 0.0104 \\
\hline Figure of merit & 0.725 & 0.732 & & \\
\hline Rotor drag & & & 2553 & 2583 \\
\hline Rotor D/q & & & 16.5 & 16.7 \\
\hline $\mathrm{L} / \mathrm{D}=\mathrm{WV} / \mathrm{P}$ & & & 9.9 & 9.8 \\
\hline
\end{tabular}


TABLE 18. COMPARISON OF LABC ROTOR PERFORMANCE FROM RC (SIZING) AND CAMRADII (COMPREHENSIVE ANALYSIS).

\begin{tabular}{|c|c|c|c|c|}
\hline & \multicolumn{2}{|c|}{$\begin{array}{l}\text { HOVER } \\
5 \mathrm{k} \mathrm{ISA}+20^{\circ} \mathrm{C}, 650 \mathrm{ft} / \mathrm{sec}\end{array}$} & \multicolumn{2}{|c|}{$\begin{array}{l}\text { CRUISE } \\
350 \text { knots, 30k ISA, } 255 \mathrm{ft} / \mathrm{sec} \\
\mathrm{V} / \mathrm{V}_{\text {tip }}=2.319, \mathrm{M}_{\mathrm{at}}=0.85\end{array}$} \\
\hline & $\mathrm{RC}$ & CAMRADII & $\mathrm{RC}$ & $\overline{\text { CAMRADII }}$ \\
\hline Thrust & 169960 & 170476 & 159068 & 159049 \\
\hline $\mathrm{C}_{\mathrm{T}} / \sigma$ & 0.0952 & 0.0955 & 1.2468 & 1.2467 \\
\hline Rotor shaft power & 32497 & 39613 & 0 & -220 \\
\hline Induced power & 30482 & 37545 & & 11668 \\
\hline Profile power & 2015 & 2068 & & 11910 \\
\hline Ind+pro power & & & 14251 & 23577 \\
\hline$\kappa_{\text {ind }}$ & 1.186 & 1.454 & & 3.414 \\
\hline $\mathrm{c}_{\mathrm{do}}$ & 0.0076 & 0.0078 & & 0.0278 \\
\hline Figure of merit & 0.791 & 0.652 & & \\
\hline Drag & & & 13268 & 22156 \\
\hline Rotor $\mathrm{L} / \mathrm{D}_{\mathrm{e}}$ & & & 12.0 & 7.2 \\
\hline $\mathrm{L} / \mathrm{D}=\mathrm{WV} / \mathrm{P}$ & & & 7.2 & 5.0 \\
\hline
\end{tabular}

TABLE 19. COMPARISON OF BASELINE DESIGNS.

\begin{tabular}{|llll|}
\hline & LCTR & LCTC & LABC \\
\hline Gross weight (lb) & 123562 & 138762 & 160636 \\
Engine power (hp) & $4 \times 6914$ & $4 \times 9684$ & $4 \times 14267$ \\
Mission fuel (lb) & 13624 & 17902 & 26008 \\
Purchase price (\$M) & 61.9 & 80.0 & 110.5 \\
DOC (cents/ASM) & 13.3 & 17.2 & 23.9 \\
\hline
\end{tabular}


TABLE 20. IMPACT OF TECHNOLOGY ON THE DESIGNS: PERCENTAGE INCREASE CAUSED BY CHANGING THE TECHNOLOGY FROM ADVANCED TO CURRENT LEVEL.

\begin{tabular}{|c|c|c|c|c|c|}
\hline & Weight & Power & Fuel & Price & DOC \\
\hline \multicolumn{6}{|l|}{ LCTR } \\
\hline Blade weight & 12 & 13 & 11 & 16 & 12 \\
\hline All structural weight & 21 & 22 & 18 & 27 & 21 \\
\hline Drive system weight & 23 & 24 & 21 & 29 & 23 \\
\hline Airframe drag $(+25 \%)$ & 6 & 14 & 14 & 12 & 12 \\
\hline All aerodynamics & 10 & 20 & 21 & 17 & 16 \\
\hline Engine technology & 23 & 28 & 70 & 28 & 46 \\
\hline Weight and power contingency & 13 & 25 & 25 & 22 & 19 \\
\hline \multicolumn{6}{|l|}{ LCTC } \\
\hline Blade weight & 9 & 9 & 8 & 11 & 9 \\
\hline All structural weight & 20 & 20 & 18 & 24 & 20 \\
\hline Drive system weight & 29 & 28 & 26 & 35 & 39 \\
\hline Airframe drag $(+25 \%)$ & 5 & 10 & 13 & 8 & 10 \\
\hline Hub drag & 9 & 22 & 24 & 17 & 20 \\
\hline All aerodynamics & 17 & 38 & 39 & 31 & 33 \\
\hline Engine technology & 48 & 63 & 124 & 60 & 87 \\
\hline Weight and power contingency & 13 & 25 & 25 & 22 & 20 \\
\hline
\end{tabular}

TABLE 21. DESIGNS FOR BASELINE (1200 nm SEGMENT) AND ALTERNATE (THREE $400 \mathrm{~nm}$ SEGMENTS) MISSION.

\begin{tabular}{|l|ll|ll|ll|}
\hline & LCTR & LCTC & LABC \\
\hline & Baseline & Alternate & Baseline & Alternate & Baseline & Alternate \\
\hline Gross weight (lb) & 123562 & 138318 & 138764 & 155540 & 160636 & 189690 \\
Engine power (hp) & $4 \times 6914$ & $4 \times 7754$ & $4 \times 9684$ & $4 \times 10819$ & $4 \times 14267$ & $4 \times 16566$ \\
Mission fuel (lb) & 13624 & 19725 & 17902 & 24894 & 26008 & 37021 \\
Purchase price (\$M) & 61.9 & 69.5 & 80.0 & 89.5 & 110.5 & 130.0 \\
DOC (cents/ASM) & 13.3 & 17.7 & 17.2 & 21.9 & 23.9 & 32.0 \\
\hline Rotor diameter (ft) & 88.7 & 93.8 & 76.7 & 81.2 & 90.4 & 98.3 \\
Disk loading (lb/ft $\left.{ }^{2}\right)$ & 10 & 10 & 15 & 15 & 25 & 25 \\
$\mathrm{C}_{\mathrm{w}} / \sigma\left(\mathrm{T}\right.$-wt, 5k ISA+20 $\left.{ }^{\circ} \mathrm{C}\right)$ & 0.141 & 0.141 & 0.141 & 0.141 & 0.090 & 0.090 \\
Number of blades per rotor & 4 & 4 & 4 & 4 & 5 & 5 \\
Chord (75\%R, ft) & 3.06 & 3.24 & 3.98 & 4.22 & 4.89 & 5.31 \\
Wing loading $\left(\mathrm{lb} / \mathrm{ft}^{2}\right)$ & 80 & 80 & 80 & 80 & & \\
Drag, D/q (ft $\left.{ }^{2}\right)$ & 37.3 & 40.7 & 50.3 & 55.0 & 38.1 & 42.23 \\
\hline
\end{tabular}


(a) Parameters independent of design conditions.

\begin{tabular}{|llll|}
\hline & LCTR & LCTC & LABC \\
\hline Disk loading, lb/ft ${ }^{2}$ & 10 & 15 & 20 \\
Total cruise drag, D/q / $(\mathrm{W} / 1000)^{2 / 3}$ & 1.5 & 1.9 & 1.3 \\
Hover C $\mathrm{w} / \sigma\left(5 \mathrm{k} \mathrm{ISA+20}{ }^{\circ} \mathrm{C}\right)$ & 0.141 & 0.141 & 0.100 \\
Number of blades & 4 & 6 & 6 \\
Solidity (thrust weighted) & 0.0881 & 0.1321 & 0.1239 \\
Blade taper & 0.8 & 0.8 & 0.333 \\
Hover tip speed, $\mathrm{ft} / \mathrm{sec}$ & 650 & 650 & 650 \\
Cruise tip speed, ft/sec & 350 & & \\
Wing loading, lb/ft & 80 & 80 & \\
\hline
\end{tabular}

(b) Parameters dependent on design speed and altitude.

\begin{tabular}{|c|c|c|c|c|c|}
\hline Design speed, knots & 250 & 250 & 250 & 350 & 350 \\
\hline Design altitude, $\mathrm{ft}$ & $5 \mathrm{k}+20^{\circ} \mathrm{C}$ & $10 \mathrm{k}$ & $20 \mathrm{k}$ & $20 \mathrm{k}$ & $30 \mathrm{k}$ \\
\hline \multicolumn{6}{|l|}{ LCTR Optimum } \\
\hline \multicolumn{6}{|l|}{ Blade twist, deg } \\
\hline inboard & -46 & -46 & -46 & -32 & -32 \\
\hline outboard & -34 & -34 & -34 & -30 & -30 \\
\hline \multicolumn{6}{|l|}{ LCTC Optimum } \\
\hline Maximum $\mathrm{M}_{\mathrm{at}}$ & 0.60 & 0.65 & 0.65 & 0.85 & 0.85 \\
\hline \multicolumn{6}{|l|}{ Blade twist, deg } \\
\hline inboard & 0 & 0 & 0 & 0 & 0 \\
\hline outboard & -12 & -12 & -12 & -12 & -12 \\
\hline \multicolumn{6}{|l|}{ LABC Optimum } \\
\hline Collective, deg & 4 & 4 & 6 & 1 & 0 \\
\hline Maximum $\mathrm{M}_{\mathrm{at}}$ & 0.80 & 0.80 & 0.80 & 0.85 & 0.85 \\
\hline \multicolumn{6}{|l|}{ Blade twist, deg } \\
\hline inboard & 0 & 0 & 0 & 0 & 0 \\
\hline outboard & -10 & -10 & -10 & -10 & -10 \\
\hline Lift offset & $0.4 \mathrm{R}$ & $0.4 \mathrm{R}$ & $0.4 \mathrm{R}$ & $0.25 \mathrm{R}$ & $0.2 \mathrm{R}$ \\
\hline
\end{tabular}


TABLE 23. HEAVY LIFT ROTORCRAFT DESIGNS FOR CRUISE AT 350 KNOTS, 30,000 FT ALTITUDE.

\begin{tabular}{|c|c|c|c|c|c|}
\hline & LCTR & LABC & LCTC & LCSC & LRDC \\
\hline Configuration & Tiltrotor & $\begin{array}{l}\text { Advancing } \\
\text { blade }\end{array}$ & $\begin{array}{l}\text { Tandem } \\
\text { compound }\end{array}$ & $\begin{array}{l}\text { Single } \\
\text { compound }\end{array}$ & $\begin{array}{l}\text { Single comp., } \\
\text { reaction drive }\end{array}$ \\
\hline Mission gross weight (lb) & 121640 & 158484 & 140233 & 139088 & 146934 \\
\hline Engine size (hp) & $4 \times 6923$ & $4 \times 18142$ & $4 \times 11094$ & $4 \times 12551$ & $4 \times 19809$ \\
\hline Rotor diameter (ft) & 88.00 & 89.84 & 77.15 & 108.66 & 111.68 \\
\hline Disk loading W/A (lb/ft $\left.{ }^{2}\right)$ & 10 & 25 & 15 & 15 & 15 \\
\hline $\mathrm{C}_{\mathrm{w}} / \sigma\left(\right.$ geom, $5 \mathrm{k}$ ISA $\left.+20^{\circ} \mathrm{C}\right)$ & 0.1328 & 0.0675 & 0.1328 & 0.1328 & 0.1328 \\
\hline $\mathrm{C}_{\mathrm{W}} / \sigma\left(\mathrm{T}-\mathrm{wt}, 5 \mathrm{k} \mathrm{ISA}+20^{\circ} \mathrm{C}\right)$ & 0.1406 & 0.0900 & 0.1406 & 0.1406 & 0.1406 \\
\hline Wing loading $\left(\mathrm{lb} / \mathrm{ft}^{2}\right)$ & 80 & & 80 & 80 & 80 \\
\hline Wing span (ft) & 104.25 & & 145.03 & 144.44 & 148.46 \\
\hline Hover figure of merit & 0.786 & 0.698 & 0.708 & 0.708 & 0.700 \\
\hline \multicolumn{6}{|l|}{ Cruise performance } \\
\hline Propulsive efficiency & 0.811 & 0.900 & 0.900 & 0.900 & 0.900 \\
\hline Drag D/q $\left(\mathrm{ft}^{2}\right)$ & 36.82 & 38.07 & 51.28 & 51.01 & 52.91 \\
\hline Wing induced drag $\left(\mathrm{ft}^{2}\right)$ & 18.00 & & 11.16 & 10.05 & 10.62 \\
\hline Oswald efficiency & 1.00 & & 0.80 & 0.82 & 0.82 \\
\hline Wing lift (\%W) & $100 \%$ & & $85 \%$ & $82 \%$ & $82 \%$ \\
\hline Rotor drag $\left(\mathrm{ft}^{2}\right)$ & & & 23.84 & 22.35 & 25.96 \\
\hline Rotor L/D & & 7.62 & & & \\
\hline Cruise power (hp) & 11268 & 31874 & 15980 & 15446 & 16572 \\
\hline \multicolumn{6}{|l|}{ Weights } \\
\hline Weight empty (lb) & 79870 & 95172 & 92753 & 91715 & 96308 \\
\hline Operating weight empty (lb) & 81320 & 96622 & 94203 & 93165 & 97758 \\
\hline Payload (lb) & 26400 & 26400 & 26400 & 26400 & 26400 \\
\hline Fuel weight (lb) & 13920 & 35462 & 19629 & 19524 & 22776 \\
\hline Rotor group weight (lb) & 13432 & 13811 & 11655 & 13567 & 16301 \\
\hline Blade weight (lb) & 6831 & 7481 & 5941 & 6383 & 8285 \\
\hline Hub weight (lb) & 6357 & 6330 & 5714 & 7184 & 8016 \\
\hline Propulsion group weight (lb) & 18049 & 31300 & 26050 & 23354 & 23464 \\
\hline Engine dry weight (lb) & 3703 & 9703 & 5933 & 6713 & 10594 \\
\hline Transmission weight (lb) & 13018 & 18543 & 17711 & 14053 & 9279 \\
\hline Flyaway cost (2005) & $\$ 66.6 \mathrm{M}$ & $\$ 131.8 \mathrm{M}$ & $\$ 94.3 \mathrm{M}$ & $\$ 93.8 \mathrm{M}$ & $\$ 118.4 \mathrm{M}$ \\
\hline DOC+I ( $\varnothing / a s m)(2005)$ & 13.66 & 29.76 & 18.91 & 18.90 & 22.77 \\
\hline Aircraft $\mathrm{L} / \mathrm{D}=\mathrm{WV} / \mathrm{P}$ & 11.60 & 5.34 & 9.43 & 9.67 & 9.52 \\
\hline Productivity, V*PL/(W-PL) & 97 & 70 & 81 & 82 & 77 \\
\hline
\end{tabular}


TABLE 24. HEAVY LIFT ROTORCRAFT DESIGNS FOR CRUISE AT 350 KNOTS, 20,000 FT ALTITUDE.

\begin{tabular}{|c|c|c|c|c|c|}
\hline & LCTR & LABC & LCTC & LCSC & LRDC \\
\hline Configuration & Tiltrotor & $\begin{array}{l}\text { Advancing } \\
\text { blade }\end{array}$ & $\begin{array}{l}\text { Tandem } \\
\text { compound }\end{array}$ & $\begin{array}{l}\text { Single } \\
\text { compound }\end{array}$ & $\begin{array}{l}\text { Single comp., } \\
\text { reaction drive }\end{array}$ \\
\hline Mission GW (lb) & 130087 & 159669 & 156468 & 155490 & 169013 \\
\hline Engine size (hp) & $4 \times 7404$ & $4 \times 16496$ & $4 \times 12378$ & $4 \times 14031$ & $4 \times 22785$ \\
\hline Rotor diameter (ft) & 91.00 & 90.18 & 81.49 & 114.88 & 119.78 \\
\hline Disk loading W/A (lb/ft $\left.{ }^{2}\right)$ & 10 & 25 & 15 & 15 & 15 \\
\hline $\mathrm{C}_{\mathrm{w}} / \sigma\left(\right.$ geom, $5 \mathrm{k}$ ISA $\left.+20^{\circ} \mathrm{C}\right)$ & 0.1328 & 0.0750 & 0.1328 & 0.1328 & 0.1328 \\
\hline $\mathrm{C}_{\mathrm{W}} / \sigma\left(\mathrm{T}-\mathrm{wt}, 5 \mathrm{k} \mathrm{ISA}+20^{\circ} \mathrm{C}\right)$ & 0.1406 & 0.1000 & 0.1406 & 0.1406 & 0.1406 \\
\hline Wing loading $\left(\mathrm{lb} / \mathrm{ft}^{2}\right)$ & 80 & & 80 & 80 & 80 \\
\hline Wing span (ft) & 107.25 & & 153.20 & 152.72 & 159.22 \\
\hline Hover figure of merit & 0.786 & 0.698 & 0.708 & 0.708 & 0.700 \\
\hline \multicolumn{6}{|l|}{ Cruise performance } \\
\hline Propulsive efficiency & 0.797 & 0.900 & 0.900 & 0.900 & 0.900 \\
\hline Drag D/q $\left(\mathrm{ft}^{2}\right)$ & 38.51 & 38.26 & 55.17 & 54.94 & 58.08 \\
\hline Wing induced drag $\left(\mathrm{ft}^{2}\right)$ & 9.59 & & 6.43 & 5.68 & 6.17 \\
\hline Oswald efficiency & 1.00 & & 0.80 & 0.82 & 0.82 \\
\hline Wing lift (\%W) & $100 \%$ & & $87 \%$ & $83 \%$ & $83 \%$ \\
\hline Rotor drag $\left(\mathrm{ft}^{2}\right)$ & & & 23.37 & 21.66 & 25.92 \\
\hline Rotor L/D & & 9.97 & & & \\
\hline Cruise power (hp) & 14326 & 29206 & 22411 & 21702 & 23781 \\
\hline \multicolumn{6}{|l|}{ Weights } \\
\hline Weight empty (lb) & 84292 & 97170 & 101210 & 100295 & 108081 \\
\hline Operating weight empty (lb) & 85742 & 98620 & 102660 & 101745 & 109531 \\
\hline Payload (lb) & 26400 & 26400 & 26400 & 26400 & 26400 \\
\hline Fuel weight (lb) & 17945 & 34649 & 27408 & 27345 & 33083 \\
\hline Rotor group weight (lb) & 14675 & 16548 & 13475 & 15736 & 19624 \\
\hline Blade weight (lb) & 7433 & 9340 & 6819 & 7343 & 9880 \\
\hline Hub weight (lb) & 6981 & 7208 & 6657 & 8392 & 9744 \\
\hline Propulsion group weight (lb) & 19302 & 30375 & 29066 & 26108 & 26990 \\
\hline Engine dry weight (lb) & 3960 & 8823 & 6620 & 7504 & 12186 \\
\hline Transmission weight (lb) & 13919 & 18681 & 19762 & 15711 & 10673 \\
\hline Flyaway cost (2005) & $\$ 71.1 \mathrm{M}$ & $\$ 125.8 \mathrm{M}$ & $\$ 104.9 \mathrm{M}$ & $\$ 104.5 \mathrm{M}$ & $\$ 135.7 \mathrm{M}$ \\
\hline DOC+I ( $\varnothing / a s m)(2005)$ & 15.99 & 28.84 & 23.56 & 23.60 & 29.27 \\
\hline Aircraft $L / D=W V / P$ & 9.75 & 5.87 & 7.50 & 7.70 & 7.63 \\
\hline Productivity, V*PL/(W-PL) & 89 & 69 & 71 & 72 & 65 \\
\hline
\end{tabular}


TABLE 25. HEAVY LIFT ROTORCRAFT DESIGNS FOR CRUISE AT 250 KNOTS, 20,000 FT ALTITUDE.

\begin{tabular}{|c|c|c|c|c|c|}
\hline & LCTR & LABC & LCTC & LCSC & LRDC \\
\hline Configuration & Tiltrotor & $\begin{array}{l}\text { Advancing } \\
\text { blade }\end{array}$ & $\begin{array}{l}\text { Tandem } \\
\text { compound }\end{array}$ & $\begin{array}{l}\text { Single } \\
\text { compound }\end{array}$ & $\begin{array}{l}\text { Single comp., } \\
\text { reaction drive }\end{array}$ \\
\hline Mission GW (lb) & 123474 & 155346 & 138116 & 139076 & 151623 \\
\hline Engine size (hp) & $4 \times 6948$ & $4 \times 16050$ & $4 \times 10926$ & $4 \times 12550$ & $4 \times 20441$ \\
\hline Rotor diameter (ft) & 88.66 & 88.95 & 76.56 & 108.65 & 113.45 \\
\hline Disk loading W/A (lb/ft $\left.{ }^{2}\right)$ & 10 & 25 & 15 & 15 & 15 \\
\hline $\mathrm{C}_{\mathrm{w}} / \sigma\left(\right.$ geom, $5 \mathrm{k}$ ISA $\left.+20^{\circ} \mathrm{C}\right)$ & 0.1328 & 0.0750 & 0.1328 & 0.1328 & 0.1328 \\
\hline $\mathrm{C}_{\mathrm{W}} / \sigma\left(\mathrm{T}-\mathrm{wt}, 5 \mathrm{k} \mathrm{ISA}+20^{\circ} \mathrm{C}\right)$ & 0.1406 & 0.1000 & 0.1406 & 0.1406 & 0.1406 \\
\hline Wing loading $\left(\mathrm{lb} / \mathrm{ft}^{2}\right)$ & 80 & & 80 & 80 & 80 \\
\hline Wing span (ft) & 104.91 & & 143.94 & 144.43 & 150.81 \\
\hline Hover figure of merit & 0.795 & 0.698 & 0.708 & 0.708 & 0.700 \\
\hline \multicolumn{6}{|l|}{ Cruise performance } \\
\hline Propulsive efficiency & 0.825 & 0.900 & 0.900 & 0.900 & 0.900 \\
\hline Drag D/q $\left(\mathrm{ft}^{2}\right)$ & 37.19 & 37.57 & 50.77 & 51.00 & 54.03 \\
\hline Wing induced drag $\left(\mathrm{ft}^{2}\right)$ & 34.69 & & 20.09 & 20.46 & 22.30 \\
\hline Oswald efficiency & 1.00 & & 0.81 & 0.82 & 0.82 \\
\hline Wing lift (\%W) & $100 \%$ & & $84 \%$ & $85 \%$ & $85 \%$ \\
\hline Rotor drag $\left(\mathrm{ft}^{2}\right)$ & & & 19.98 & 19.84 & 23.75 \\
\hline Rotor L/D & & 9.29 & & & \\
\hline Cruise power (hp) & 7537 & 17867 & 8731 & 8776 & 9620 \\
\hline \multicolumn{6}{|l|}{ Weights } \\
\hline Weight empty (lb) & 80775 & 95010 & 91656 & 91708 & 98795 \\
\hline Operating weight empty (lb) & 82225 & 96460 & 93106 & 93158 & 100245 \\
\hline Payload (lb) & 26400 & 26400 & 26400 & 26400 & 26400 \\
\hline Fuel weight (lb) & 14848 & 32486 & 18610 & 19518 & 24978 \\
\hline Rotor group weight (lb) & 13700 & 15890 & 11422 & 13565 & 16993 \\
\hline Blade weight (lb) & 6961 & 8963 & 5828 & 6382 & 8619 \\
\hline Hub weight (lb) & 6491 & 6927 & 5594 & 7183 & 8375 \\
\hline Propulsion group weight (lb) & 18268 & 29552 & 25657 & 23352 & 24213 \\
\hline Engine dry weight (lb) & 3716 & 8584 & 5844 & 6712 & 10932 \\
\hline Transmission weight (lb) & 13212 & 18176 & 17444 & 14052 & 9575 \\
\hline Flyaway cost (2005) & $\$ 67.1 \mathrm{M}$ & $\$ 122.5 \mathrm{M}$ & $\$ 93.0 \mathrm{M}$ & $\$ 93.8 \mathrm{M}$ & $\$ 122.0 \mathrm{M}$ \\
\hline DOC+I ( $\varnothing / a s m)(2005)$ & 16.96 & 32.29 & 22.02 & 22.68 & 28.97 \\
\hline Aircraft $\mathrm{L} / \mathrm{D}=\mathrm{WV} / \mathrm{P}$ & 12.57 & 6.67 & 12.14 & 12.16 & 12.09 \\
\hline Productivity, V*PL/(W-PL) & 68 & 51 & 59 & 59 & 53 \\
\hline
\end{tabular}


TABLE 26. HEAVY LIFT ROTORCRAFT DESIGNS FOR CRUISE AT 250 KNOTS, 10,000 FT ALTITUDE.

\begin{tabular}{|c|c|c|c|c|c|}
\hline & LCTR & LABC & LCTC & LCSC & LRDC \\
\hline Configuration & Tiltrotor & $\begin{array}{l}\text { Advancing } \\
\text { blade }\end{array}$ & $\begin{array}{l}\text { Tandem } \\
\text { compound }\end{array}$ & $\begin{array}{l}\text { Single } \\
\text { compound }\end{array}$ & $\begin{array}{l}\text { Single comp., } \\
\text { reaction drive }\end{array}$ \\
\hline Mission GW (lb) & 130681 & 160246 & 153435 & 155225 & 178628 \\
\hline Engine size (hp) & $4 \times 7353$ & $4 \times 16556$ & $4 \times 12138$ & $4 \times 14007$ & $4 \times 24081$ \\
\hline Rotor diameter (ft) & 91.21 & 90.34 & 80.70 & 114.79 & 123.14 \\
\hline Disk loading W/A (lb/ft $\left.{ }^{2}\right)$ & 10 & 25 & 15 & 15 & 15 \\
\hline $\mathrm{C}_{\mathrm{W}} / \sigma\left(\right.$ geom, $5 \mathrm{k}$ ISA $\left.+20^{\circ} \mathrm{C}\right)$ & 0.1328 & 0.0750 & 0.1328 & 0.1328 & 0.1328 \\
\hline $\mathrm{C}_{\mathrm{w}} / \sigma\left(\mathrm{T}-\mathrm{wt}, 5 \mathrm{k} \mathrm{ISA}+20^{\circ} \mathrm{C}\right)$ & 0.1406 & 0.1000 & 0.1406 & 0.1406 & 0.1406 \\
\hline Wing loading $\left(\mathrm{lb} / \mathrm{ft}^{2}\right)$ & 80 & & 80 & 80 & 80 \\
\hline Wing span (ft) & 107.46 & & 151.71 & 152.59 & 163.69 \\
\hline Hover figure of merit & 0.795 & 0.698 & 0.708 & 0.708 & 0.700 \\
\hline \multicolumn{6}{|l|}{ Cruise performance } \\
\hline Propulsive efficiency & 0.815 & 0.900 & 0.900 & 0.900 & 0.900 \\
\hline $\operatorname{Drag} \mathrm{D} / \mathrm{q}\left(\mathrm{ft}^{2}\right)$ & 38.63 & 38.35 & 54.45 & 54.88 & 60.26 \\
\hline Wing induced drag $\left(\mathrm{ft}^{2}\right)$ & 19.38 & & 12.04 & 11.89 & 13.68 \\
\hline Oswald efficiency & 1.00 & & 0.80 & 0.82 & 0.82 \\
\hline Wing lift $(\% \mathrm{~W})$ & $100 \%$ & & $85 \%$ & $85 \%$ & $85 \%$ \\
\hline Rotor drag $\left(\mathrm{ft}^{2}\right)$ & & & 20.36 & 19.45 & 24.65 \\
\hline Rotor L/D & & 12.14 & & & \\
\hline Cruise power (hp) & 8519 & 16363 & 11571 & 11486 & 13134 \\
\hline \multicolumn{6}{|l|}{ Weights } \\
\hline Weight empty (lb) & 84548 & 97459 & 99625 & 100156 & 113254 \\
\hline Operating weight empty (lb) & 85998 & 98909 & 101075 & 101606 & 114704 \\
\hline Payload (lb) & 26400 & 26400 & 26400 & 26400 & 26400 \\
\hline Fuel weight (lb) & 18282 & 34937 & 25959 & 27219 & 37524 \\
\hline Rotor group weight (lb) & 14763 & 16637 & 13130 & 15700 & 21117 \\
\hline Blade weight (lb) & 7476 & 9390 & 6653 & 7327 & 10592 \\
\hline Hub weight (lb) & 7025 & 7246 & 6477 & 8373 & 10525 \\
\hline Propulsion group weight (lb) & 19335 & 30485 & 28502 & 26064 & 28525 \\
\hline Engine dry weight (lb) & 3933 & 8855 & 6492 & 7491 & 12879 \\
\hline Transmission weight (lb) & 13983 & 18749 & 19379 & 15684 & 11280 \\
\hline Flyaway cost (2005) & $\$ 70.9 \mathrm{M}$ & $\$ 126.3 \mathrm{M}$ & $\$ 102.9 \mathrm{M}$ & $\$ 104.3 \mathrm{M}$ & $\$ 143.4 \mathrm{M}$ \\
\hline DOC+I ( $\not / a s m) ~(2005)$ & 19.10 & 33.94 & 26.80 & 27.73 & 37.71 \\
\hline Aircraft L/D=WV/P & 11.77 & 7.51 & 10.17 & 10.37 & 10.43 \\
\hline Productivity, V*PL/(W-PL) & 63 & 49 & 52 & 51 & 43 \\
\hline
\end{tabular}


TABLE 27. HEAVY LIFT ROTORCRAFT DESIGNS FOR CRUISE AT 250 KNOTS, 5000 FT ISA $+20^{\circ} \mathrm{C}$.

\begin{tabular}{|c|c|c|c|c|c|}
\hline & LCTR & LABC & LCTC & LCSC & LRDC \\
\hline Configuration & Tiltrotor & $\begin{array}{l}\text { Advancing } \\
\text { blade }\end{array}$ & $\begin{array}{l}\text { Tandem } \\
\text { compound }\end{array}$ & $\begin{array}{l}\text { Single } \\
\text { compound }\end{array}$ & $\begin{array}{l}\text { Single comp., } \\
\text { reaction drive }\end{array}$ \\
\hline Mission GW (lb) & 136168 & 171348 & 163345 & 166719 & 201915 \\
\hline Engine size (hp) & $4 \times 7662$ & $4 \times 17703$ & $4 \times 12922$ & $4 \times 15044$ & $4 \times 27221$ \\
\hline Rotor diameter (ft) & 93.11 & 93.42 & 83.26 & 118.96 & 130.92 \\
\hline Disk loading W/A (lb/ $\left.\mathrm{ft}^{2}\right)$ & 10 & 25 & 15 & 15 & 15 \\
\hline $\mathrm{C}_{\mathrm{W}} / \sigma\left(\right.$ geom, $5 \mathrm{k}$ ISA $\left.+20^{\circ} \mathrm{C}\right)$ & 0.1328 & 0.0750 & 0.1328 & 0.1328 & 0.1328 \\
\hline $\mathrm{C}_{\mathrm{W}} / \sigma\left(\mathrm{T}-\mathrm{wt}, 5 \mathrm{k} \mathrm{ISA}+20^{\circ} \mathrm{C}\right)$ & 0.1406 & 0.1000 & 0.1406 & 0.1406 & 0.1406 \\
\hline Wing loading $\left(\mathrm{lb} / \mathrm{ft}^{2}\right)$ & 80 & & 80 & 80 & 80 \\
\hline Wing span (ft) & 109.36 & & 156.53 & 158.14 & 174.03 \\
\hline Hover figure of merit & 0.795 & 0.698 & 0.708 & 0.708 & 0.700 \\
\hline \multicolumn{6}{|l|}{ Cruise performance } \\
\hline Propulsive efficiency & 0.810 & 0.900 & 0.900 & 0.900 & 0.900 \\
\hline Drag D/q $\left(\mathrm{ft}^{2}\right)$ & 39.70 & 40.10 & 56.78 & 57.55 & 65.39 \\
\hline Wing induced drag $\left(\mathrm{ft}^{2}\right)$ & 17.06 & & 10.82 & 10.77 & 13.05 \\
\hline Oswald efficiency & 1.00 & & 0.80 & 0.82 & 0.82 \\
\hline Wing lift (\%W) & $100 \%$ & & $85 \%$ & $85 \%$ & $85 \%$ \\
\hline Rotor drag $\left(\mathrm{ft}^{2}\right)$ & & & 21.13 & 20.78 & 27.60 \\
\hline Rotor L/D & & 12.68 & & & \\
\hline Cruise power (hp) & 9146 & 17336 & 12866 & 12923 & 15377 \\
\hline \multicolumn{6}{|l|}{ Weights } \\
\hline Weight empty (lb) & 87434 & 103049 & 104812 & 106215 & 125891 \\
\hline Operating weight empty (lb) & 88884 & 104499 & 106262 & 107665 & 127341 \\
\hline Payload (lb) & 26400 & 26400 & 26400 & 26400 & 26400 \\
\hline Fuel weight (lb) & 20884 & 40449 & 30683 & 32654 & 48173 \\
\hline Rotor group weight (lb) & 15586 & 18372 & 14266 & 17266 & 24843 \\
\hline Blade weight (lb) & 7873 & 10383 & 7198 & 8016 & 12357 \\
\hline Hub weight (lb) & 7440 & 7989 & 7068 & 9250 & 12487 \\
\hline Propulsion group weight (lb) & 20147 & 32597 & 30343 & 27993 & 32244 \\
\hline Engine dry weight (lb) & 4098 & 9468 & 6911 & 8046 & 14558 \\
\hline Transmission weight (lb) & 14570 & 20048 & 20630 & 16845 & 12751 \\
\hline Flyaway cost (2005) & $\$ 73.8 \mathrm{M}$ & $\$ 134.9 \mathrm{M}$ & $\$ 109.3 \mathrm{M}$ & $\$ 111.9 \mathrm{M}$ & $\$ 162.0 \mathrm{M}$ \\
\hline DOC+I ( $\varnothing /$ asm) (2005) & 20.72 & 37.65 & 29.89 & 31.30 & 45.17 \\
\hline Aircraft L/D=WV/P & 11.42 & 7.58 & 9.74 & 9.90 & 10.07 \\
\hline Productivity, V*PL/(W-PL) & 60 & 46 & 48 & 47 & 38 \\
\hline
\end{tabular}



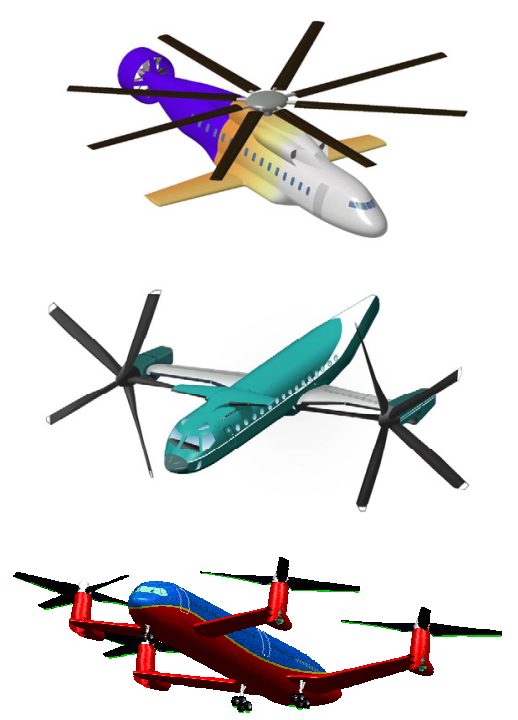

Figure 1. Runway Independent Aircraft (RIA) industry concepts from 2002: Sikorsky Reverse Velocity Rotor (top), Boeing Tiltrotor (center), Bell Quad Tiltrotor (bottom).

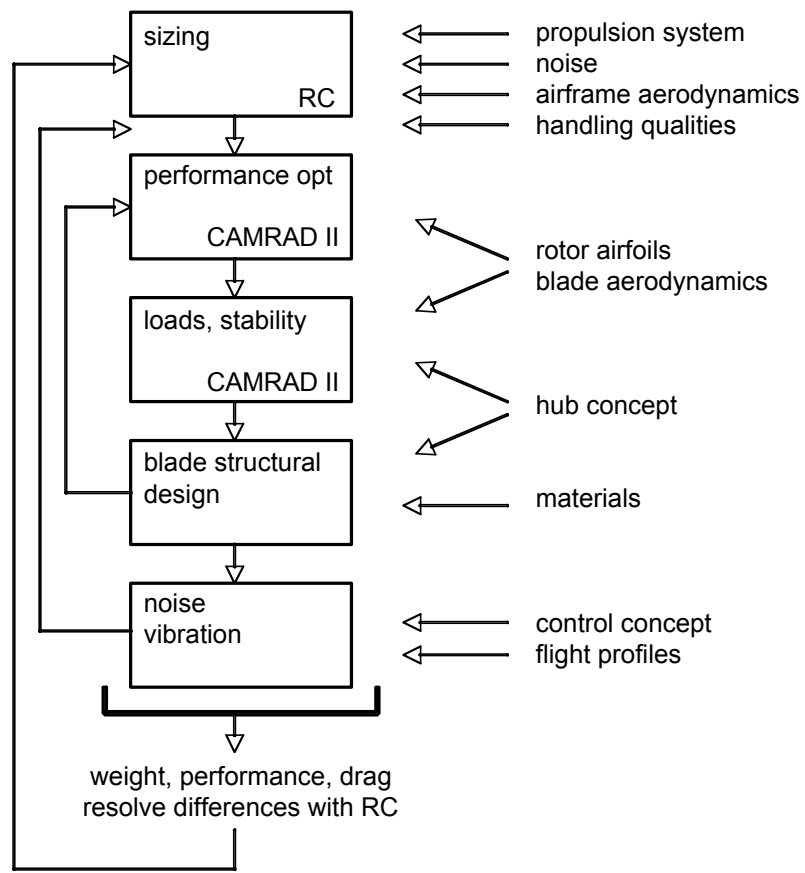

Figure 2. Outline of iterative design process.

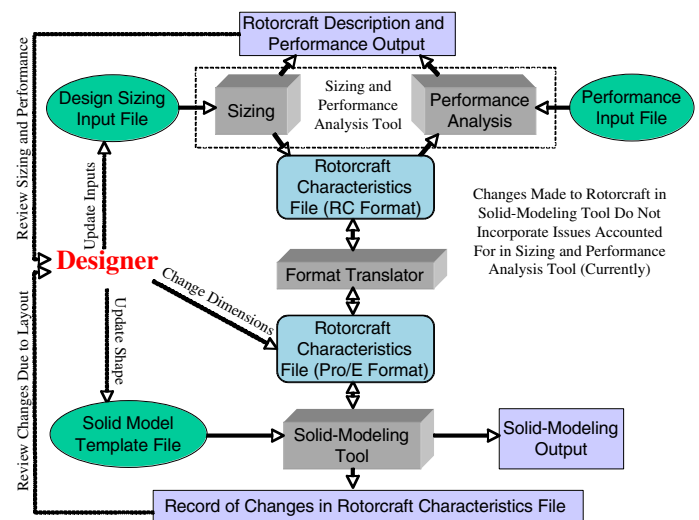

Figure 3. Simplified conceptual design process.

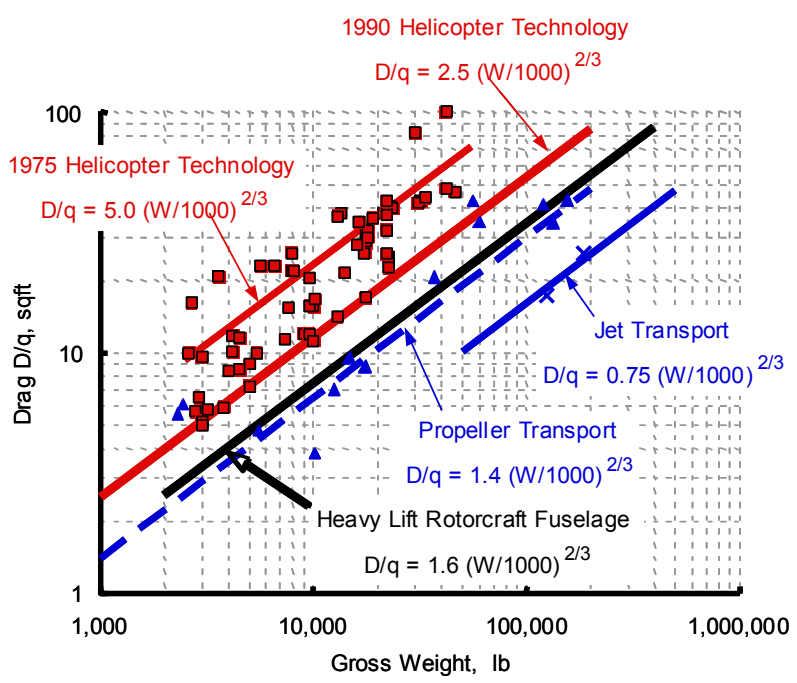

Figure 4. Aircraft drag trends (courtesy F. D. Harris).

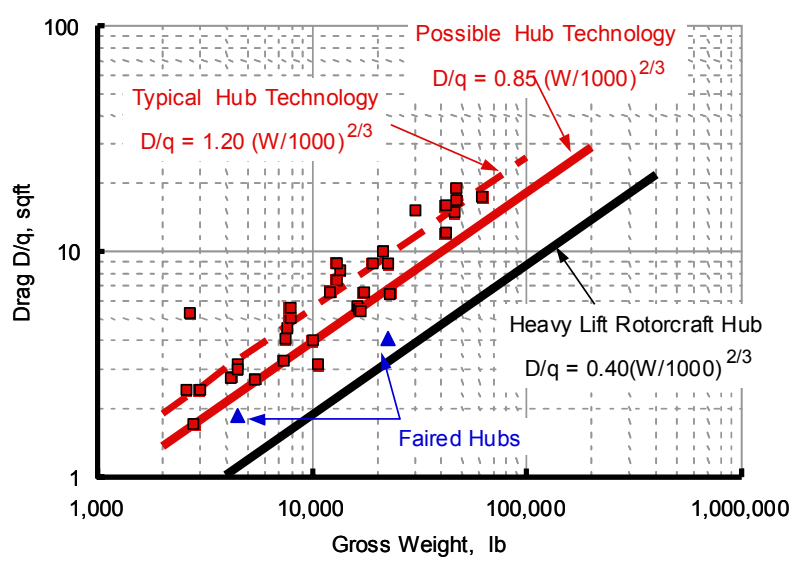

Figure 5. Helicopter hub drag trends (courtesy F. D. Harris). 


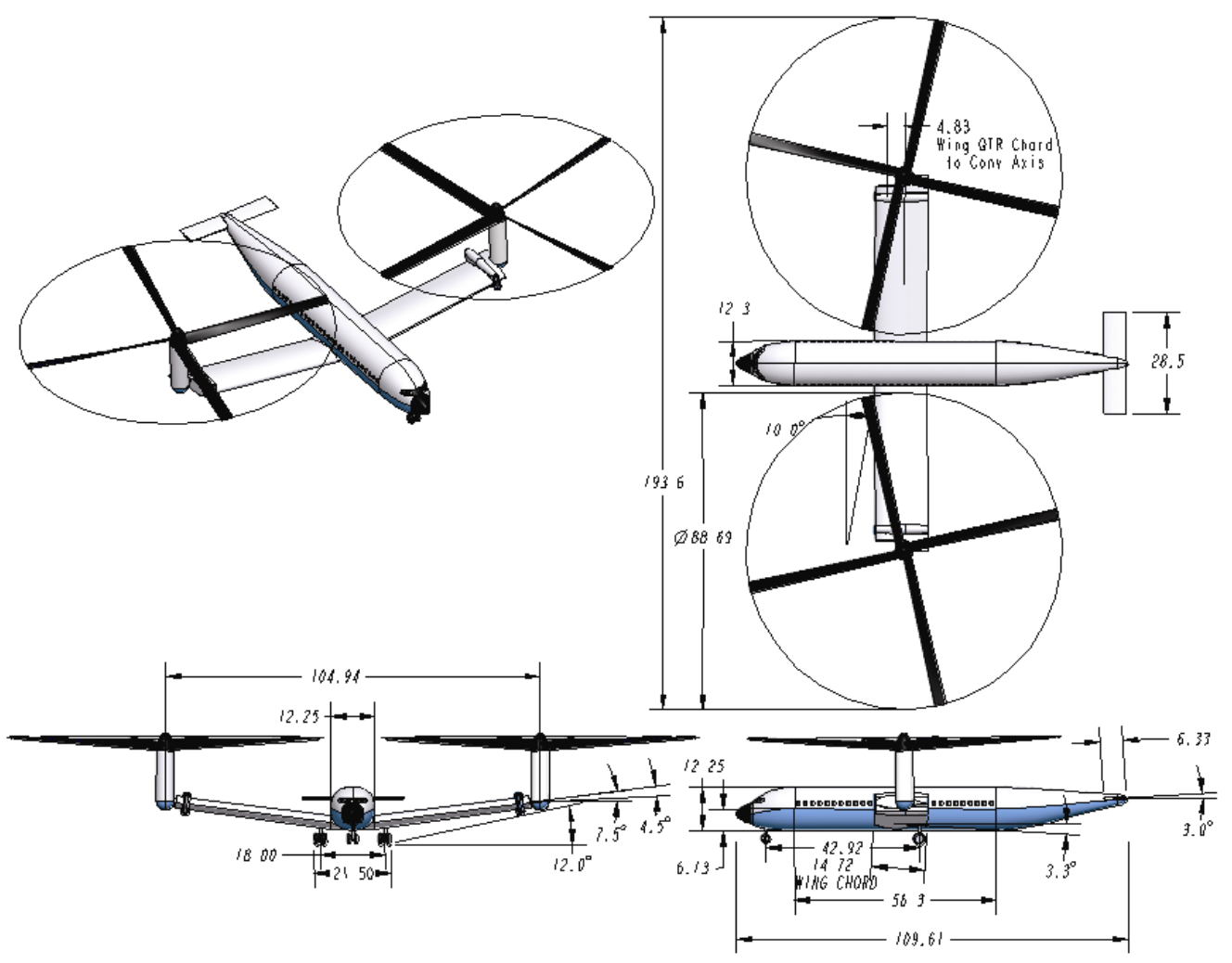

Figure 6. Three-view of Large Civil Tiltrotor (LCTR).

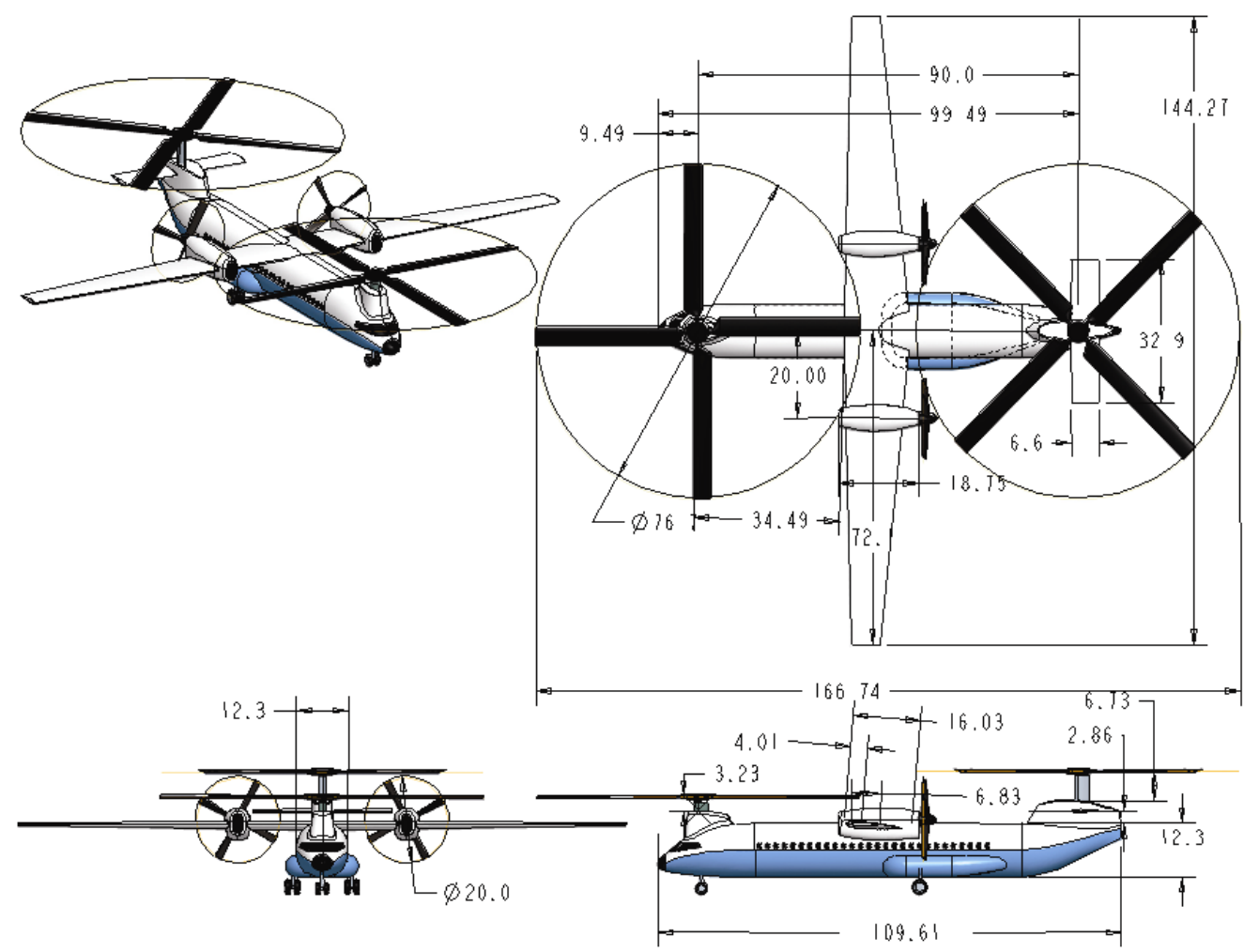

Figure 7. Three-view of Large Civil Tandem Compound (LCTC). 

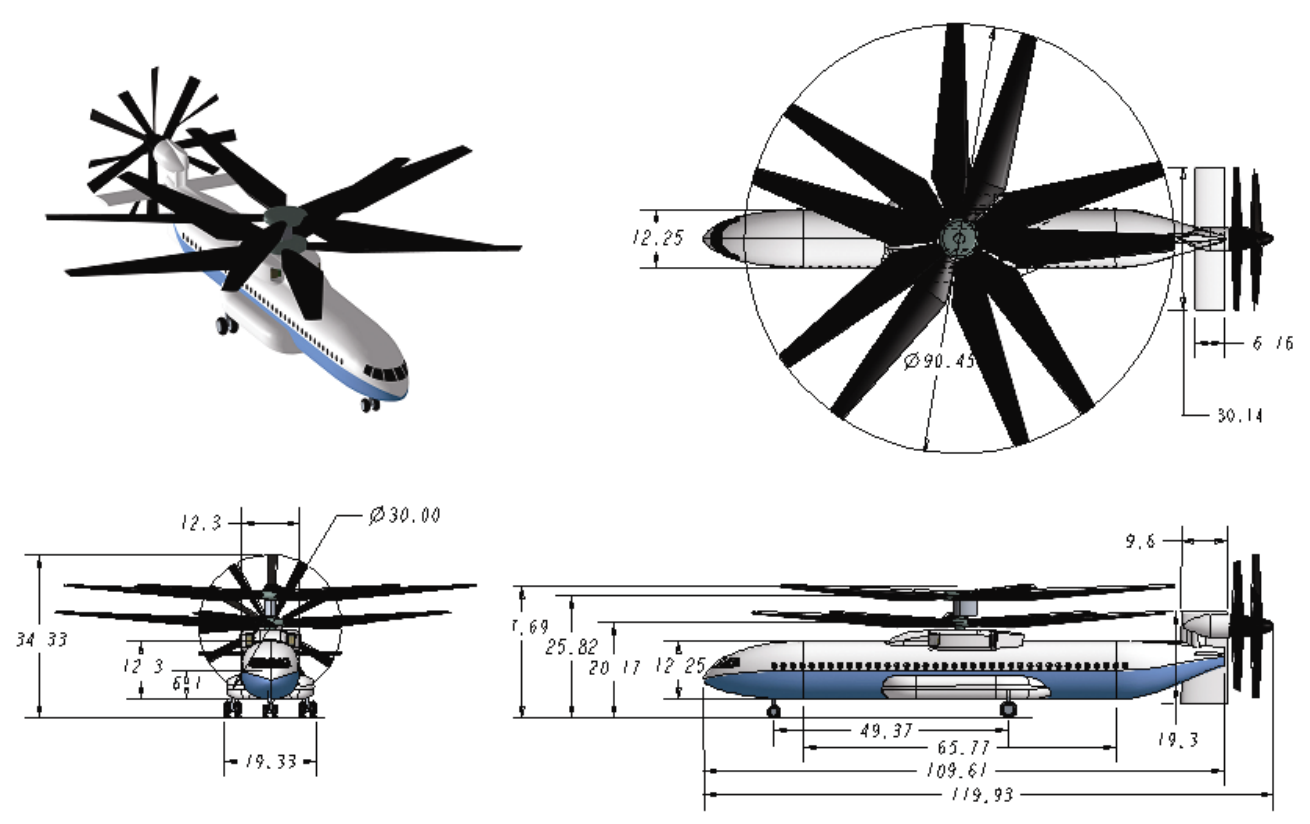

Figure 8. Three-view of Large Advancing Blade Concept (LABC)

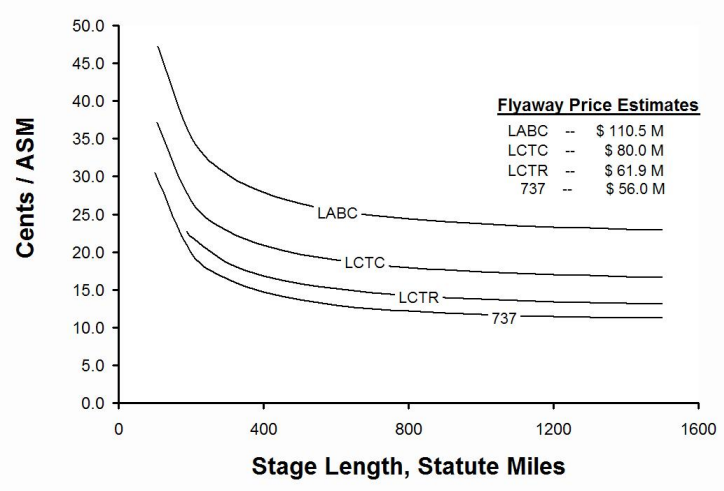

Figure 9. Flyaway price (2005 USD) and DOC+I (2005 cents/ASM) comparisons for baseline designs. $\square$ Maintenance $\square$ Crew $\square$ Fuel $\square$ Depreciation $\square$ Insurance $\square$ Finance

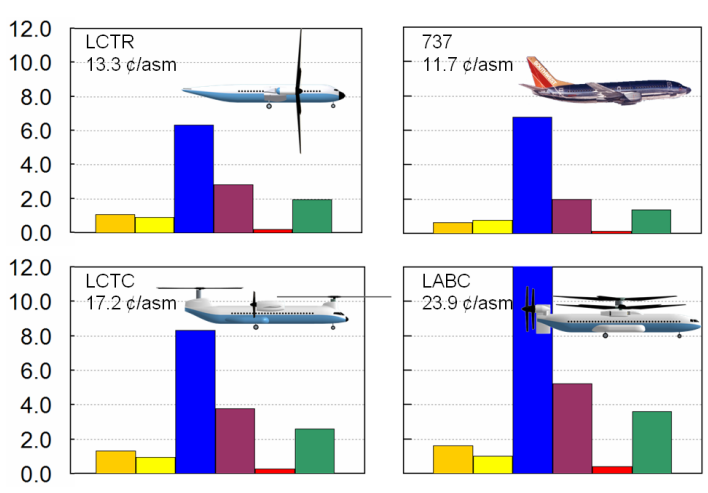

Figure 10. Cost elements compared for heavy lift rotorcraft and B737 $(1200 \mathrm{~nm}, 120$ passengers, including technology factors for rotorcraft costs). 

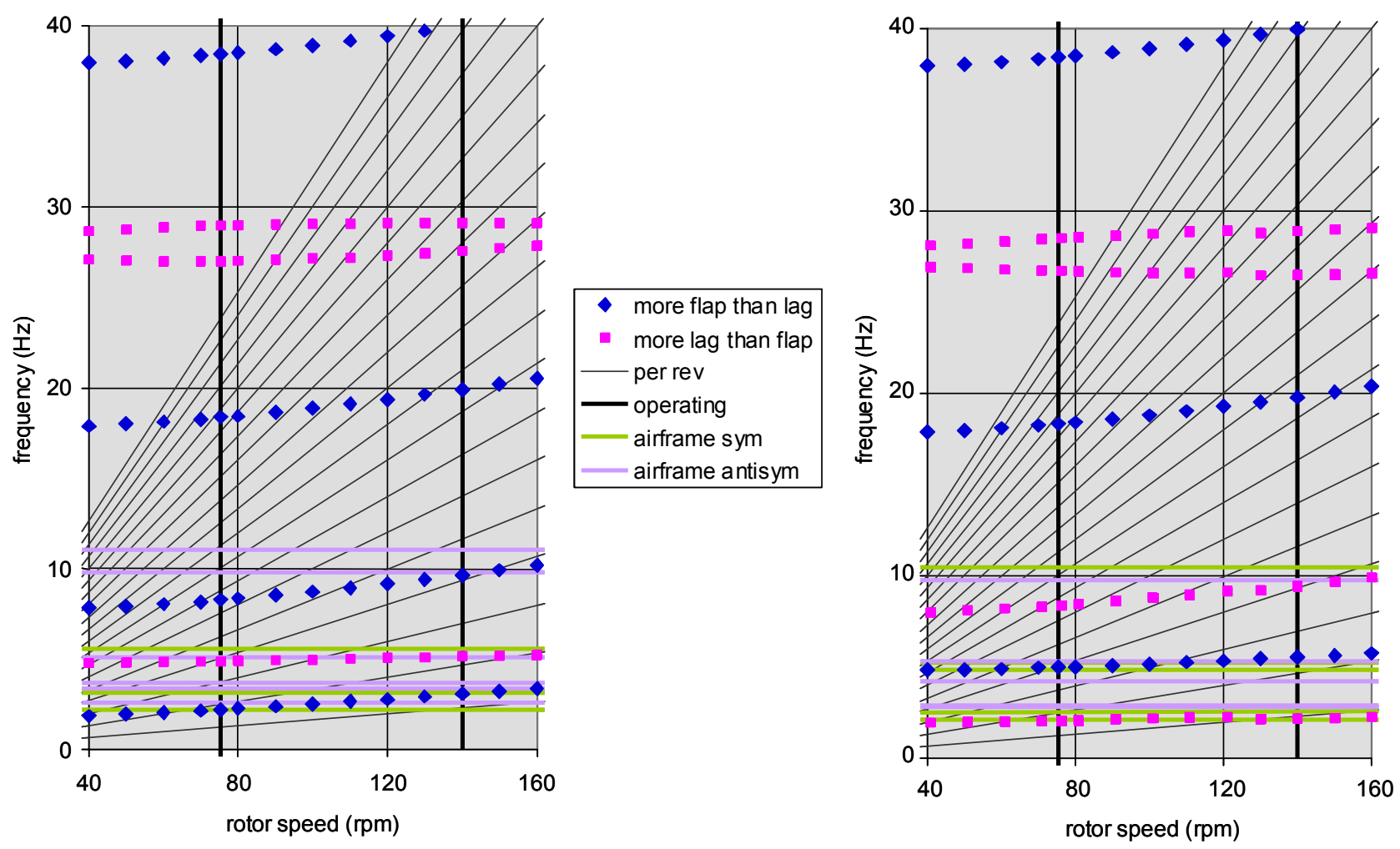

Figure 11. LCTR blade and airframe frequencies. Collective $=0 \mathrm{deg}$ (left figure, appropriate for $140 \mathrm{rpm}$ operation) and collective $=60 \mathrm{deg}$ (right figure, $75 \mathrm{rpm}$ operation).

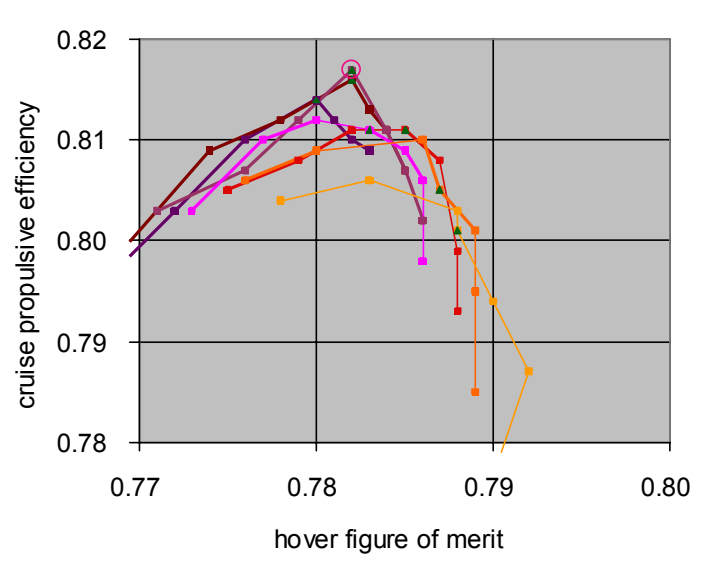

Figure 12. LCTR twist optimization.
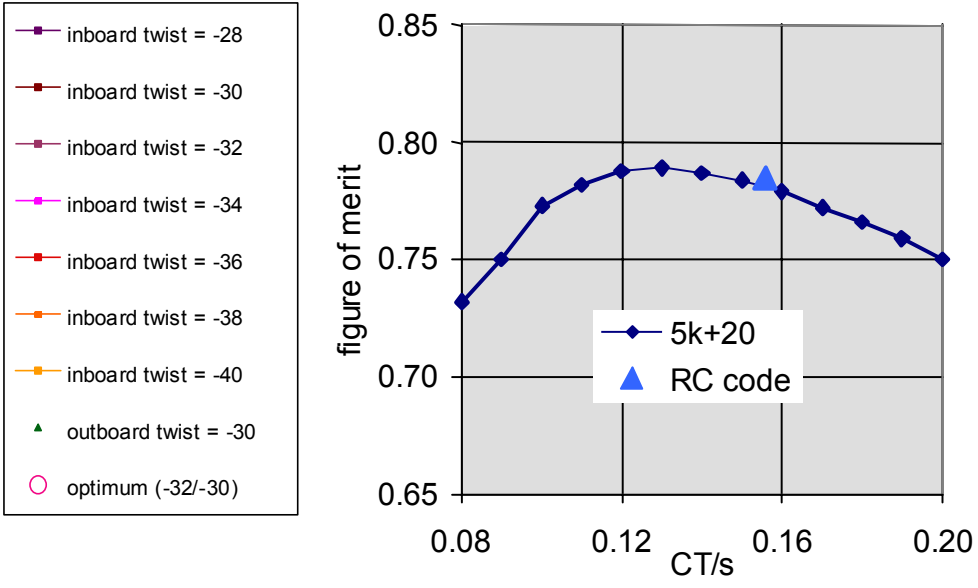

Figure 13. LCTR rotor hover performance. 

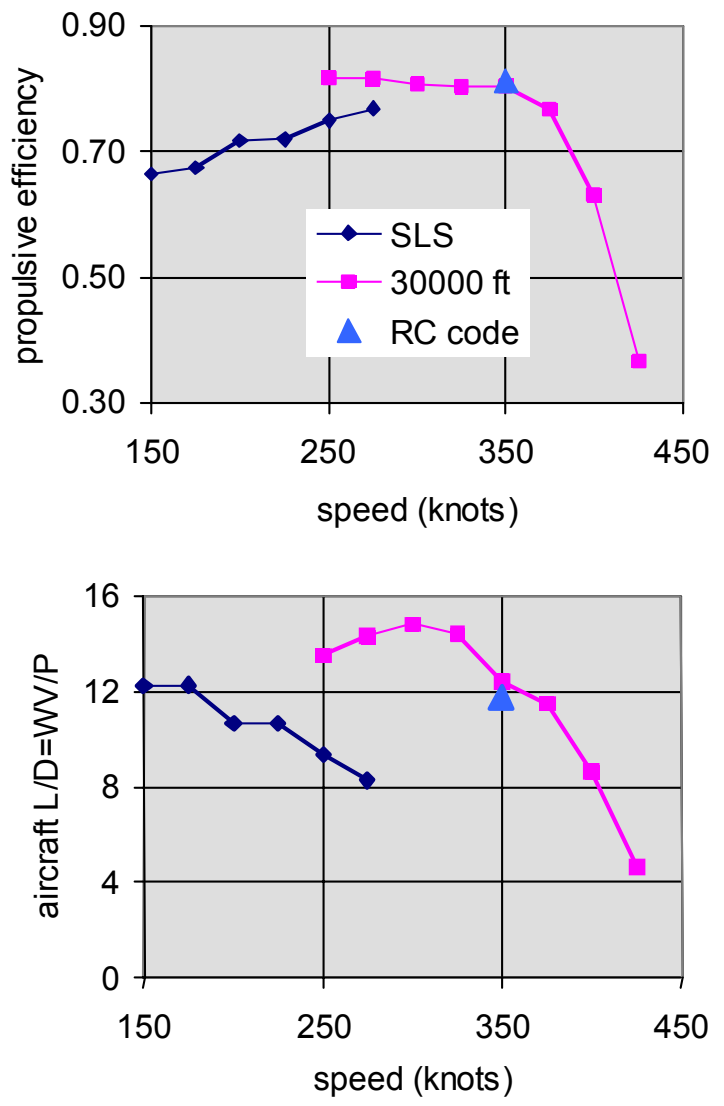

Figure 14. LCTR rotor cruise performance.

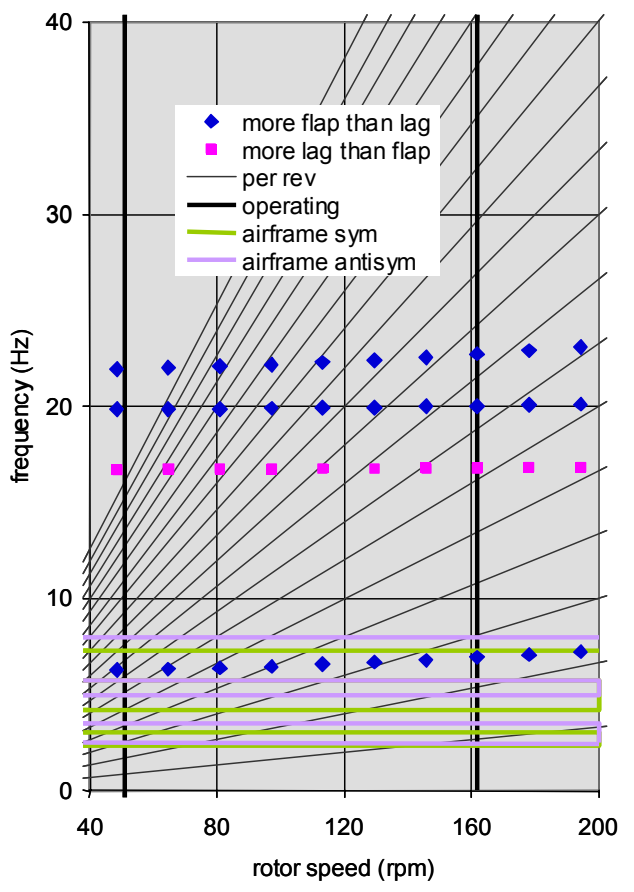

Figure 15. LCTC blade and airframe frequencies (collective $=10$ ).

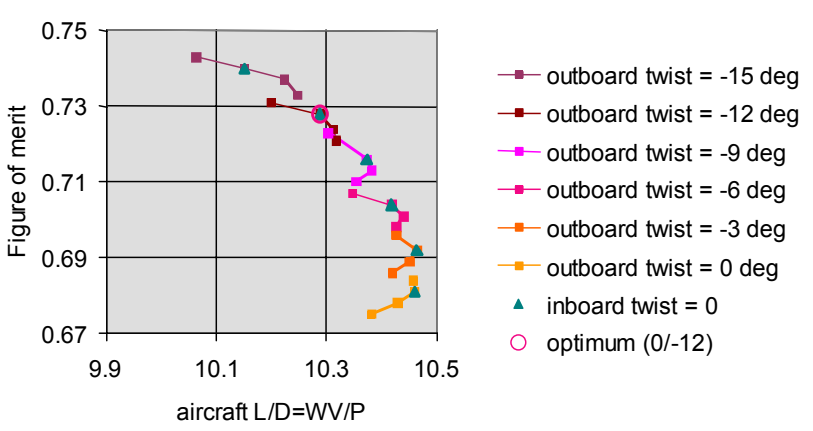

Figure 16. LCTC twist optimization (inboard twist $=$ $3,0,-3,-6 \mathrm{deg})$.

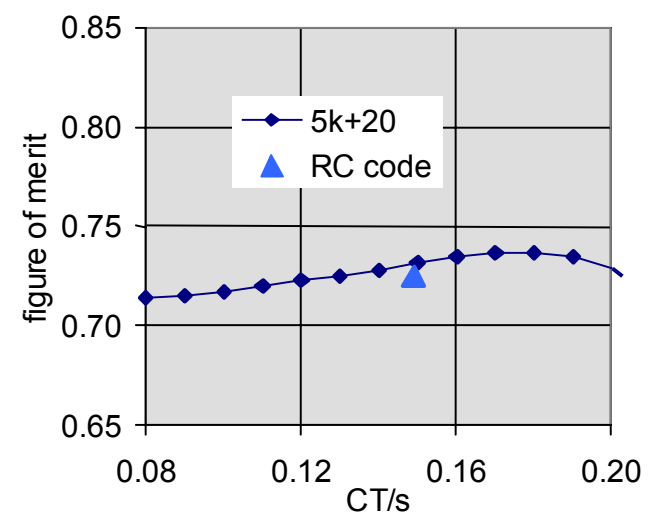

Figure 17. LCTC rotor hover performance.

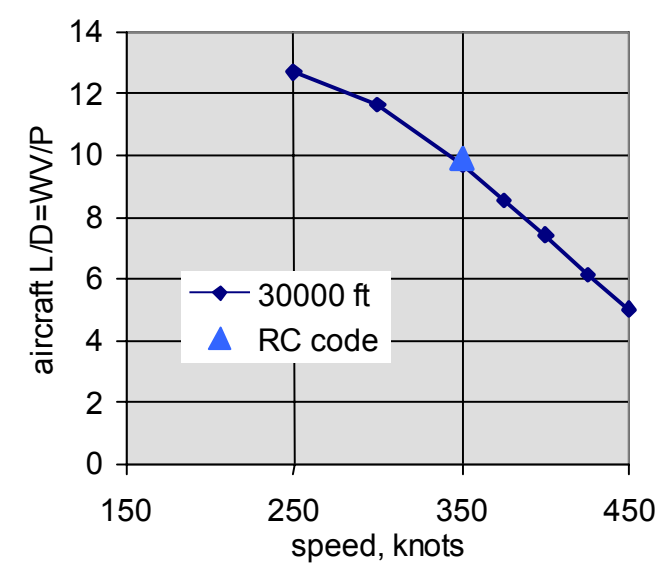

Figure 18. LCTC aircraft cruise performance. 


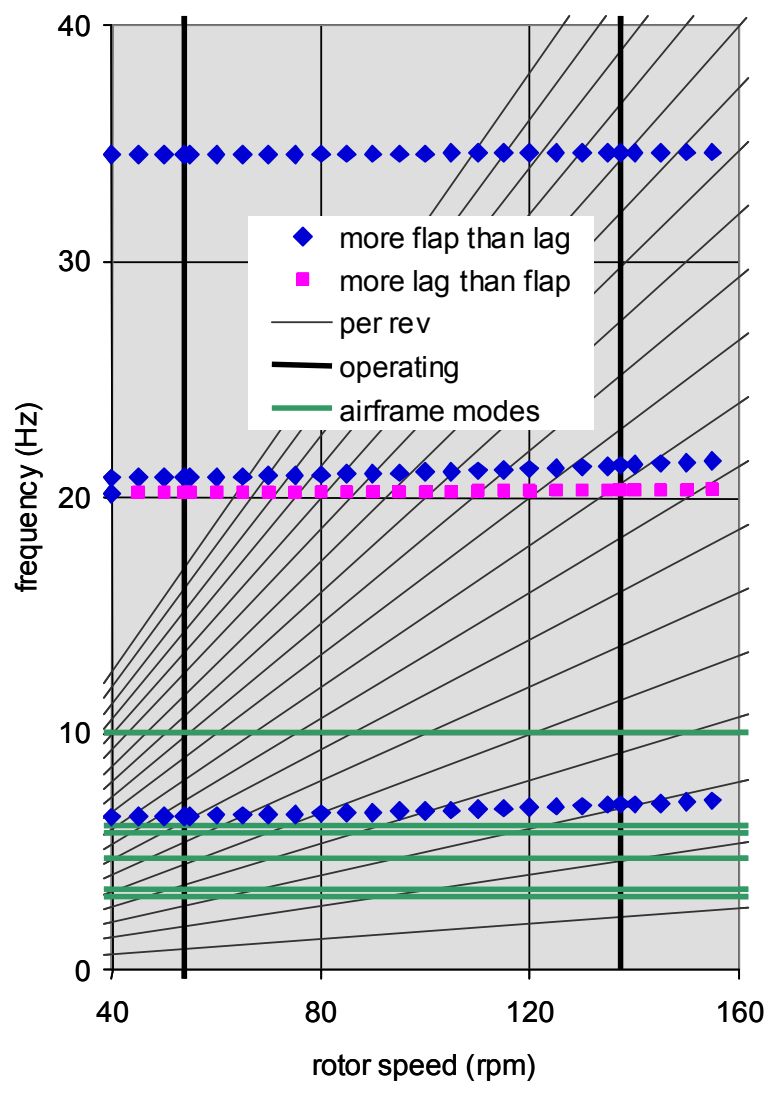

Figure 19. LABC blade and airframe frequencies (collective $=0$ ).

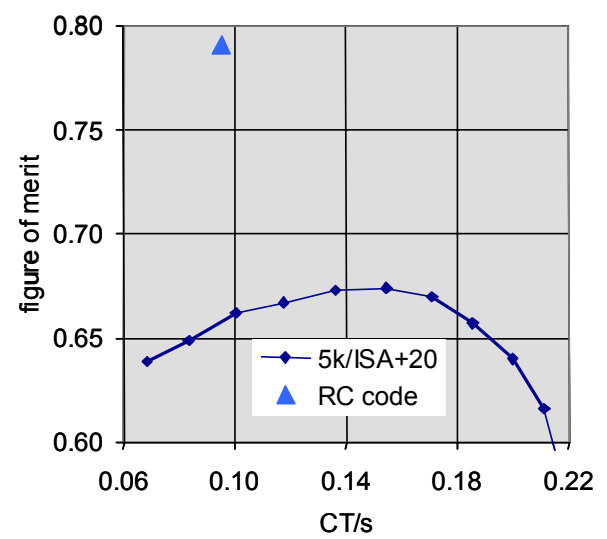

Figure 20. LABC rotor hover performance.

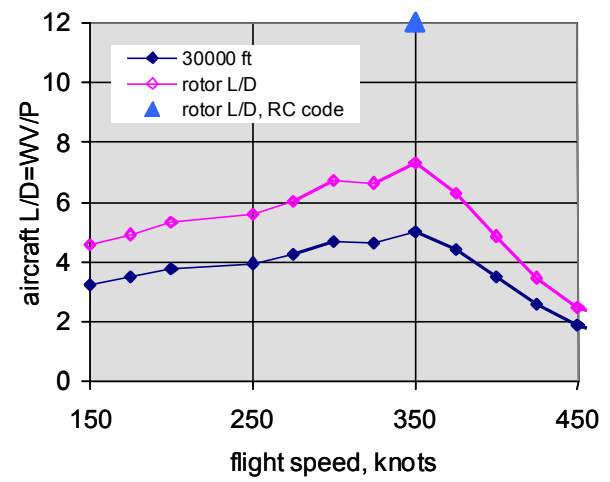

Figure 21. LABC aircraft cruise performance.
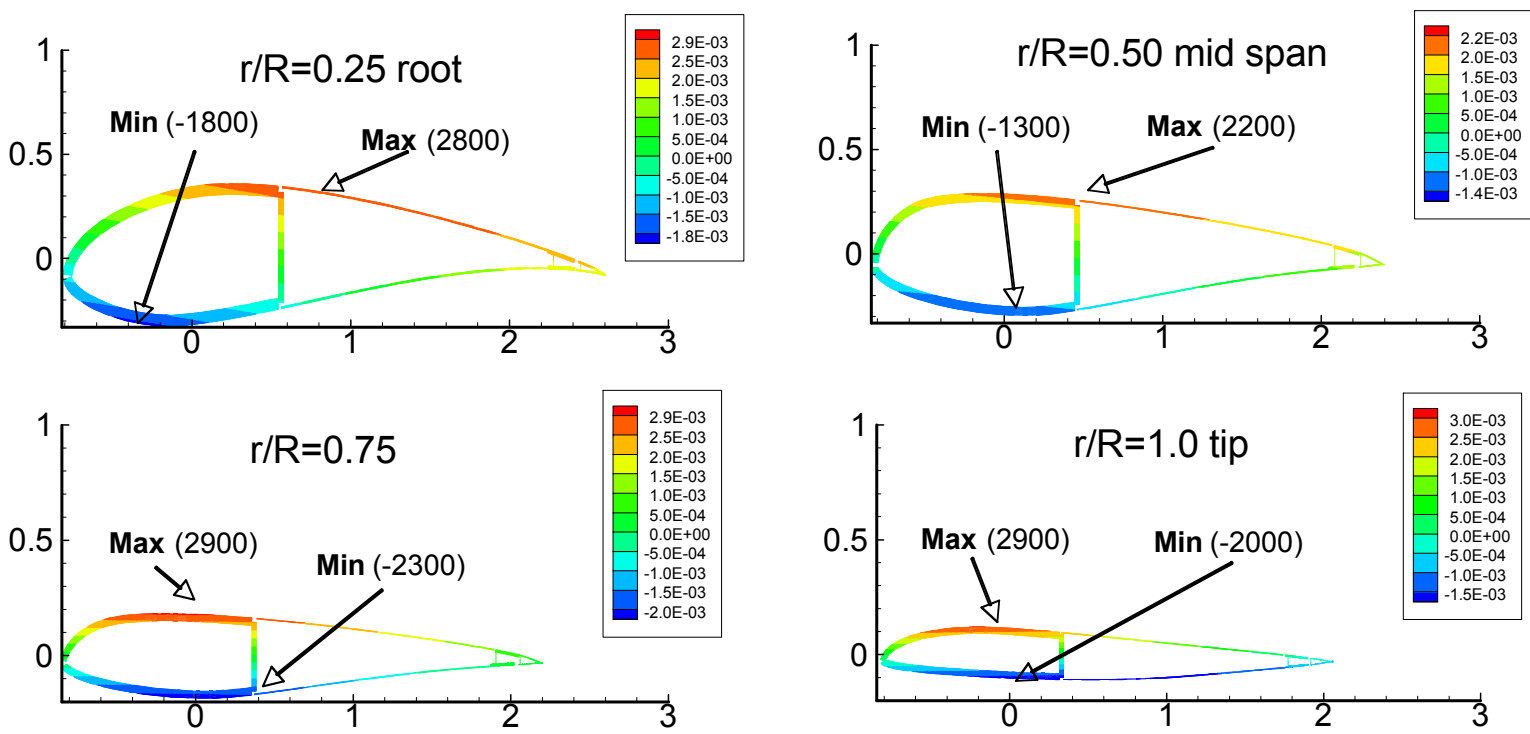

Figure 22. LCTR blade section design; normal strain (microstrain). 

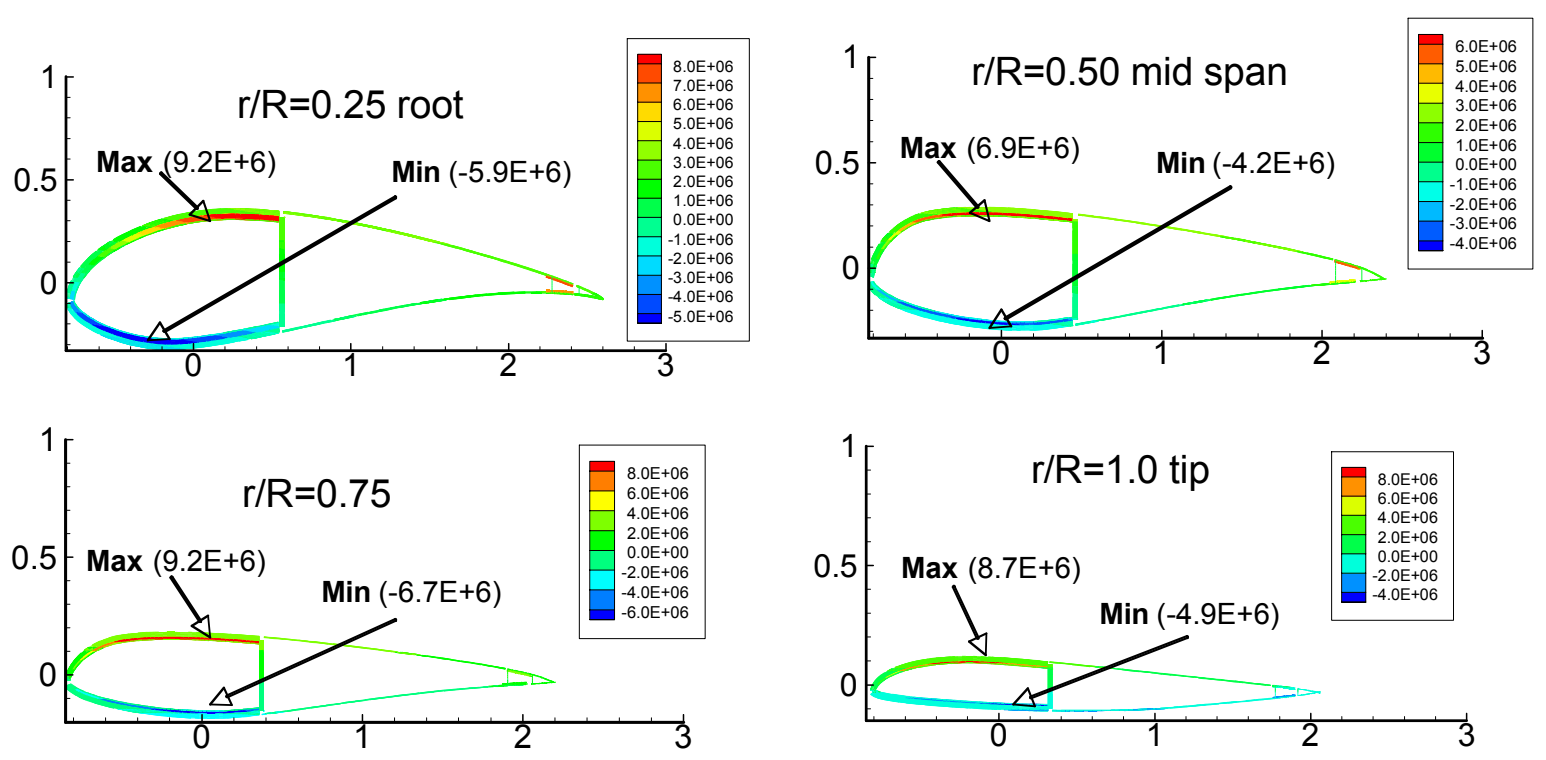

Figure 23. LCTR blade section design; normal stress (lb/ft ${ }^{2}$ ).

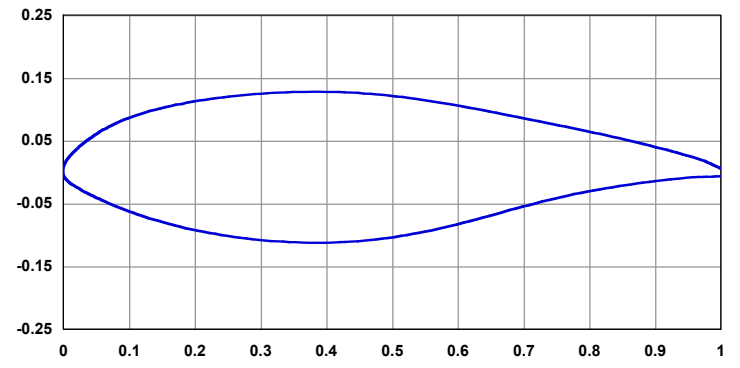

Figure 24. LCTR wing section (24\% thick).

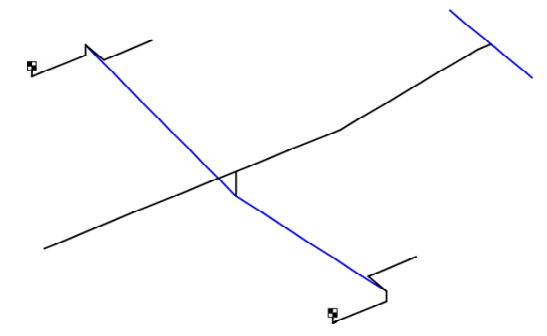

Figure 25. LCTR NASTRAN model (non-structural masses not shown).

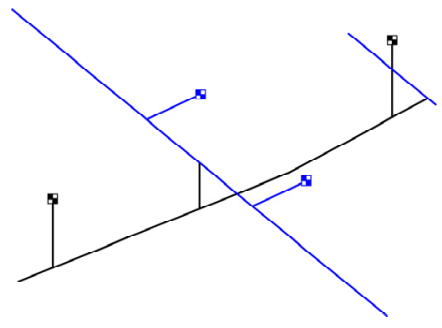

Figure 26. LCTC NASTRAN model (non-structural masses not shown).

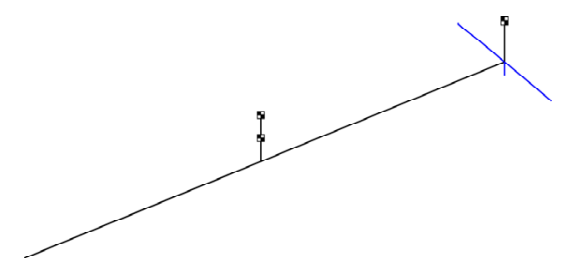

Figure 27. LABC NASTRAN model (non-structural masses not shown). 


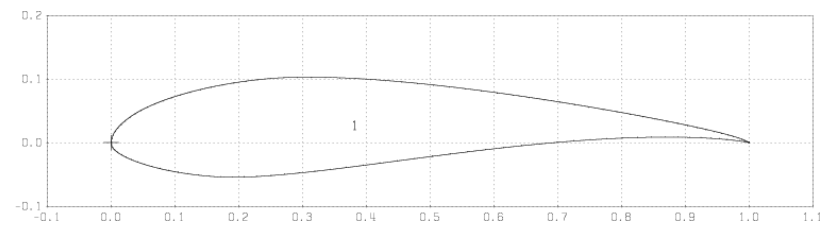

(a) Root section: AFDD CTR1544, $\mathrm{c}_{\mathrm{m}}=-0.160$, $\mathrm{t} / \mathrm{c}=15.3 \%$.

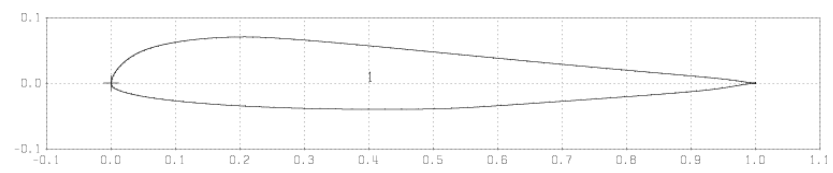

(b) Mid-span section: AFDD CTR4475, $\mathrm{c}_{\mathrm{m}}=0.027$, $\mathrm{t} / \mathrm{c}=11.3 \%$.

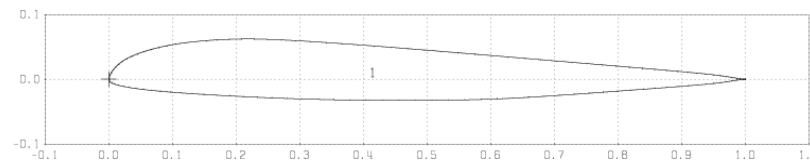

(c) Tip section: AFDD CTR7500, $\mathrm{c}_{\mathrm{m}}=0.014, \mathrm{t} / \mathrm{c}=$ $9.0 \%$.

Figure 28. LCTR airfoil sections.

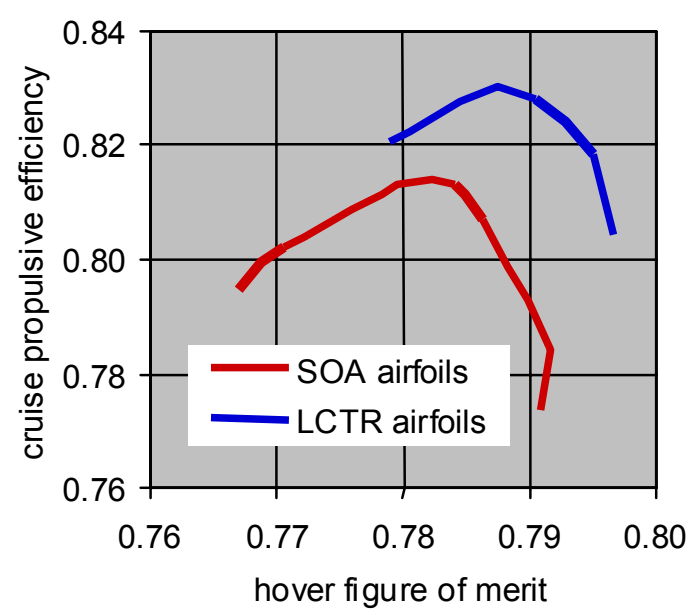

Figure 29. Influence of airfoils on LCTR hover and cruise performance.

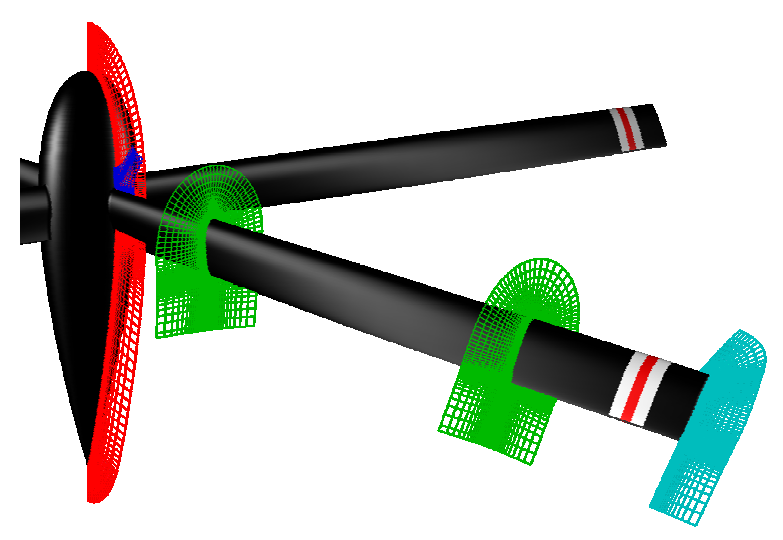

Figure 30. OVERFLOW grid for LCTR rotor and spinner analysis.

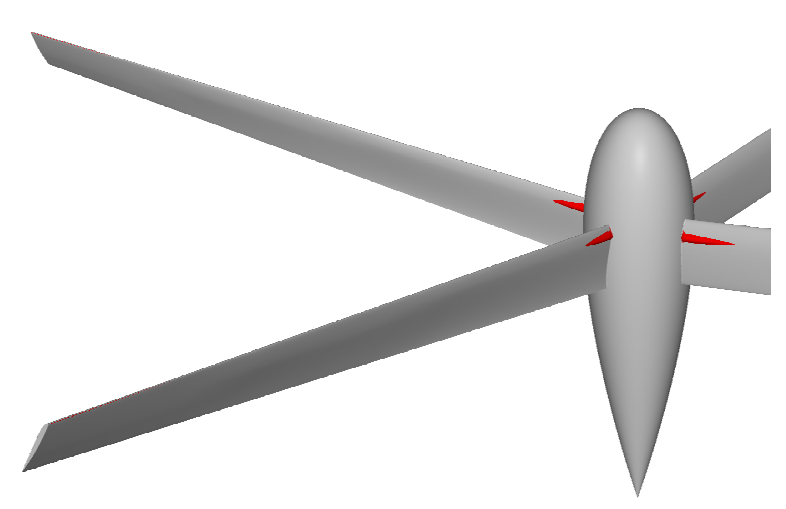

(a) Simple spinner geometry.

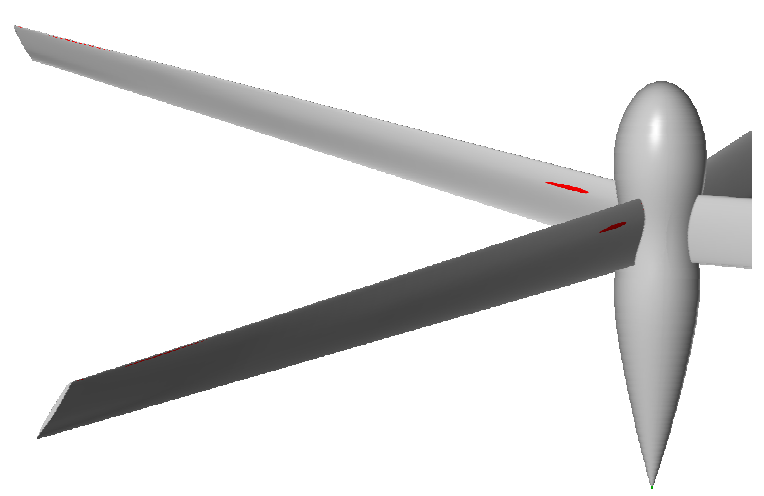

(b) Improved spinner geometry.

Figure 31. Regions of supersonic flow (red area) on LCTR in cruise. 


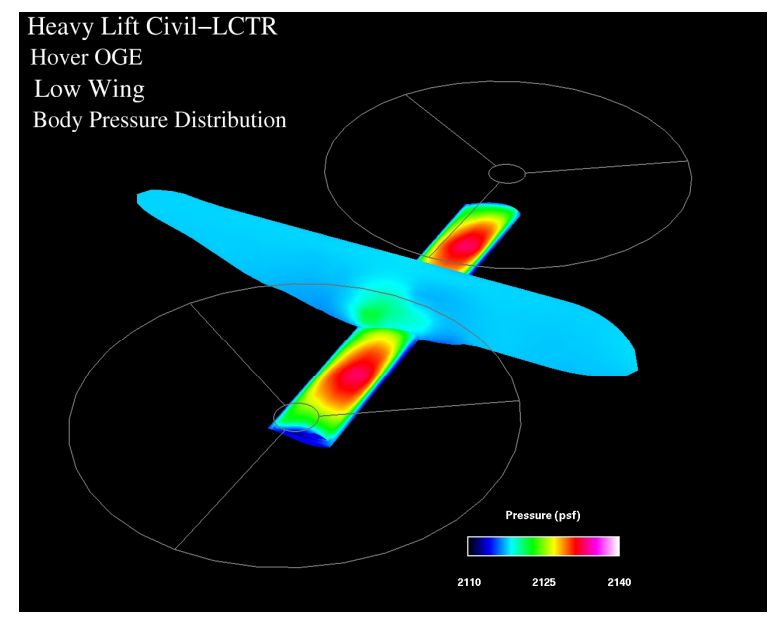

(a) Low wing.

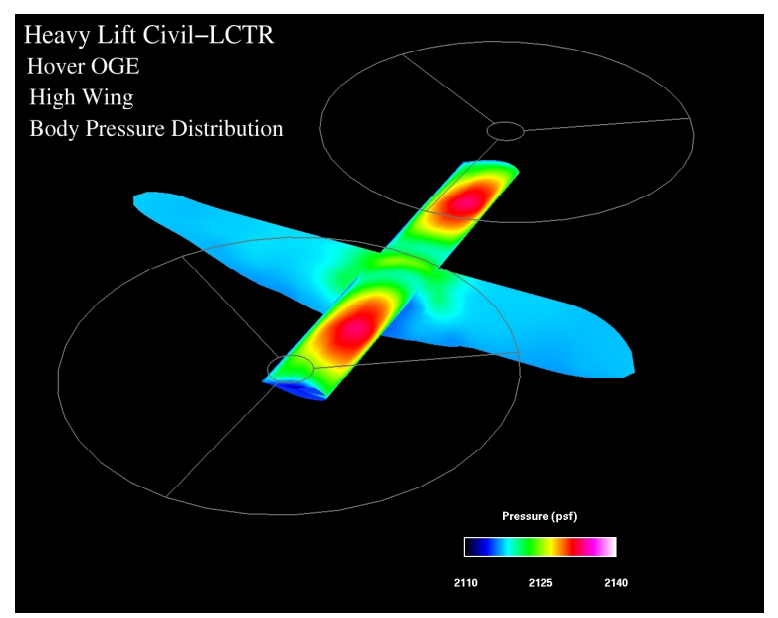

(b) High wing.

Figure 32. Hover download calculation for LCTR: wing and body pressures, comparing high wing and low wing configurations.

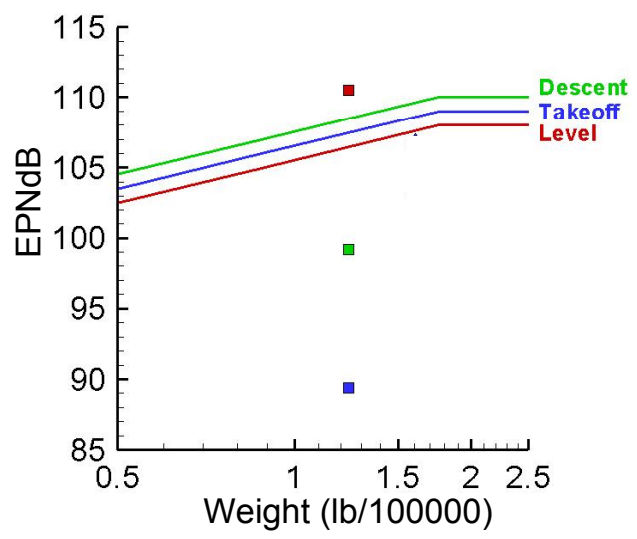

(a) Descent, takeoff, and level flight.

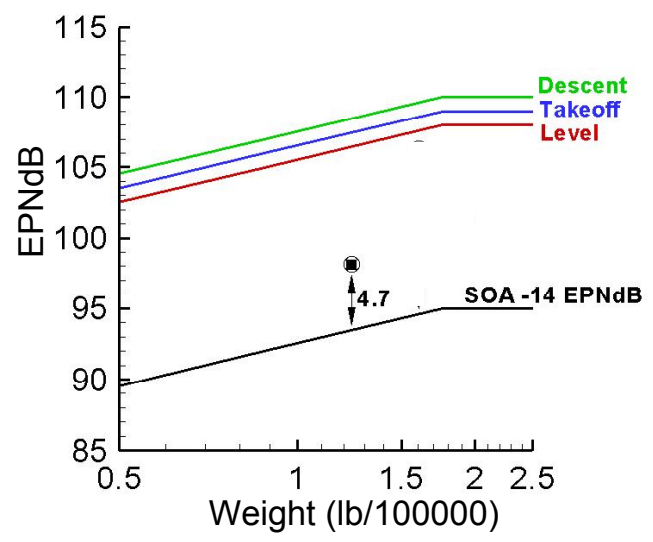

(b) Average.

Figure 33. Assessment of LCTR noise: calculated rotational noise relative current certification requirements and technology goals. 


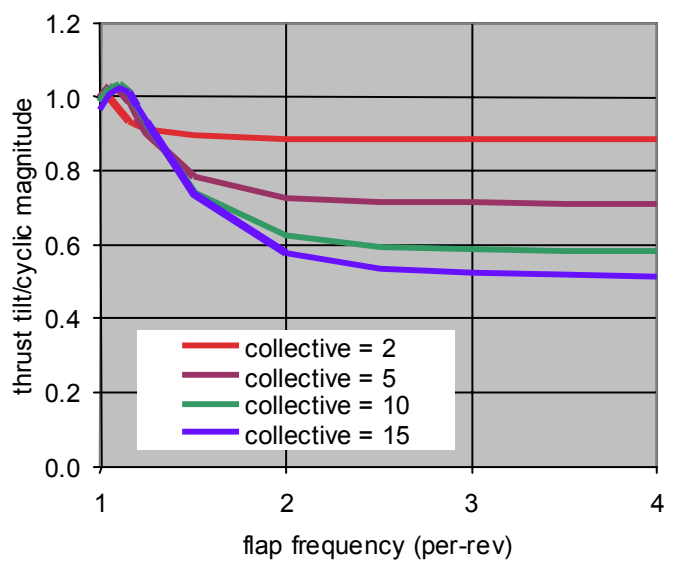

Figure 34. Rotor thrust vector tilt with cyclic control (deg/deg).

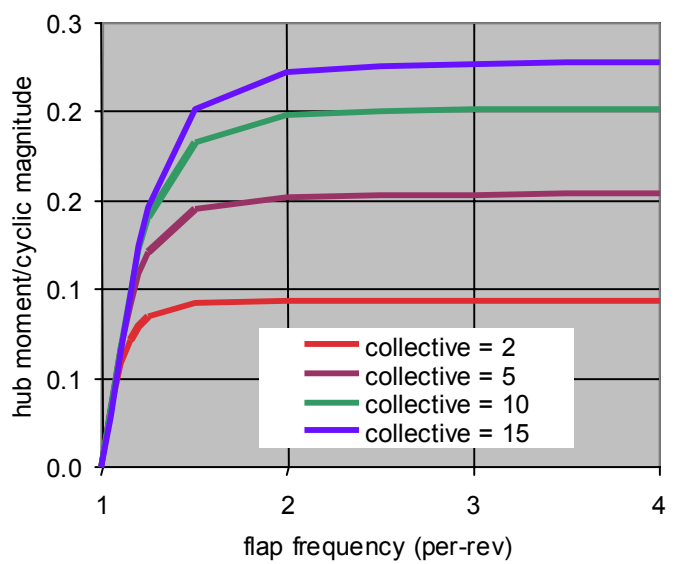

Figure 35. Hub moment produced by cyclic control $\left(\mathrm{C}_{\mathrm{M}} / \sigma\right.$ per rad $)$.
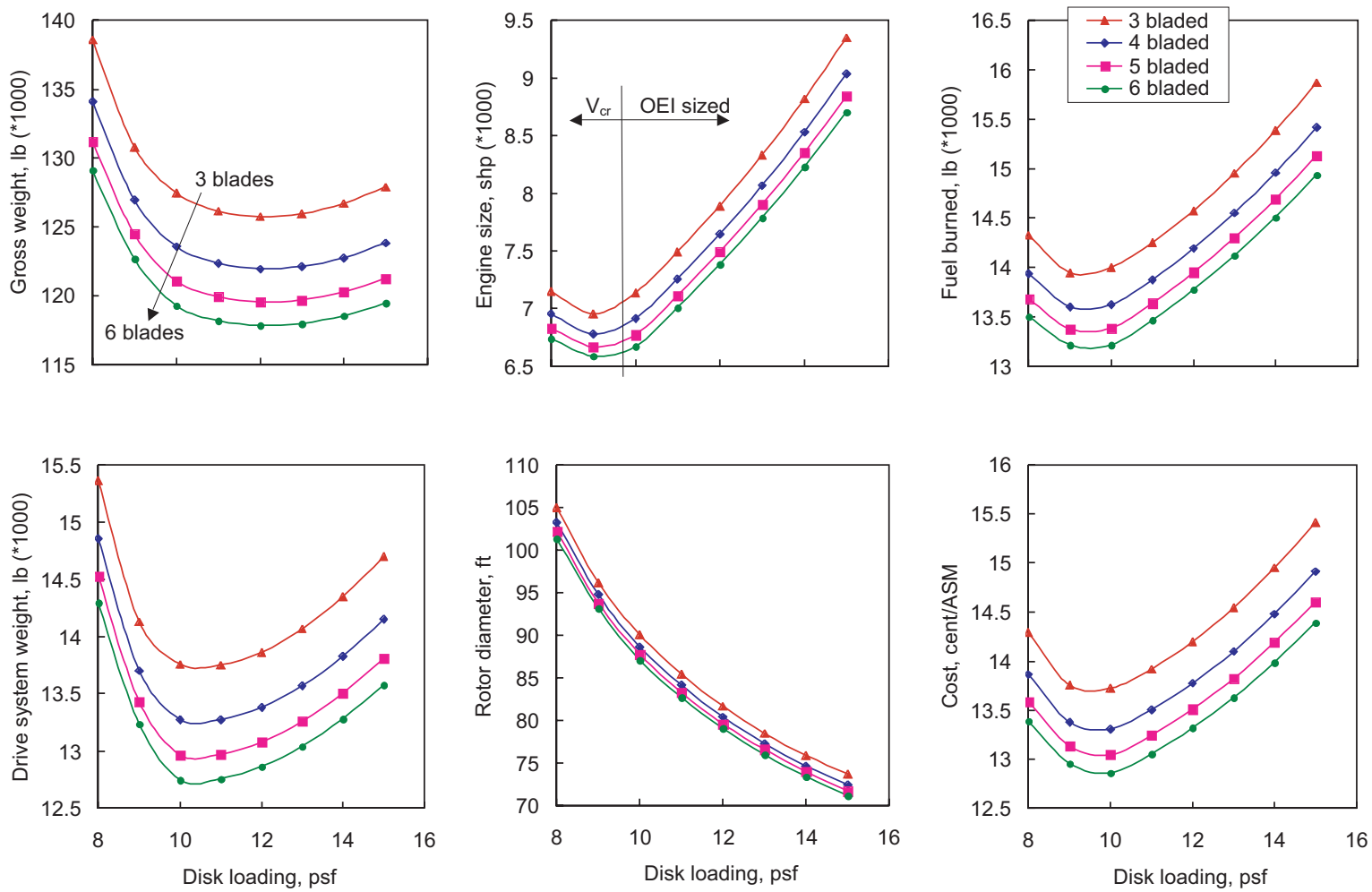

Figure 36. Influence of disk loading and number of blades on the LCTR design (hover tip speed $650 \mathrm{ft} / \mathrm{sec}$, cruise tip speed $350 \mathrm{ft} / \mathrm{sec}$, 4 engines). 

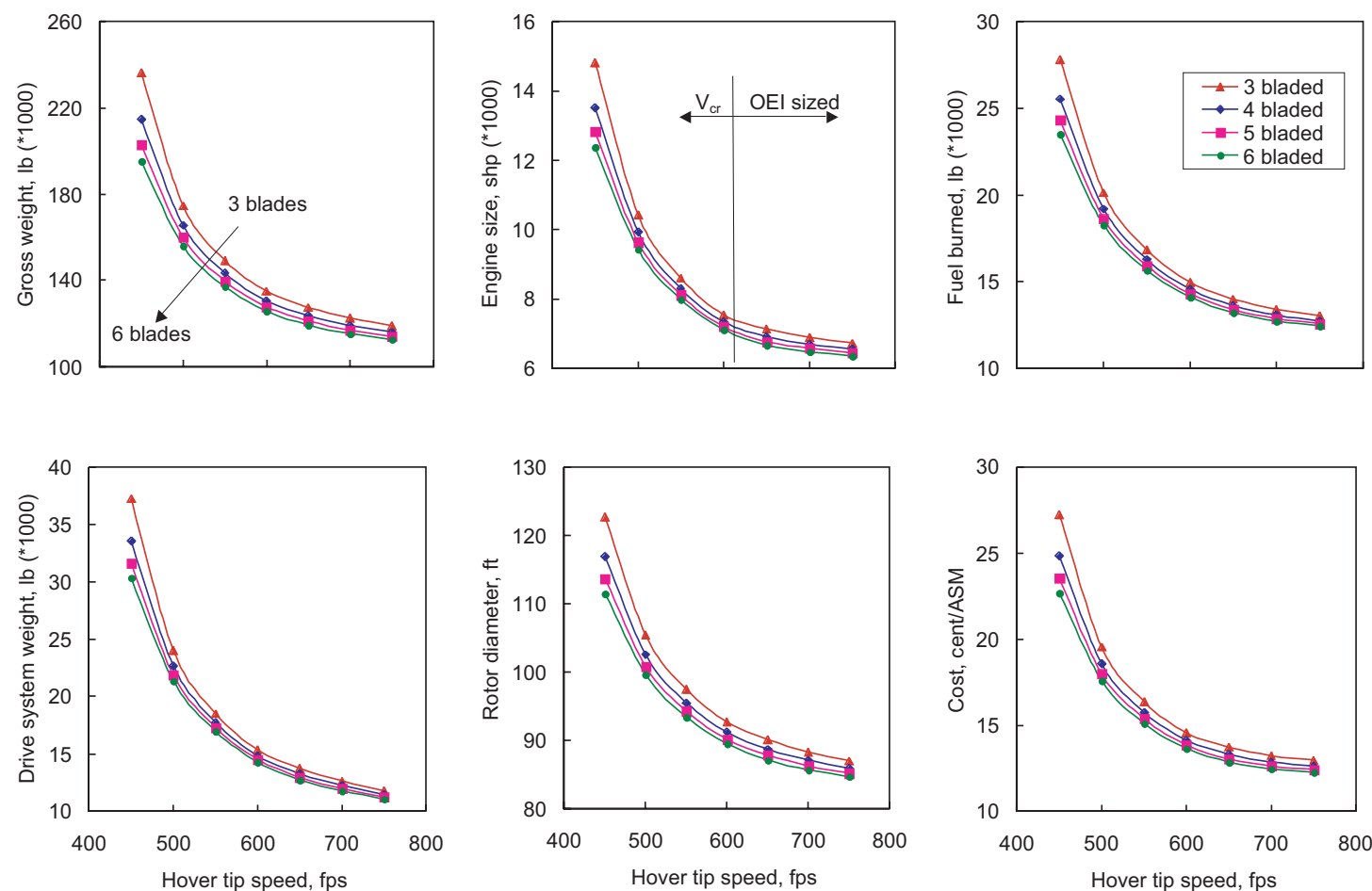

Figure 37. Influence of hover tip speed and number of blades on the LCTR design (cruise tip speed $350 \mathrm{ft} / \mathrm{sec}$, disk loading $10 \mathrm{lb} / \mathrm{ft}^{2}, 4$ engines).
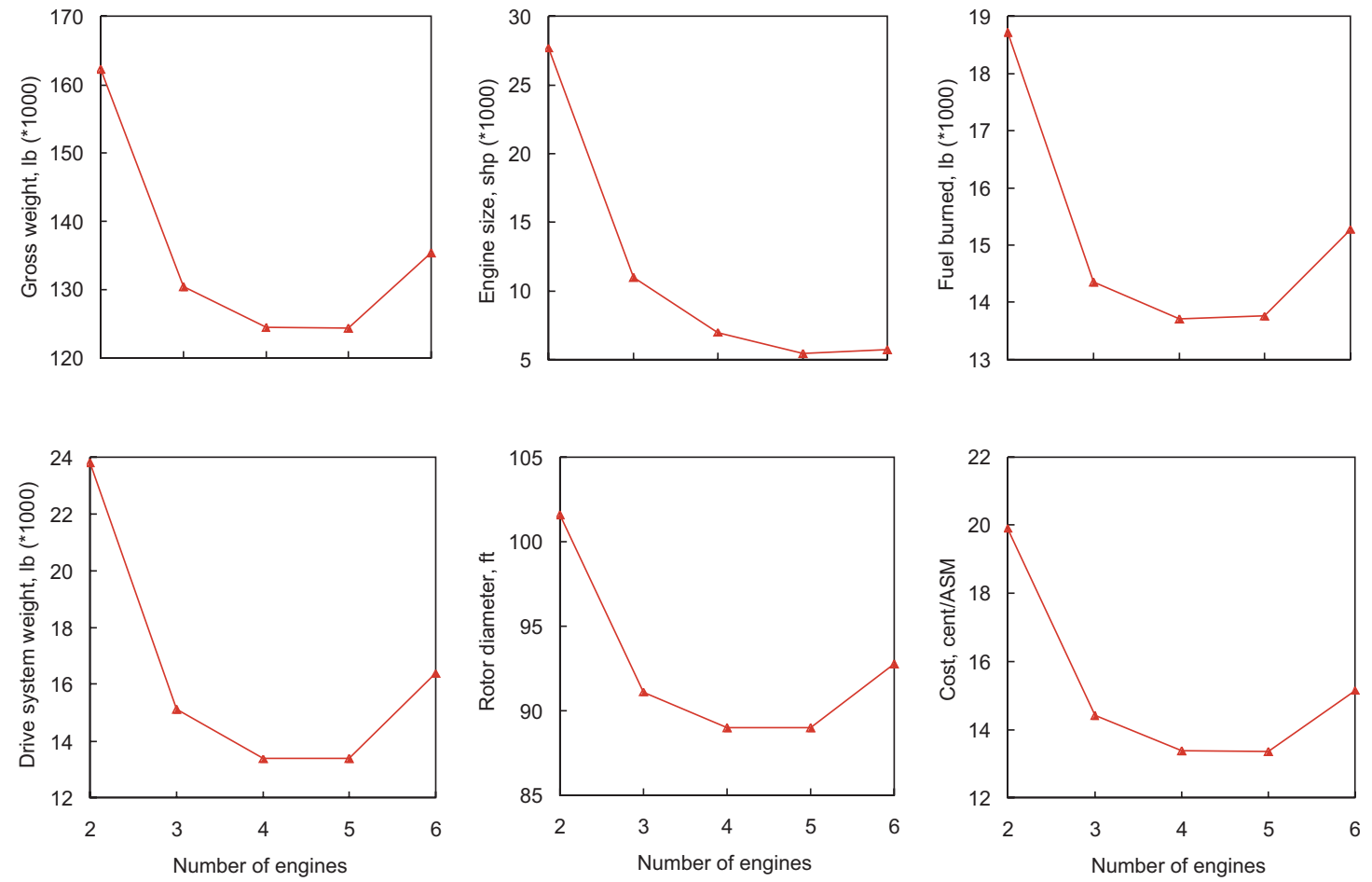

Figure 38. Influence of number of engines on the LCTR design (hover tip speed $650 \mathrm{ft} / \mathrm{sec}$, cruise tip speed $350 \mathrm{ft} / \mathrm{sec}$, disk loading $10 \mathrm{lb} / \mathrm{ft}^{2}, 4$ blades; for 6-engine case there is no cross-shafting, so OEI condition is loss of one engine on each side). 

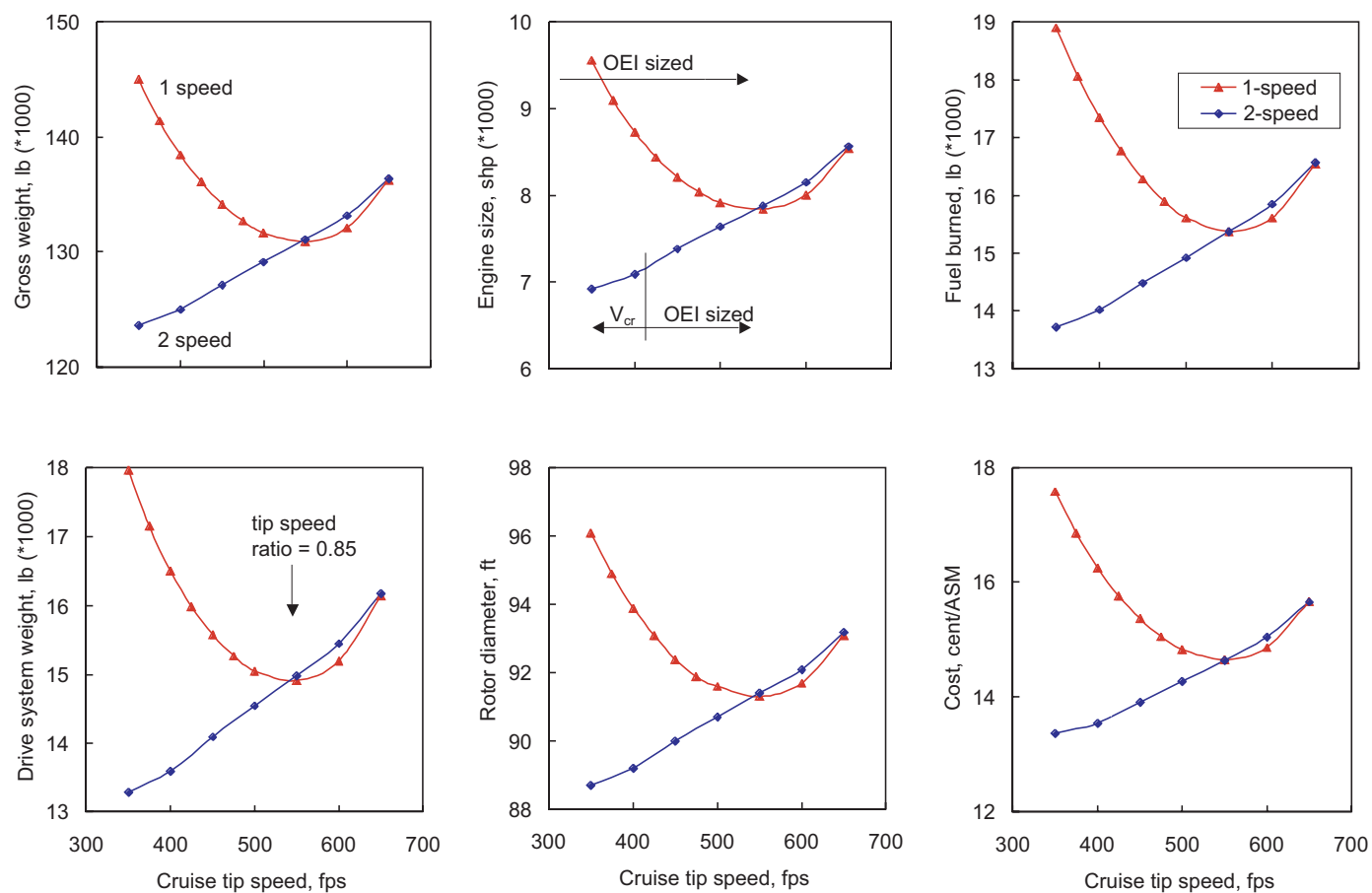

Figure 39. Influence of cruise tip speed on the LCTR design (hover tip speed $650 \mathrm{ft} / \mathrm{sec}$, disk loading $10 \mathrm{lb} / \mathrm{ft}^{2}, 4$ engines, 4 blades), for 1-speed transmission (conventional tiltrotor approach, variable engine rpm) and for 2-speed transmission (optimum engine rpm, with no transmission penalty).
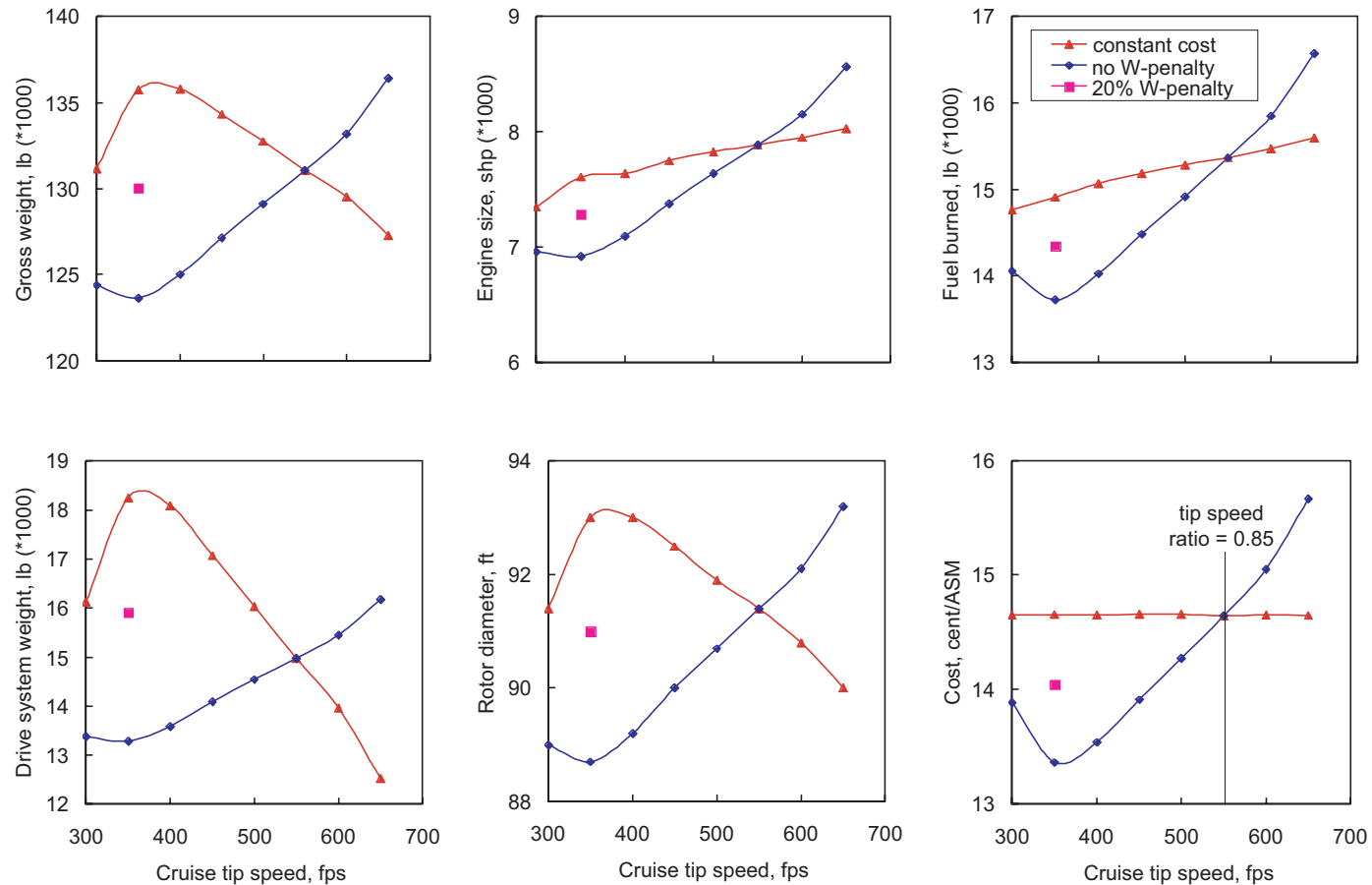

Figure 40. Break-even weight assessment for 2-speed drive system. Influence of cruise tip speed on the LCTR design with 2-speed transmission: with no drive system weight penalty, with $20 \%$ transmission weight penalty, and with transmission weight adjusted for constant operating cost (hover tip speed $650 \mathrm{ft} / \mathrm{sec}$, disk loading $10 \mathrm{lb} / \mathrm{ft}^{2}, 4$ engines, 4 blades). 

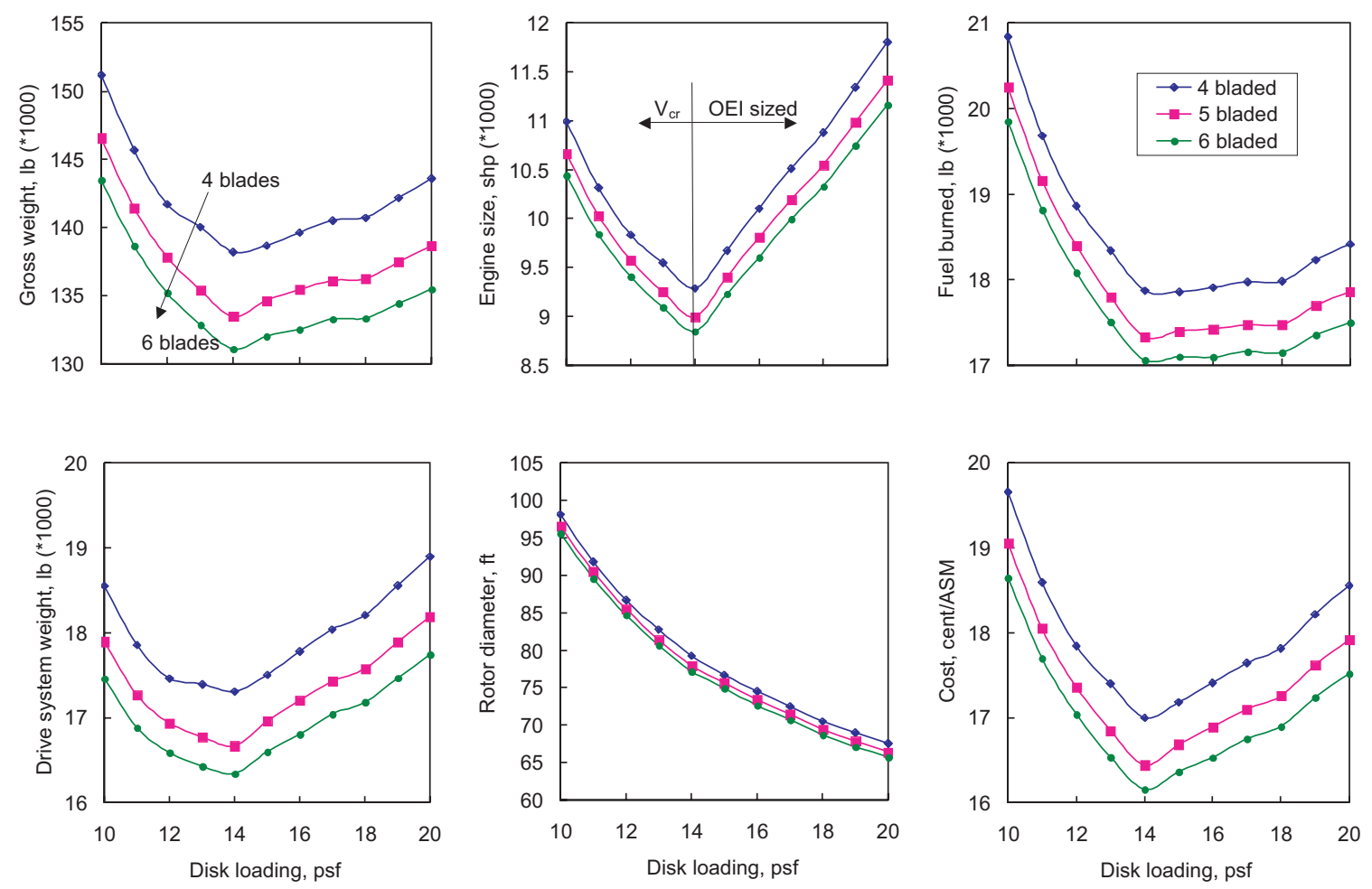

Figure 41. Influence of disk loading and number of blades on the LCTC design (hover tip speed $650 \mathrm{ft} / \mathrm{sec}$, cruise tip speed $205 \mathrm{ft} / \mathrm{sec}, 4$ engines).
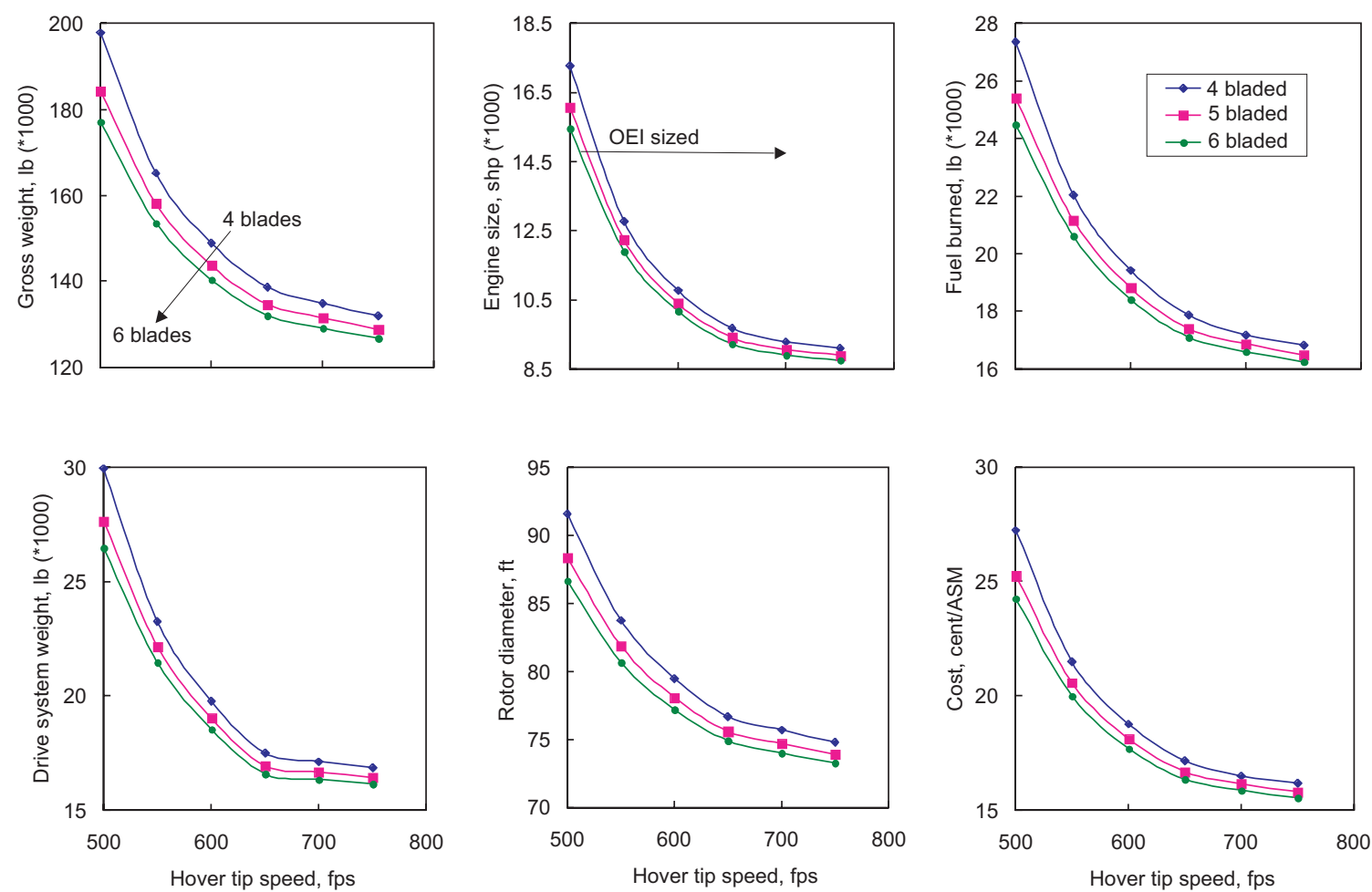

Figure 42. Influence of hover tip speed and number of blades on the LCTC design (cruise tip speed $205 \mathrm{ft} / \mathrm{sec}$, disk loading $15 \mathrm{lb} / \mathrm{ft}^{2}, 4$ engines). 

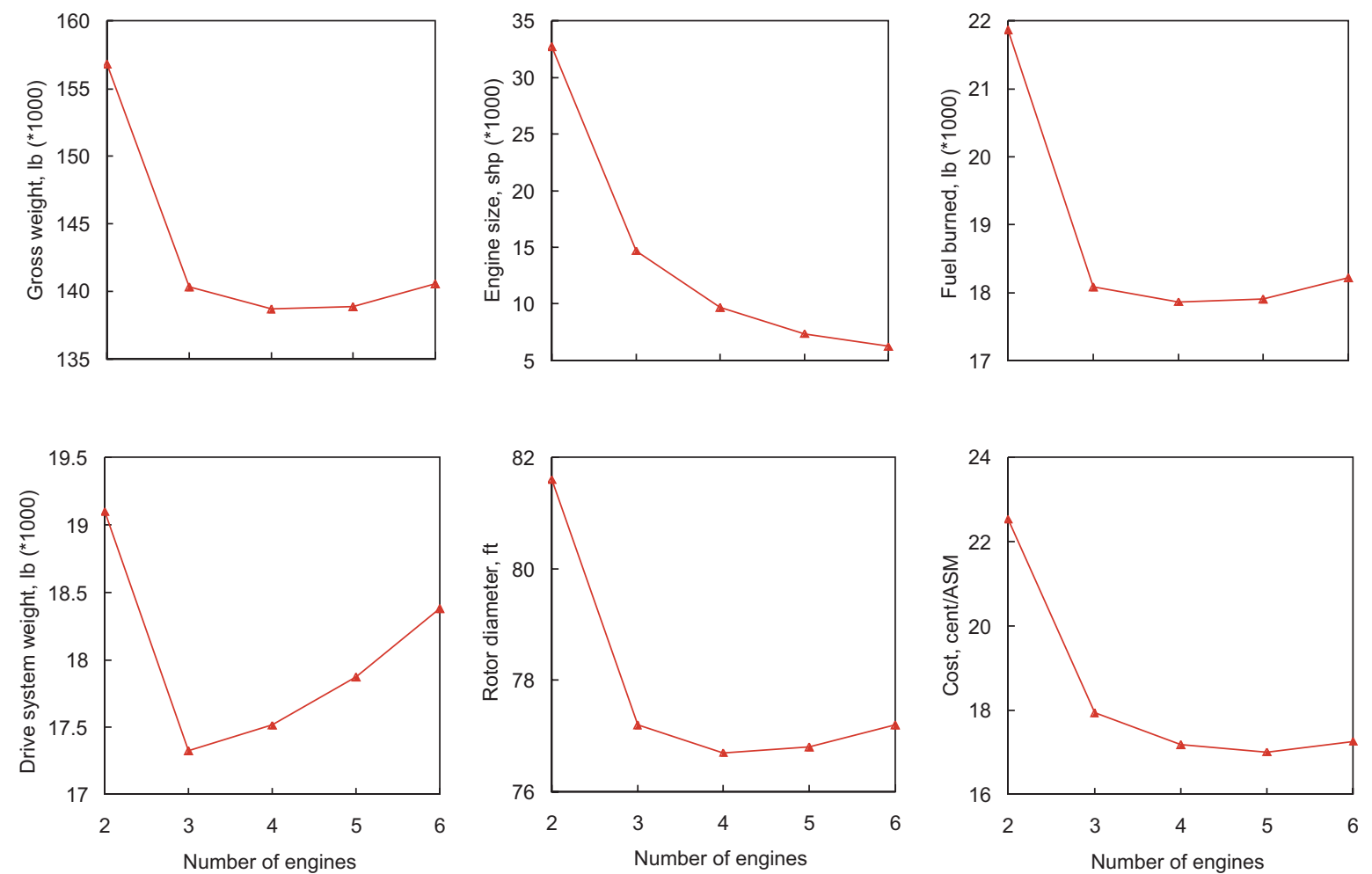

Figure 43. Influence of number of engines on the LCTC design (hover tip speed $650 \mathrm{ft} / \mathrm{sec}$, cruise tip speed $205 \mathrm{ft} / \mathrm{sec}$, disk loading $15 \mathrm{lb} / \mathrm{ft}^{2}, 4$ blades). 
LCTR

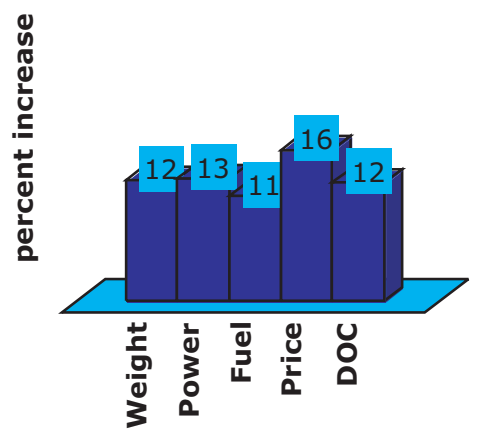

LCTC

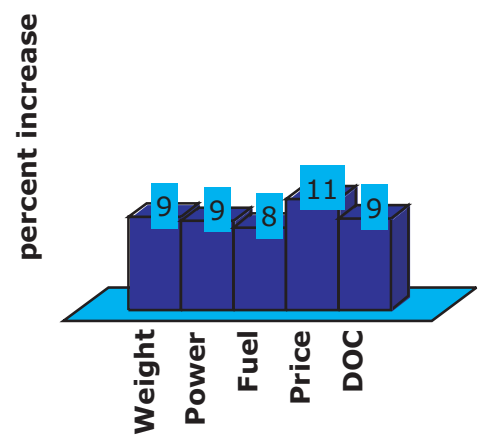

(a) Rotor blade and hub weight (advanced technology factors 0.79 and 0.96 respectively).
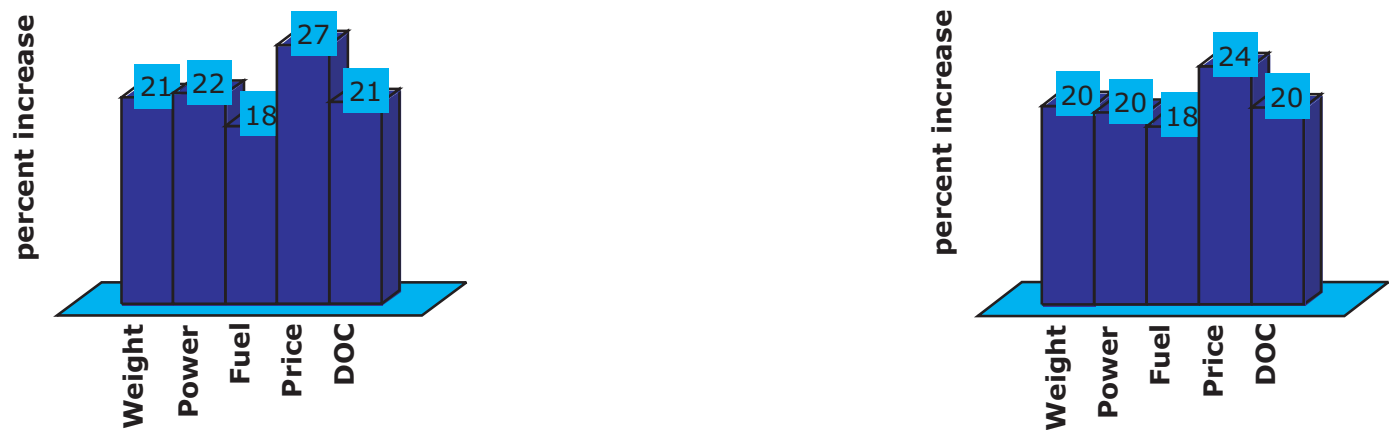

(b) All structural weight.
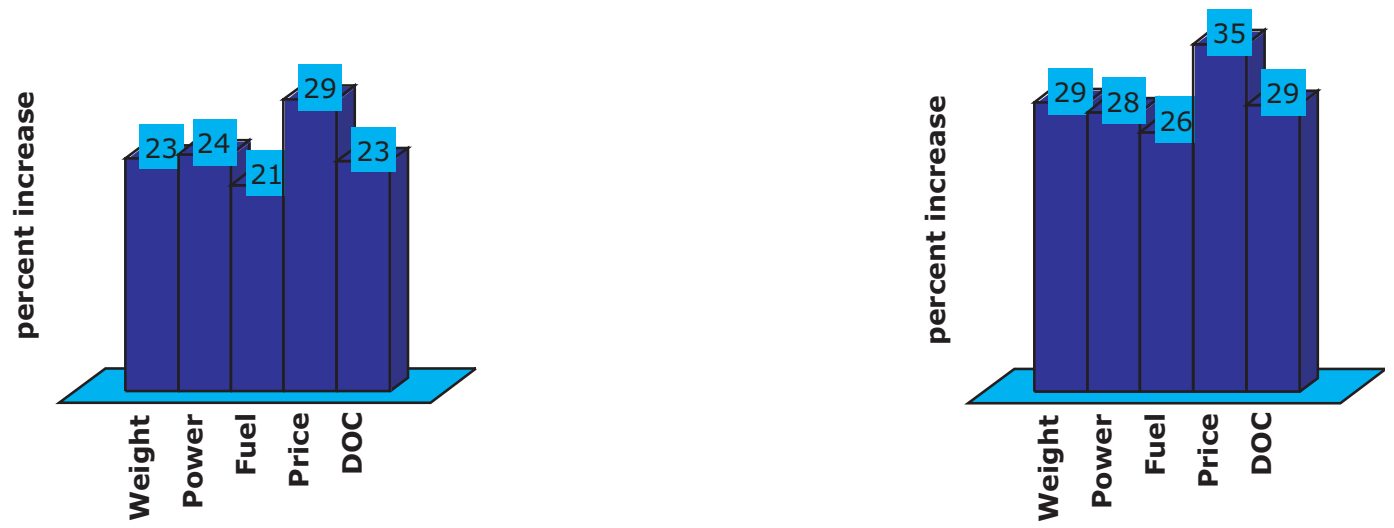

(c) Drive system weight (advanced technology factor 0.67).

Figure 44. Impact of technology on the LCTR and LCTC designs: percentage increase caused by changing the technology from advanced to current level. 


\section{LCTR}

$\square+0.25 \mathrm{D} / \mathrm{q}$

$\square-0.25 \mathrm{D} / \mathrm{q}$

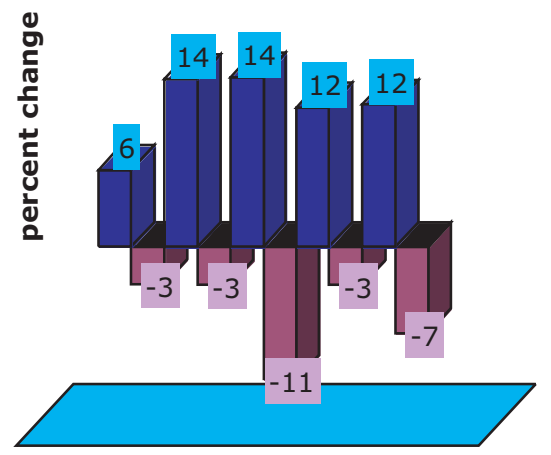

(a) Airframe drag ( $\pm 25 \%$ relative baseline).
LCTC

$\mathbf{\square}+0.25 \mathrm{D} / \mathrm{q}$

$\square-0.25 \mathrm{D} / \mathrm{q}$

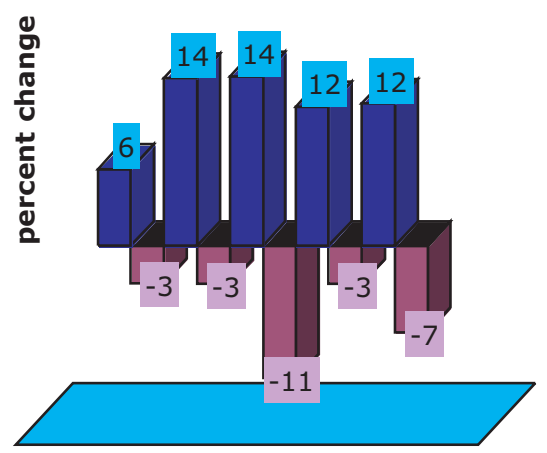

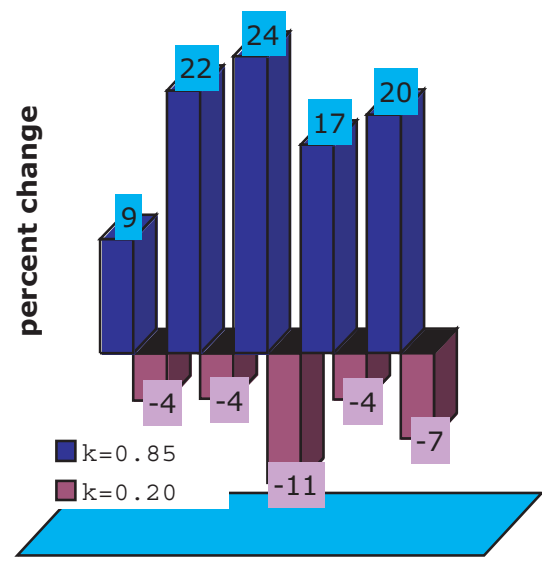

(b) Hub drag, $\mathrm{D} / \mathrm{q}=\mathrm{k}(\mathrm{W} / 1000)^{2 / 3}(\mathrm{k}=0.85(\mathrm{SOA})$ and 0.20 , relative baseline $\mathrm{k}=0.44)$.
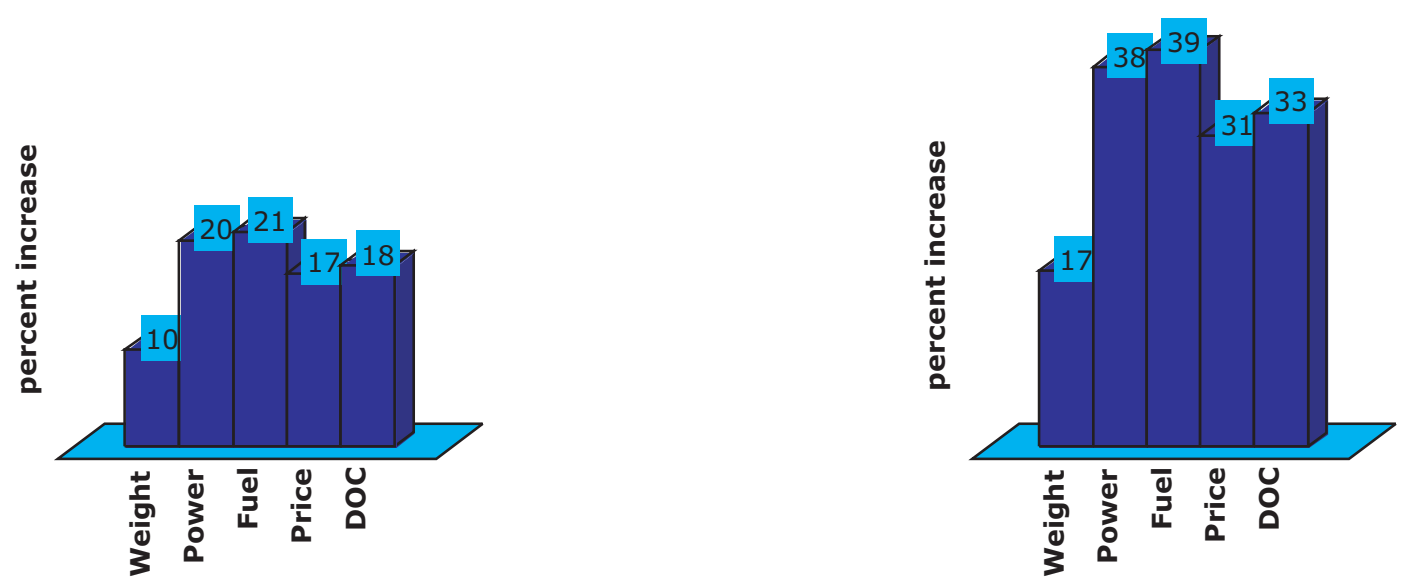

(c) All aerodynamics.

Figure 45. Impact of technology on the LCTR and LCTC designs: percentage increase caused by changing the technology from advanced to current level. 


\section{LCTR}

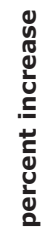

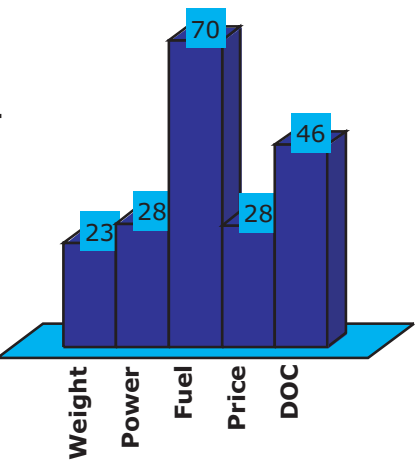

\section{LCTC}

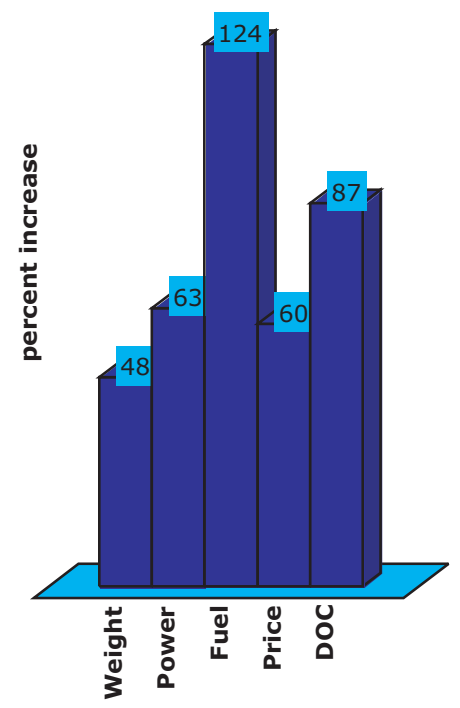

(a) Engine technology (current relative advanced; note change of scale relative other figures).
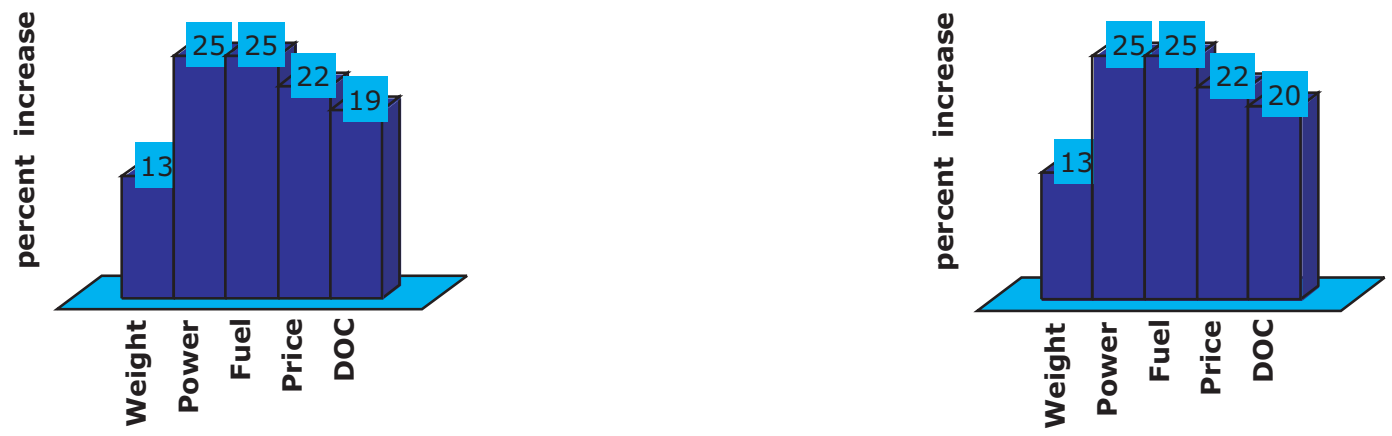

(b) Penalty for weight and power contingency.

Figure 46. Impact of technology on the LCTR and LCTC designs: percentage increase caused by changing the technology from advanced to current level. 


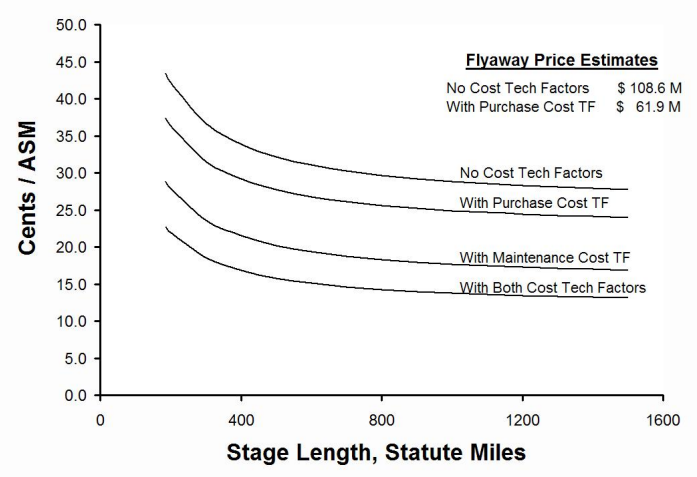

Figure 47. Effect of cost technology factors on flyaway price (2005 USD) and DOC+I (2005 cents/ASM) for LCTR.
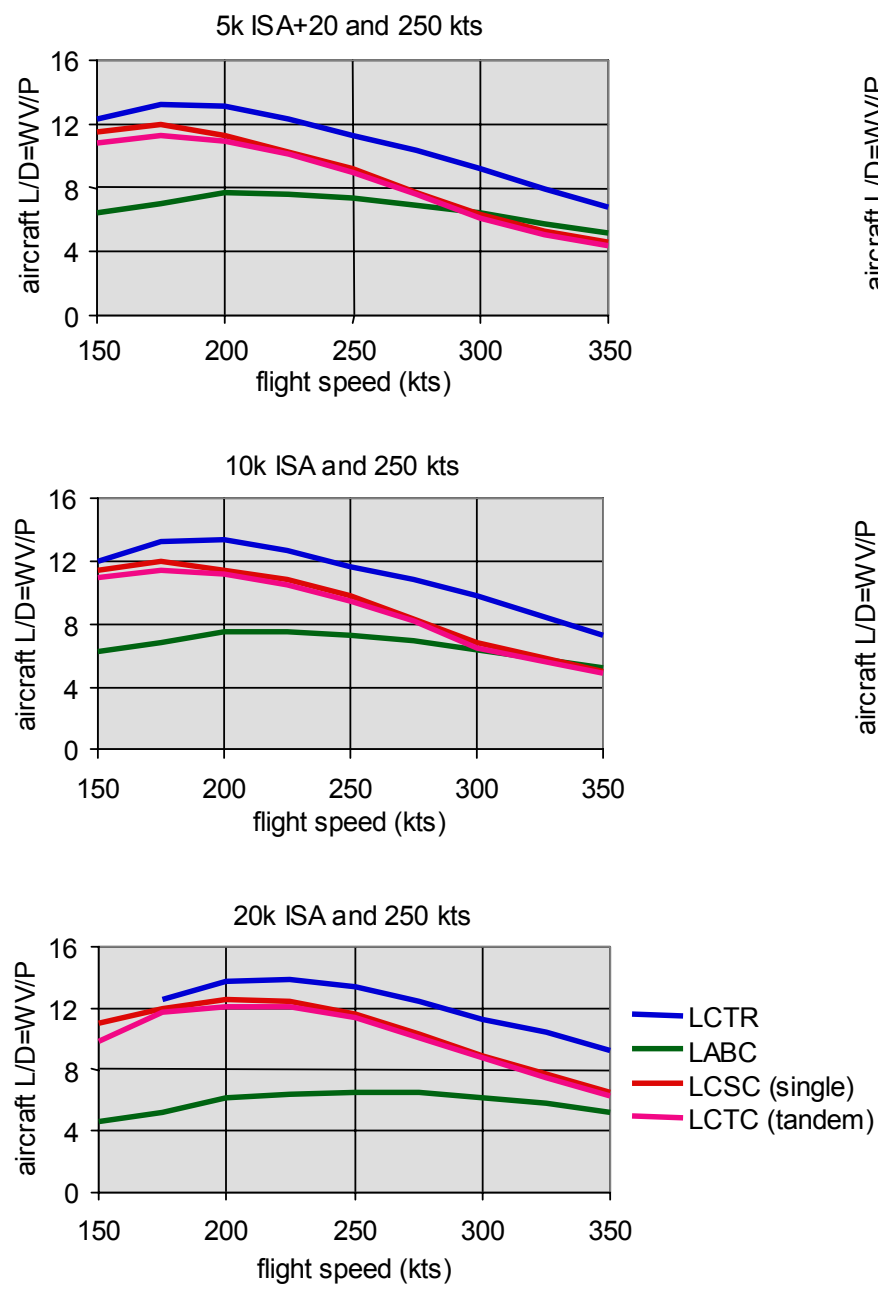

Figure 49. Aircraft L/D for different design conditions. $\square$ Maintenance $\square$ Crew $\square$ Fuel $\square$ Depreciation $\square$ Insurance $\square$ Finance

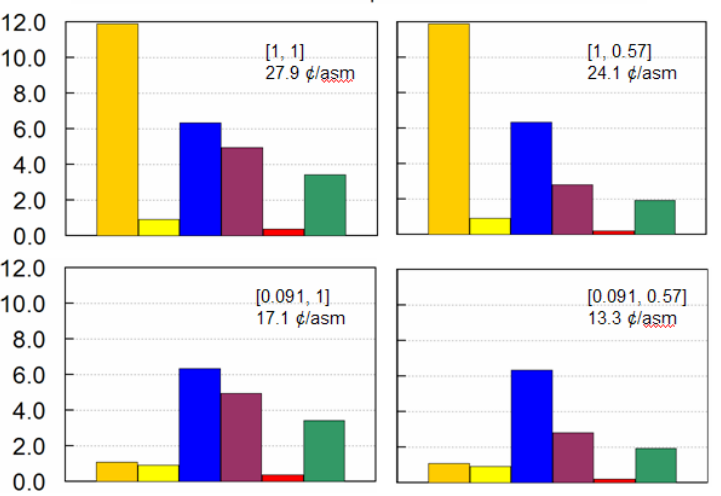

Figure 48. Cost elements compared for LCTR with and without cost technology factors for lift rotorcraft (1200 nm, 120 passengers); in legend $[\mathrm{x}, \mathrm{y}], \mathrm{x}$ is maintenance factor and $\mathrm{y}$ is price factor.
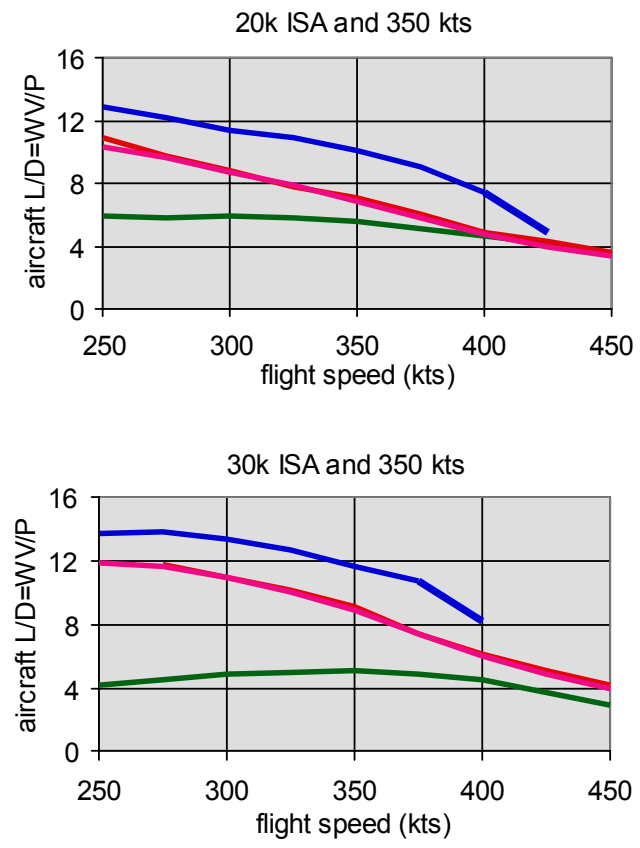


\section{APPENDIX A}

\section{ROTORCRAFT SECTOR GOTCHA}

The Rotorcraft Sector goals, objectives, technical challenges, and approaches (GOTChA) are presented in table 2, and in more detail in figures A1 and A2.

\section{Hover Efficiency Goal}

The hover efficiency goal is $\mathrm{W} / \mathrm{P}=6(\mathrm{SOA}=4.3)$, where $\mathrm{W}$ is the gross weight $(\mathrm{lb})$ and $\mathrm{P}$ the installed power (hp).

The SOA is derived from the V-22 and $\mathrm{CH}-53 \mathrm{X}$ :

$$
\begin{array}{ll}
\text { V-22: } & \mathrm{W}=53000 \mathrm{lb}, \mathrm{P}=12300 \mathrm{HP} \\
\mathrm{CH}-53 \mathrm{X}: & \mathrm{W}=80000 \mathrm{lb}, \mathrm{P}=18605 \mathrm{HP}
\end{array}
$$

which gives $\mathrm{W} / \mathrm{P}=4.3$.

The objective is to increase overall hover efficiency by $40 \%$ for large rotorcraft.

The disk loading of the V-22 and CH-53X is approximately $20 \mathrm{lb} / \mathrm{ft}^{2}$. For the 120 -passenger notional vehicle, the rotor size will be larger than SOA but the weight and disk loading must be reduced from SOA levels in order to increase hover efficiency and have the low power required. Assume a target disk loading of $10 \mathrm{lb} / \mathrm{ft}^{2}$ for the notional vehicle and a figure of merit $(\mathrm{M})$ unchanged from SOA levels. The disk loading is W/A, and the definition of figure of merit gives $\mathrm{W} / \mathrm{P}=\mathrm{M}(2 \rho \mathrm{A} / \mathrm{W})^{9 / 2}$. So a factor of 2 reduction in disk loading gives $\mathrm{W} / \mathrm{P}=4.3 * 2^{1 / 2}=6$.

\section{Efficient Cruise Goal}

The efficient cruise goal is $\mathrm{L} / \mathrm{D}=12(\mathrm{SOA}=6.5)$, where $\mathrm{L}$ is the aircraft lift $(\mathrm{lb})$ and $\mathrm{D}$ is the aircraft drag (lb).

The SOA value of 6.5 is based on the approximate L/D of the V-22 airframe in airplane mode at $\mathrm{W}=$ $53000 \mathrm{lb}$ (ref. V-22 Aerodynamic Report 901-909-6, Rev A, Sheet 70.5).

The objective is to reduce the drag by $44 \%$ at a cruise Mach number of 0.6 .

From plots of airframe drag D/q ( $\mathrm{ft}^{2}$ ) versus aircraft gross weight W (courtesy F. D. Harris), $\mathrm{D} / \mathrm{q}=\mathrm{K}(\mathrm{W} / 1000)^{2 / 3}$, with $\mathrm{K}=2.5$ for 1980 helicopter technology and $\mathrm{K}=1.4$ for 1980 propeller driven fixedwing aircraft. Taking propeller driven fixed-wing drag levels as the goal, the percent reduction is $100 *(2.5-$ $1.4) / 2.5=44 \%$. This reduction in drag increases the airframe L/D from 6.5 to 11.6.

\section{Empty Weight Goal}

The empty weight fraction (excluding engine) goal is $\mathrm{W}_{\mathrm{e}} / \mathrm{W}=0.41(\mathrm{SOA}=0.55)$, where $\mathrm{W}$ is the gross weight (lb), and for this purpose 


$$
\mathrm{W}_{\mathrm{e}}=\text { gross } \mathrm{wt}-\text { fuel } \mathrm{wt}-\text { payload } \mathrm{wt}-\text { operating item } \mathrm{wts}-\text { engine } \mathrm{wt}
$$

or

$\mathrm{W}_{\mathrm{e}}=$ airframe structure $\mathrm{wt}+$ airframe systems and equipment (including furnishings) $\mathrm{wt}+$ rotor system $w t+$ transmission/drive system wt

The rotor system is defined as the rotor blades, the control system (swash plate, linkages, etc.), and hub.

The SOA value is based on the V-22 (weights obtained from Bell-Agusta and "Pocket Guide V-22 Osprey" by the Bell-Boeing Team, March 2000):

$$
\begin{aligned}
& \text { gross weight }=53000 \mathrm{lb} \\
& \text { engine weight }=2(1889)=3778 \mathrm{lb} \\
& \text { fuel }+ \text { payload weight }=20000 \mathrm{lb}
\end{aligned}
$$

So $\mathrm{W}_{\mathrm{e}}=53000-20000-3778=29222$ and $\mathrm{W}_{\mathrm{e}} / \mathrm{W}=29222 / 53000=0.55$. Note that the conventional definition of operating empty weight is gross weight less fuel and payload, giving OWE/GW = 33000/ $53000=0.62$.

The objectives are (1) reduce rotor weight by $25 \%$; (2) reduce subsystem weight (drive system, high-lift, etc.) by $25 \%$; (3) reduce airframe structural weight by $25 \%$. Assuming all weight sources contributing to $\mathrm{W}_{\mathrm{e}}$ are reduced by $25 \%$ gives a goal of $\mathrm{W}_{\mathrm{e}} / \mathrm{W}=0.75(0.55)=0.41$.

\section{Community Noise Goal}

The community noise goal is a reduction of $14 \mathrm{EPNdB}$ below SOA level (SOA = Stage 2 certification microphones average level over 3 flight conditions).

The SOA noise level is a function of helicopter gross weight and flight condition. For a given rotorcraft, the SOA will be the average value measured by the 3 certification microphones during take-off, approach, and level flight.

The Goal assumes a reduction in the measured sound pressure level of $80 \%: 20 * \log (.2)=-14 \mathrm{db}$.

The objectives are (1) reduce source noise by design and active control; (2) reduce noise impact by flight operational procedures; ( 1 and 2 combined) reduce rotorcraft system noise by $80 \%$.

For rotorcraft, noise reduction will be achieved through a combination of source noise reduction and lownoise flight operational procedures. Assigning noise reduction metrics to each objective is not appropriate. Noise reductions achieved via objective 1 or 2 separately are not necessarily additive. A reduction of rotorcraft system noise by $80 \%$ is consistent with the Goal of $14 \mathrm{EPNdB}$ noise reduction.

\section{Flight Control Goal}

The flight controls and systems goal is to enable certifiable near-all-weather operations (CAT IIIC; SOA = Special VFR). 
The SOA is GPS helicopter IFR. Current operations are similar to ground-based non-directional beacon, to a point in space with final approach to landing done with visual reference. This typically requires "Special VFR" operation (1000 ft ceiling and 1 mile visibility). Lower visibility requirements are attainable with appropriate equipment at airports. This requires use of the ground-based Instrument Landing System (ILS) and use of an approved helicopter IFR approach, typically flown at a constant speed of 90 knots until breakout into visual conditions. The 90 knots speed requires some visibility for the deceleration to landing.

Cat. IIIA goal for "austere" operations: IFR approach to Cat. IIIA visibility (decision height less than 100 feet and visibility of 700 feet RVR) without extensive ground infrastructure or equipage (FAA AC-120-28D).

Cat. IIIC goal at "equipped" airports: "Zero" visibility IFR operations at sites with some ground infrastructure (e.g. differential GPS) and surveyed approach/departure paths and sanitized touch-down surface.

The objective is to remove restrictions for rotorcraft operations in zero visibility and near all weather conditions (CAT IIIC).

\section{Advanced Engine Performance Goal}

The advanced engine performance goal is SFC of SOA-10\%, and SHP/eng-wt of $120 \%$ SOA.

The CT7-8 (commercial version of the GE T-700) is defined as the SOA engine.

The SFC and SHP/eng-wt goals were established under IHPTET/VAATE. The SFC metric under IHPTET was SOA-40\%, but since IHPTET was initiated nearly 20 years ago, the SOA has changed and therefore the metric was changed to SOA-10\%.

The objectives are (1) capitalize on new engine technology to improve performance, weight, noise of rotorcraft systems; (2) reduce engine weight by $20 \%$.

\section{Cabin Noise and Vibration Goals}

The cabin noise and vibration goal is reduction to $77 \mathrm{dbA}$ and $0.05 \mathrm{~g}$ throughout the flight envelope (SOA = $88 \mathrm{dBA}$ and $0.15 \mathrm{~g})$.

The SOA interior noise levels were provided by a technical representative of a large US rotorcraft manufacturer and indicate the interior noise and vibration of a large commercial passenger helicopter with a VIP interior cabin treatment. Average interior noise levels in cruise range from 86 to $90 \mathrm{~dB}(\mathrm{~A})$ with an average level of $88 \mathrm{~dB}(\mathrm{~A})$. Hover levels averaged $79 \mathrm{~dB}(\mathrm{~A})$. Vibration levels are $0.15 \mathrm{~g}$ or below.

The desired interior noise for rotorcraft is $77 \mathrm{~dB}(\mathrm{~A})$, which is the average interior noise of the existing fixedwing subsonic commercial aircraft fleet as of 2003. The desired interior vibration levels are $0.05 \mathrm{~g}$, a $10 \mathrm{~dB}$ reduction relative the current SOA.

The objective is passenger acceptance: noise and vibration levels comparable to current fixed-wing subsonic aircraft. 


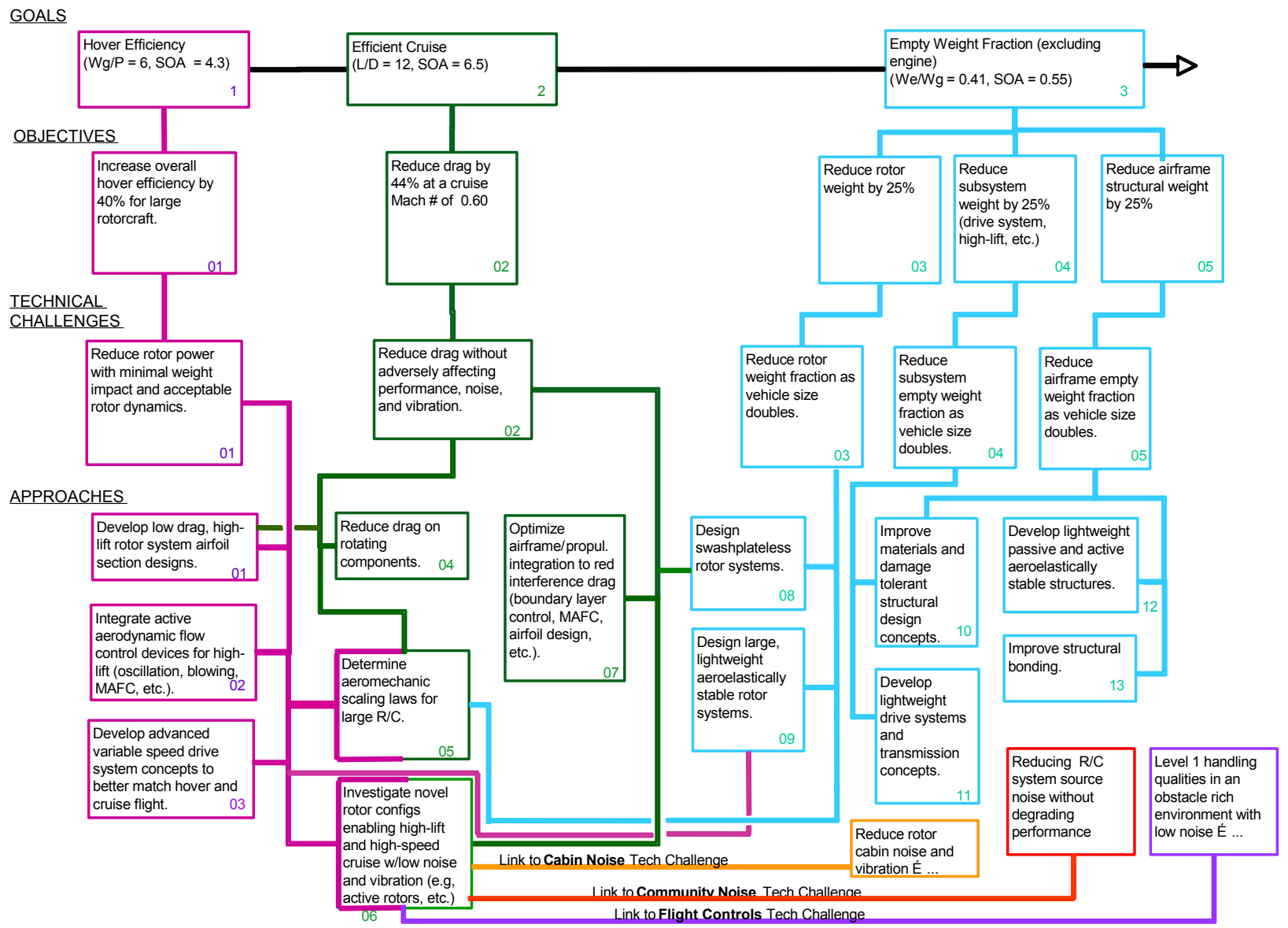

Figure A1. Rotorcraft Sector goals, objectives, technical challenges, and approaches (Rev 051005). 


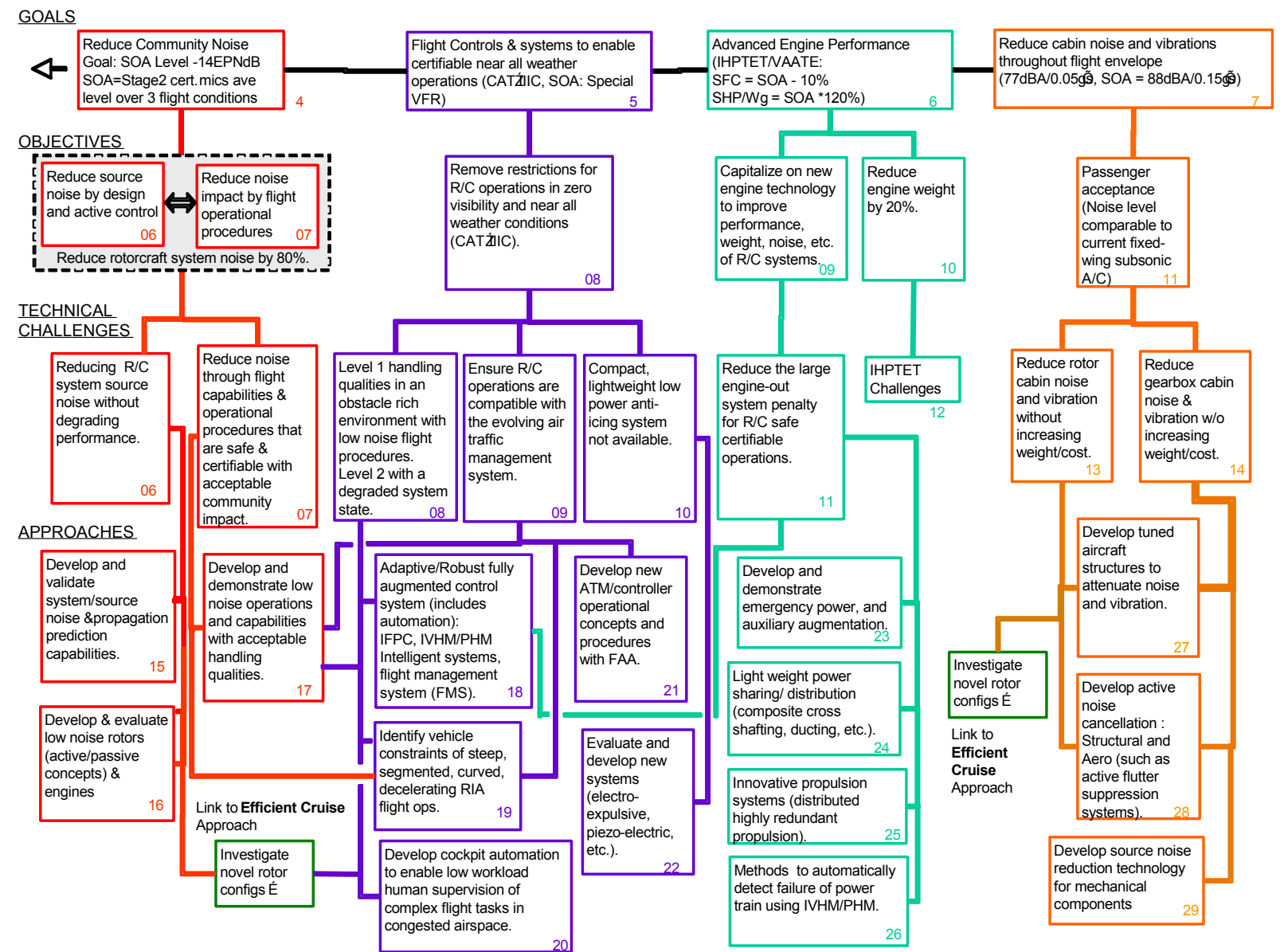

Figure A2. Rotorcraft Sector goals, objectives, technical challenges, and approaches (Rev 051005). 


\section{APPENDIX B}

\section{RISK REDUCTION FOR HEAVY LIFT ROTORCRAFT}

The NASA Heavy Lift Rotorcraft Systems Investigation was a focused and coordinated analytical effort to select the best configuration for meeting the Rotorcraft Sector vehicle technology goals (table 1). Three aircraft configurations were the primary subject of the Investigation:

1) Large Civil Tiltrotor (LCTR)

2) Large Civil Tandem Compound (LCTC)

3) Large Advancing Blade Concept (LABC)

The conclusion of this investigation was that the LCTR is the configuration with the most promise to meet the Rotorcraft Sector technology goals. The LCTR had the best cruise efficiency, hence the lowest weight and lowest cost. The LCTC exhibited good cruise efficiency, but less than the tiltrotor, and with higher development risk than the tiltrotor. The LABC had lower cruise efficiency than the tiltrotor for the NASA civil mission.

During the course of the investigation, high risk areas were identified. The definition of high risk is one or both of the following: capability or attribute unavailable today, so it is necessary to assume advanced technology will be available in the future in order for the aircraft to achieve the technology goals; or cost prevents the vehicle from being economically competitive, so the payoff of advanced technology is essential to achieving the goals. The following high risk areas were identified for the LCTR:

a) High torque, lightweight drive system.

b) High performance, structurally efficient rotor/wing system.

c) Low noise aircraft.

d) Super-integrated vehicle management system.

If the heavy lift configuration selected had an edgewise rotor (LCTC or LABC), then the high risk areas would also include low hub drag, and high advance ratio dynamics. In general, the top-level risks associated with the development of a high-speed, heavy lift rotorcraft are not configuration dependent.

Plans were developed to mitigate the above four risks. The risk reduction plans provide the strategic direction to support a heavy-lift rotorcraft development. Because of the significant overlap between the LCTR, LCTC, and LABC in terms of the risk mitigation technology, the plans are applicable to all three configurations. There are other rotorcraft goals and missions for which the LCTC and LABC are viable concepts, hence specific tasks for these two configurations are included where appropriate.

The risk reduction plans parallel a prototype development program, and feed design solutions at high technology readiness levels (TRL) to the prototype program. Although a prototype is not part of the NASA plan, it serves to provide schedule pull for the required tasks. The risk reduction program elements are technology readiness level benchmarks, program tasks, and strategic direction. Figure B1 illustrates the program. Technology readiness level benchmarks are major milestones demonstrating significant increases in TRL, principally by integrated hardware tests. There are two primary thrusts (fig. B1): early technology leading to advanced technology and supporting a possible year 7 prototype; advanced technology leading to a year 10 prototype. The risk reduction plan has the following technology readiness level benchmarks (fig. B1). 
a) Full-scale propulsion system ground test: complete transmission and engine arrangement; metrics are weight, cost, and noise.

b) Full-scale structure ground test: rotor blade and hub, airframe components, wing components; metrics are weight, cost, and interior noise.

c) Large-scale rotor system wind tunnel test: dynamically scaled rotor and hub; metrics are performance, loads, vibration, control, and noise.

d) Flight simulation test: including elastic airframe and load control system; metrics are handling qualities, control, and noise.

e) Noise and control flight test: existing aircraft, with rotor active control and low-noise operations; metrics are noise, vibration, control, and handling qualities.

f) Integrated large-scale wind tunnel test: utilize propulsion, structure, rotor systems from earlier benchmarks; metric is system integration.

The following sections describe the tasks identified for each of the four risk areas. The tasks are organized by discipline (propulsion, structures, aeromechanics, acoustics, and handling qualities) although all elements are connected because of the interdisciplinary nature of rotorcraft problems. Background information is provided for each of the discipline areas. Detailed task descriptions are presented next, including schedules showing ground test, wind tunnel test, flight test, and decision milestones, together with connections to the TRL benchmarks (figs. B2-B7). The tasks constitute the work required to achieve the TRL Benchmarks. Finally, a strategic direction providing guidance for selecting highest priority activities, aimed at the highest risk areas of heavy lift rotorcraft development, is presented.

\section{Concept Development}

The first year of the risk reduction program is also devoted to further refinement of the rotorcraft concept (fig. B2). Decisions must be made to narrow the focus of the program elements, since parallel research lines can not be afforded. It is essential to focus the work on areas of high payoff for heavy lift rotorcraft. This concept development should be conducted by several companies, for the selected heavy lift rotorcraft configuration (the LCTR for the NASA mission). The first phase would be completed within 12 months. A second phase would be completed in year 5, for the advanced technology thrust. A number of LCTR configuration features require decisions: the wing (high or low), nacelle (engine tilt or not), tail configuration, and number of engines. Corresponding decisions for the LCTC are whether it has single or tandem rotors, powered or auto rotating, tail configuration, and number of engines. For the LABC, the auxiliary propulsion configuration, tail configuration, and number of engines must be selected.

For the propulsion system, it is first necessary to establish what engine technology is available, in particular the possibility for maintaining good SFC over a wide engine rpm range (by design point, or variable geometry, or a multi-speed output shaft gearbox). The required engine development must be defined; then the transmission requirements can be defined, including the system configuration.

Structural design concepts must be identified for light-weight, heavy lift rotorcraft, for the blade and hub, for the airframe, and for the wing. A blade and hub concept must be identified that first and foremost is a solution to the stability issues (whirl flutter for the LCTR, high advance ratio for the LCTC), and also a solution for the strength and weight requirements. The requirement for active control of loads must be established, and the approach defined (flight condition limiting, active load control, others). The requirement for control of noise, 
vibration, gust and performance, must be established, and the control method selected (IBC, or on-blade, or airframe).

Design guidelines for noise must be established (such as minimum blade-passage frequency), based on physiological and psychological effects on human response. Low noise concepts and approaches must be identified (design features, active control, flight operations). Certification and community noise impact requirements must be defined. The requirements and certification approach for handling qualities must be established, including one-engine inoperative.

The technology contributions to reduction of purchase price and maintenance cost must be identified. A public benefit model and reality-based cost model should be developed.

\section{Technology Background}

\section{Propulsion}

Based on the operational requirements of all three configurations proposed for the heavy lift rotorcraft program, all require the propulsion system to vary in speed and in some cases to unload rotors and power propellers for forward flight. The speed of the rotating rotors and propellers need much larger speed changes than have been designed into the V-22 and BA-609. Therefore, the propulsion system needs to vary speed up to or greater than $50 \%$ or more from the helicopter hover mode. Speed change can be achieved by having gas turbine engines that have wide operational range or a drive system that has multiple or variable speed capability. For the designs, as currently configured, the propulsion system may require a combination of both a variable speed engine and drive system.

The propulsion system will also have to be highly reliable, maintenance free, and cost effective if the heavy lift rotorcraft is to approach fixed wing operation on a dollars per average seat mile basis. While the heavy lift rotorcraft propulsion system will handle more power than any previously built rotorcraft, the reliability and cost aspects need to be designed into the system. This means that low cost (procurement and operating) needs to be a highly valued design constraint. This may require a propulsion system that may weigh more, but will have a much longer life or mean time between overhaul. The mean time between overhaul is on the order of 25,000 flight hours for current fixed wing aircraft and the propulsion system for the heavy lift rotorcraft needs to be at least as good as that of fixed wing aircraft.

\section{Design \& Configuration Study}

As an initial attempt at design of the propulsion system for the three proposed concepts, the various configurations that would lead to variable propulsion system need to be evaluated. In all current rotorcraft the drive systems have been fixed ratio. Variable speed or multi-speed drive systems have only been developed to the production stage for land based systems (automobiles, farm equipment, etc.). For two of three concepts the typical load-carrying rotors need to operate in a torque-unloaded fashion during forward flight leaving this end of the high speed flight to propellers. Therefore, transition and power shifting requires careful attention.

Varying speed will be accomplished using the engine, the drive system or the combination of both. Also, the proposed propulsion systems all have four engines requiring 28,000 to nearly $52,000 \mathrm{hp}$, depending upon the aircraft. In order to keep the drive system weight down, many of the recent improvements developed under the Army's Advanced Rotorcraft Transmission (I \& II) and the Rotorcraft Drive System for the 21st Century projects must be applied, and component programs must continue to evolve to support the program goals for the heavy lift rotorcraft program. Some of these recent technologies include face gears, low-noise spiral bevel gears, split path gearing (or split torque), hybrid bearings, and other technology improvements. 
For the gas turbine engine's part of the propulsion system, a fairly flat specific fuel consumption (SFC) rating is required over a wide operating range. Smooth power through the transition from vertical to horizontal flight and back again is essential for passenger comfort and acceptance. While this program does not include an engine development task, other programs will be required to make the necessary investments to have the engine requirements in-hand when needed in the 7-year time frame. Cruise power levels required for the study aircraft may size the engines. Increased engine size may be required to achieve objective cruise power and engine life. A significant investment in engine technology development is required to achieve objective SFC levels and to raise the Technology Readiness Level.

The configuration study aspect of this program will determine the high risk technologies needing development from a low to high technology readiness level. Variable speed propulsion is a necessary technology for the heavy lift rotorcraft to be successful.

\section{Component Development and Concept Validation}

Once a variable speed propulsion system configuration is chosen, the necessary design, analysis, and concept tests need to be performed. On a parallel path, the evolution of propulsion system technologies that feed into improvements of the future must be continued for future system improvements. As far as the drive system, the variable/multi-speed aspects most likely will be located close to the engine at the highest speed and lowest torque part of the system-much like the location of the over-running clutch as required on multi-engine rotorcraft. This will permit the variable/multi-speed aspect of the design to be as light as possible.

The variable speed engine capabilities need to be addressed. Previous studies have shown that power turbine efficiency can vary significantly when run at off-design speeds. Engine technologies exist that could be applied to flatten out the SFC curve and thereby deliver part of the variable speed requirement. System trade studies are required to optimize drive system speed ratios and power turbine speed ranges. The drive system may only need to have two or more speeds without variability in between.

For the drive system, the component development aspects include: analytical tools, component improvements for gears, bearings, shafts/couplings, housings, clutches and rotor brakes. Also, loss-of-lubrication, efficiency, and health and usage monitoring (diagnostics and prognostics) research and technology development needs to be continued. These technologies feed into longer life, reliability, and lower operating costs.

For gears and bearings, advanced materials are necessary to increase power-to-weight capability through increases in bending and allowable contact levels. These improvements are validated through conducting statistically significant testing that requires a great deal of test time and data to substantiate improvements.

Engineered surfaces are another technology area that holds great promise for drive system improvements. These improvements are accomplished through paying particular attention to the surface of the mating components during operation. Some of the recent technologies that have been under consideration include super finishing and thin film coatings. Improvements at the surface level can increase performance and extend operation of components during compromised lubrication conditions.

Advanced bearing technologies will have a drastic effect on operational capabilities and possible design arrangements. Recent technologies that are currently under evaluation include hybrid (ceramic rolling elements) and wave-journal bearings. Hybrid bearings offer lighter weight (this can be a sizable savings for large bearings) and wider operating range in terms of rotational speed and temperature. Wave-journal bearings proposed for use in high bypass ratio fans for advanced civil transport can carry high loads in a small package. This permits planetary gear systems to have a reduced size (reduced weight) because of the bearing 
envelope being much smaller. These technologies, while showing great promise, need further investigation to validate their operation in future rotorcraft systems.

Another area of enhancement for the drive system is lubrication and performance (efficiency) improvements. These lubrication system enhancements not only will be applied to the emergency operation of the drive system but for the normal operation investigating the windage loss reduction that could enhance drive system performance during all operating conditions. In the large power-speed requirements as proposed for the propulsion system, windage losses will be substantial and careful attention to the design of the necessary shrouding and other techniques will be useful to the efficient operation of these systems. For the emergency or loss-of-lubrication requirements for rotorcraft (30 minutes of operation in this mode), several technologies require continued research to reduce the weight and size of the system necessary to operate the rotorcraft after occurrence. One possible solution being considered for future rotorcraft is called vapor/mist lubrication. This system injects a special, once-through lubricant into strategic high-heat generation areas of the drive system to provide the necessary lubrication to permit the rotorcraft to operate and finish the mission (flight segment).

Diagnostics/prognostics are another technology area that needs further and continued research to improve detection, location, and time to failure capabilities. This technology area will improve safety (possibly lower insurance and other cost elements) and permit maintenance on a "condition based" assessment. False alarms need to be eliminated from current capabilities and missed failures are not acceptable. Current advancements such as data fusion and fuzzy logic techniques need to be further refined for advance components (such as ceramic bearings, journal bearings, housings, clutches, etc.).

Also, manufacturing technology for the large mechanical components envisioned for the heavy lift rotorcraft is necessary. While large components are made for various applications (non-aerospace), making gears, bearings, and housings to the large sizes envisioned for this program requires careful consideration. Special processing (machining, processing, heat treatment, final grinding, etc.) techniques will require development because of the tolerances required for successful mechanical system operation. For the heavy lift rotorcraft this also means investigating low cost manufacturing while improving component performance (power to weight). Technologies such as near net forging require further investigation for application to gears and other components for the drive system.

Finally, an enhanced analytical development at the basic design level for optimizing configuration layout would also be of great use for this and future programs. Currently, mechanical systems are configured conceptually by the designer then worked at the design level on a gear or bearing mesh basis through the gear system. An optimization process using a minimal amount of input information would be useful for arriving at a satisfactory drive system arrangement early in the design stage. The process would also help reduce system design cost.

\section{Scaled Subsystem Demonstration}

Once the variable/multi-speed configuration is chosen for the heavy lift rotorcraft, the arrangement needs to be validated on a scaled or subsystem basis. This will require an analytical effort as well to determine scalability of the technology for the full scale demonstration to follow. Validation testing will include the entire variable/multi-speed aspects of the drive system on a subscale basis. Testing will be used to validate the configuration and to understand the operation constraints or boundaries. The testing will simulate the overall system requirements so that the tests are valid for the large full scale tests to follow. 


\section{Full Scale Propulsion System Demonstration}

A full scale demonstration of the propulsion system will need to be performed. At this time there is not an available testing facility in the U.S.A. that could be utilized for the complete propulsion system, and therefore a new facility will need to be designed, fabricated, and built.

The full scale propulsion system will be based on attributes, capabilities, and compromises found in the subscale tests. The full scale propulsion test will require the entire system as a ground test article. The system test is necessary to validate operation of the complete system through the entire expected flight spectrum. As mentioned earlier, the propulsion system operation should be transparent to the pilots and passengers from vertical to forward flight, and should not detract from passenger acceptance. Also, program objectives for power to weight, cost, and reliability must be validated for the propulsion system at this stage.

\section{Structures and Materials}

\section{Low-Velocity Impact and Impact Damage Tolerance}

For heavy lift rotorcraft, new rotorcraft structural concepts must be developed to meet strength, weight, and performance goals. The fuselage must be able to support much higher loads than previous rotorcraft. These new structural concepts may include sandwich construction with integrated stiffeners, thick skins, thick cores, and new advanced lightweight cores (e.g., X-Cor). The rotorcraft will also likely include some type of through-thickness reinforcement such as Z-Fiber. Advanced joint concepts will also be developed. All of these new structural concepts and construction techniques must be evaluated for susceptibility to impact damage and subsequent damage tolerance. In addition, the effect of cyclic loading on the impact damage must also be investigated. Damage from low-velocity impacts, or static concentrated out-of-plane loads, is a major threat to the structural integrity of this type of rotorcraft. Debris or hail, accelerated by the vehicle propulsion system, will impact the exterior surface. In addition, cargo handling and passenger usage will cause interior impacts and high out-of-plane concentrated loads. Maintenance activities will also result in both interior and exterior impact damage. Before these new structural concepts and construction techniques can be applied, the impact performance must be well understood and simplified design and analytical tools must be developed that can predict the impact damage and the corresponding post-impact performance and strength. The designers will require these types of tools to correctly size and design the structure to minimize weight and improve performance.

\section{Delamination and Debonding Analysis Tools}

To date, analysis codes have not been used to certify composite rotorcraft components. Of primary concern is the need to characterize and analyze delamination and debonding as mixed-mode fracture involving crack opening (mode I), sliding shear (mode II) and tearing shear (mode III). Furthermore, although separation of energy release rates into contributions from the three fracture modes has been routinely achieved in research studies, additional work is required to provide efficient analysis tools that can be easily integrated into design practice. The virtual crack closure technique (VCCT) is widely used for computing energy release rates based on results from continuum (2D) and solid (3D) finite element analyses to supply the mode separation required when using the mixed-mode fracture criterion. However, present techniques typically require geometric nonlinear finite element analyses with additional post processing routines that are currently not an integral part in most commercial codes. ABAQUS recently announced the release of a new add-on for ABAQUS 6.5 called ABAQUS-VCCT. The other large commercial finite element codes such as MSC NASTRAN or ANSYS, which are frequently used by the helicopter industry, do not offer the choice for calculating mixed mode energy release rates VCCT. Full implementation of Interlaminar Fracture Mechanics (ILFM) in design requires a continuing development effort of codes to calculate energy release rates, advancements in delamination growth criteria under mixed mode conditions, and consideration of three-dimensional geometry and spectrum loading including out-of-plane loads. 


\section{Flexible Multifunctional Composite Structures}

Future advanced vehicles will require flexible structures to achieve improved aerodynamic performance. For example, helicopter rotor hubs are subjected to bending and torsion loading, as well as tension. Currently, composite rotor hubs are manufactured which accommodate these loads, by varying the flexbeam thickness along the length. Studies to-date have investigated the effect of combined tension and bending loads on subscale tapered flexbeam components. These studies have applied a fracture-mechanics approach, using finiteelement modeling along with laboratory testing to understand and predict the durability and damage tolerance of these flexbeams. This fatigue life methodology, which relies on accurate data from delamination characterization tests, has been applied to several different geometries and materials with reasonable success. However, many issues remain to be studied. Current investigations have been limited to 2-D models, using delamination characterization data from fatigue tests in modes I and II. There are currently no standardized mode II tests (static or fatigue) and no mixed-mode fatigue test standard. In addition, the flexbeam modeling should be extended to full 3-D, which would require mode III material data. Current tests have also been limited to constant amplitude loading. The effects of a more realistic spectrum loading should be investigated. Embedded sensors, both active and passive, have been proposed as a means of adding multi-functionality to aircraft structures. The viability of these embedded sensors in flexbeams or other highly flexible structures should be investigated to determine the effect of the embedded element on the durability of the structure and the integrity of the embedded component under fatigue loading. In addition, the effect of typical manufacturing flaws on the fatigue life of rotor and wing components will need to be evaluated. A fatigue life methodology to establish accept/reject criteria for manufacturing flaws in rotor and wing components must be developed.

\section{Through-Thickness Reinforced, Self-Healing, Polymeric Matrix Composites}

One of the major limitations of laminated polymeric matrix composite structures is the potential for the formation and growth of ply interface cracking, known as delamination. This problem may be alleviated using through-thickness reinforcement, which involves the placement of continuous fibers or stitches through the laminate thickness. An example of this technology involves pultruded carbon/BMI pins inserted through the laminate thickness using an ultrasonic method. The pins (known as z-pins, due to the insertion direction) resist the opening of delaminating surfaces, and thus enhance the resistance to delamination growth. Additionally, the energy dissipated as the z-pins are pulled out from the laminate result in a significant increase in the fracture toughness. Tests have shown that a $2 \%$ areal density of z-pins results in an increase of twenty times the mode I fracture toughness of a standard carbon/epoxy laminate. In addition, new polymeric matrix materials are being developed that incorporate microcapsules of uncured resin that release when a delamination crack grows between the layers, which reacts with a catalyst in the matrix to heal the crack. To date these self-healing polymers have only been developed in resin and filament wound composite form with room temperature cured matrices. Furthermore, a finite amount of time is required for the self-healing reaction to occur. The resistance to delamination growth supplied by the z-pins will suppress the opening displacements between the delaminating surfaces allowing the self-healing to occur. Hence, the addition of $\mathrm{z}$ pins to polymer matrix composites with these self-healing matrices offers the synergy of extremely durable and damage tolerant lightweight composite structures.

\section{Bonded Joining Technology for Primary Structure}

Heavy lift rotorcraft will likely utilize bonded joints in the fuselage, wing section and rotor components. Many candidate material systems and reinforcing technologies exist for use in bonded joints, such as fiber metal laminates, z-pinning in PMC's for enhancing damage tolerance, and self-healing polymers to enhance the durability of bonded joints. These joints will be subjected to dynamic and cyclic loads that may cause delaminations in the laminate material and debonding of the joint structure. ASTM test standards have been developed to characterize the opening mode I and mixed-mode I/II (opening and sliding shear) fracture toughness. In addition, a standard for characterizing delamination onset under mode I fatigue loading has 
been developed. Test standards are also under development for evaluating the delamination resistance of laminates subject to mode II and mode III loading, although further work is required to solve problems related to the test methods. In order to fully understand the delamination behavior of bonded joints under a mixedmode cyclic loading scenario representative of a service load spectrum, the current delamination test standards need to be extended to include the characterization of delamination growth under cyclic loading. Furthermore, the interaction between the opening, sliding shear and scissoring shear (mode III) fracture modes needs to be understood and characterized. Recent developments in failure analysis need to be applied and extended, utilizing decohesive-zone elements that emulate material damage, to predict the delamination and debonding behavior of joints. Existing analytical models for predicting delamination growth in throughthe-thickness reinforced laminates also must be extended and incorporated into the finite element models.

\section{Selectively Reinforced Metallic Structure}

The next generation of structural materials for aerospace application is selectively reinforced metals. Selectively reinforced metals are the marriage of the best features of metals and fiber reinforced composite materials. Selective reinforcement (SR) is the local (intelligent) application of reinforcing material to otherwise conventional metal structure to compensate for deficiencies (such as damage tolerance, durability, stiffness and strength) associated with the base material and structure. It is equally applicable to wing, fuselage and rotor structures. Two selective reinforcement approaches are lamination and in-situ. An example of the laminate approach is the adhesive bonding of commercially available fiber metal laminates to conventional metallic fuselage/wing skin and stiffeners. In-situ SR is less mature than the lamination approach although the potential performance gains surpass what is capable via lamination. In-situ SR volumetrically replaces base metallic material with high stiffness/strength reinforcement only where needed, not in a uniform distribution as is performed in PMC materials. Typical total reinforcement volume fraction ranges between 3 and 10 percent. Studies by Alcoa indicate that potential weight reductions using advanced lamination or in-situ SR techniques, as compared to current fiber reinforced PMC materials, range from 10 to 20 percent.

\section{Tailored Wing Structure}

One of the principal design challenges for high-speed tiltrotor transport aircraft is achieving acceptable proprotor aeroelastic stability margins, which can restrict the operating airspeed of the tiltrotor aircraft in the high-speed airplane mode. In a typical tiltrotor wing design, the rotor pylon pitches up as the wing bends upward in the symmetric wing beamwise bending mode. To increase the stability boundary it is necessary to minimize the ratio of the pylon pitch motion $(\theta)$ to the wing tip deflection $(\mathrm{z})$ in the fundamental wing mode to increase the proprotor stability by reducing the rotor destabilizing forces. For a conventional tiltrotor composite wing design with structurally balanced skin laminates, the wing provides no structural pitch/bending coupling to resist the nose-up pitch due to pylon mass offsets. Unbalanced composite skins, on the other hand, can create nose-down structural twist as the wing bends upward to offset the pitch-up tendency from the pylon mass offsets. The objective is to reduce the wing weight for a given thickness ratio.

\section{Reliability-Based Design}

To date, the design procedures for most aerospace vehicle structures are based on combinations of factors of safety on the loads and knockdown factors on the strength. The factors of safety and knockdown factors account for uncertainties in material properties, dimensions, loads, and other quantities that govern a design. These procedures use deterministic analyses methods and provide no information about the risk of structural failure. A design technology referred to as reliability-based design (RBD) accounts for uncertainty by using probabilistic methods. RBD seeks a design that has a probability of failure that is less than an acceptable small value. The principal benefits of RBD are: increasing the confidence in analysis tools; reducing the design cycle time, cost and risk; and increasing the structures performance while ensuring that reliability requirements are met. In addition to performing a reliability analysis, a sensitivity analysis will be performed 
to determine which parameters have the greatest influence on the structures. There are several codes (e.g., Unipass, ProFES, RDCS, ROBO, and DAKOTA) that can be used to perform multidisciplinary reliabilitybased design.

\section{Aeromechanics}

Heavy lift rotorcraft require high hover efficiency, hence low disk loading and very large rotor diameter. The large size implies high weight fraction, and high speeds introduce stability issues. Productivity requirements drive designs well beyond the limits of state-of-the-art rotorcraft, with severe demands on structural efficiency for low weight and aerodynamic efficiency for high performance. Meeting these challenges requires innovative designs (probably with unconventional dynamics), a comprehensive and highly integrated design optimization process, and advances in design/analysis tools and supporting test data. In the following sections, several key areas of aeromechanics are discussed: aerodynamic efficiency, dynamics and loads, active control, and wing design.

\section{Aerodynamic Efficiency: Efficient Rotor and Aircraft}

Aerodynamic efficiency is key to economically-competitive heavy-lift rotorcraft. Existing aerodynamic databases and analysis tools are inadequate for design of such large rotorcraft. Required airframe drag levels have not been achieved by the rotorcraft industry. Edgewise rotor hub drag at the level of current helicopters would not be acceptable.

Optimized efficient rotors. The rotor system must be optimized for aerodynamic efficiency in both hover and cruise while achieving maneuver capability in edgewise flight. Tiltrotors operate in axial flow at the critical design conditions, but require high twist in cruise which compromises hover efficiency. Optimum twist cannot be matched for both hover and cruise, and reduced cruise tip speed will lead to a greater difference in optimized rotors than any yet tested or flown. Three-dimensional flow effects are known to substantially improve tiltrotor lift capability in hover, but the hover performance database is extremely limited for highly twisted rotors, adding risk to design and optimization.

Conventional edgewise rotors face a severe, rapidly changing aerodynamic environment at high advance ratios, with large areas of reverse flow, which is greatly exacerbated at the high speeds required for heavy lift rotorcraft productivity. Compound rotorcraft use a wing to unload the rotor in cruise, thereby eliminating lift imbalance, but there remains the challenge of reducing high-speed drag while retaining good hover performance and adequate stability when unloaded. Coaxial rotors balance lift in cruise with counter-rotating rotors, but (roughly) half the rotor is non-lifting at high speed, adding weight and drag. Slowed-rotor concepts deliberately place much of the rotor in reverse flow, further increasing the drag penalty.

All edgewise rotors require airfoils that have high maximum lift for maneuvers, good lift/drag performance in forward flow at both low (hover) and very high (cruise) speeds, and very low drag in reverse flow. Tiltrotors must compromise blade twist distribution, therefore their airfoils must have good behavior (low drag and pitching moment) at non-optimum angles of attack. Airfoils must be developed uniquely for high-speed rotorcraft. Heavy-lift rotorcraft will extend the airfoil environment to higher Reynolds numbers than existing rotor airfoils, and their higher speeds will expand the range of Reynolds numbers over which rotor airfoils must retain good performance.

Blade planforms are constrained by structural requirements: high taper reduces weight, but may reduce performance. Hub/blade structural integration may further constrain aerodynamic optimization. For good hover performance, coning must be limited, which constrains the structural design and affects dynamics. Local blade section lift-curve slope strongly affects stability at high speeds. Consequently, aerodynamic optimization cannot be carried out independently of rotor dynamic design. 
Component drag reduction. Edgewise rotors, especially coaxials, suffer from very high hub drag. Tiltrotors experience spinner/root interference, and design solutions are complicated by the need for very large blade pitch travel.

For the LCTC and LABC, the heavy lift rotorcraft program must identify candidate passive (fairings) and active flow control methods, with detailed analysis and component tests to develop practical low drag concepts, concluding with large scale tests to demonstrate the selected concept(s). A parallel effort must be carried out for LCTR spinner drag reduction.

Aerodynamic interference. High-speed rotorcraft face significant flow-interference effects: rotor/wing interference for compounds and tiltrotors; rotor/rotor for coaxials and tandems; rotor/tail and rotor/prop for compounds, including coaxials; and rotor/inlet for compounds (and to a lesser extent, tiltrotors).

A special case of interference is wing download for compounds and tiltrotors, which is a substantial penalty. The fuselage affects download, so a high-wing vs. a low-wing layout can, in theory, make a significant difference, but there is no comparative database to guide design decisions. Numerous methods of reducing wing download have been proposed, notably those including active aerodynamics, but few have been tested at adequate scale.

Auxiliary propulsion. Compound and coaxial rotorcraft require efficient, low noise propellers for cruise propulsion. Although propeller design is highly developed for fixed-wing aircraft, those machines do not suffer rotor/prop interference effects. Therefore, the LCTC and LABC will require thorough analysis and testing of auxiliary propeller designs, including large-scale wind-tunnel tests of a complete airframe in order to properly quantify interference effects and demonstrate good performance.

Test data and design tools. Available analysis and design tools have been proven only for conventional designs, or for advanced concepts at small scale; some proposed design features have never been tested at adequate scale. There exists a very large database for edgewise-rotor performance, loads, and stability, but little at large scale (e.g., CH-53), and nothing at both large scale and high speed. There have been no large compounds (excepting a few, marginally successful British or Soviet machines with non-representative technology). There has been only one high-speed coaxial helicopter (XH-59) and but a few high-speed compound helicopters (e.g., AH-56, RSRA), none with nearly the required performance or payload; none reached production.

The large-scale test database for tiltrotors is limited to a handful of rotors, all with similar twist distributions, and none optimal for LCTR. Only one coaxial rotor has been tested at large scale (at least in the U.S.), and only at limited speeds. No large-scale, slowed rotors have been tested at anywhere near the required speeds. The available database against which to test design tools is consequently inadequate. In addition, rotor/airframe interactions, including rotor/wing lift sharing, have not been fully studied for the proposed concepts.

Extensive aerodynamic performance tests are, therefore, required to validate design and analysis tools. They include medium- to large-scale wind tunnel tests, with representative blade and control-system dynamics, to define and confirm aerodynamic behavior and predictive capability. At least two separate test series are warranted: a near-term series with extrapolations of existing technology (e.g., new twist distributions for tiltrotors), and a longer-term series with advanced technology (e.g., new structural concepts). Both low- and high-speed tests are required, because of the radically different aerodynamic environments. These tests should lead to an integrated, full-scale wind tunnel test utilizing propulsion, structures, and rotor systems from earlier 
benchmarks - the goal being demonstration of full system integration of the down-selected concept(s), ultimately leading to flight test.

Considerations for airframe aerodynamic design are covered in detail elsewhere. The issue is relevant here because of rotor/airframe interference. There must eventually be a complete airframe wind-tunnel test, including rotors, wings, tail, and auxiliary propulsion (as appropriate for the down-selected concept), to demonstrate that aerodynamic interference issues are properly understood and controlled for in the final design. Specific tests include LCTR wing download and LABC rotor/prop interference.

\section{Dynamics and Loads: Light-weight, Strong, Stable, Low-maintenance Rotor System}

Reducing the weight fraction of the rotor system is crucial to economically-competitive designs, and low disk loading is essential for acceptable hover efficiency. The consequences of substantially reduced weight and low disk loading include large, relatively light rotors with novel hub and control concepts. Such rotors will have radically altered dynamic characteristics compared to current rotors. The objective is a light-weight design that is inherently stable. Emerging active load-control technology should be integrated into the design to minimize loads and hence weight.

Blade and hub concept. Tip speeds must be kept subsonic, leading to low rpm for large diameter rotors, but light-weight construction will prevent blade frequencies from scaling down with rpm. Large, light rotors will consequently exhibit higher frequencies relative to rpm than existing designs. A major objective of the heavy lift rotorcraft program is to exploit this relative frequency shift to reduce the weight penalty that would otherwise be prohibitive for very large rotors.

Instability mechanisms are different for tiltrotors (axial flow), compounds (edgewise flow), and coaxials (stiff rotors). Moreover, rotor/wing dynamic coupling creates the threat of whirl flutter for tiltrotors: although the wing can be stiffened to compensate, this adds undesirable weight and otherwise compromises the wing design. Hingeless, gimbaled, and articulated rotors have different susceptibility to instabilities, hence have different requirements for active stability augmentation (if used) and impose different stiffness requirements on tiltrotor wing design. Hingeless rotors are simpler and lighter than gimbaled or articulated rotors, and have better high-speed stability but higher loads. There is, therefore, a tradeoff between loads and stability; risk/payoff issues and demonstrated technology levels drive heavy-lift designs to hingeless rotors with loads control.

Although not needed for the concepts studied here, active stability augmentation should not be neglected. Of immediate relevance is the requirement that active controls not introduce any instabilities. Passive stability enhancements (e.g., structural tailoring) may be required to fully exploit the potential of some designs.

Coaxial rotors are also susceptible to instabilities, but their designs tend to be driven by the absolute requirement to avoid rotor/rotor tip contact. They require extremely stiff blades, structural coupling to minimize blade tip clearance, and/or active flapping control. They may also require active control for good cruise performance, which must be compatible with stability and contact avoidance.

Also desired are a minimum number of components, simple conditional monitoring, and ease of inspection and repair. Designs must be compatible with durability and damage tolerance requirements.

Active load control and automatic limiting. Rotor designs must withstand extreme dynamic loads without incurring excessive fatigue damage. Compared to traditional metal blades, composite blades have better fatigue characteristics but are less tolerant of large load excursions. Rotor load limiting, implying active control, is needed for full utilization of the structural capability of modern materials. It is here assumed that 
there will be no significant extension of materials technology beyond the best already qualified; therefore, the greater loads capability demanded of heavy-lift rotorcraft must be achieved by improved rotor design and control concepts.

The requirement for active control of loads can be approached two ways: by imposing limits upon the flight condition, which implies integration with the full aircraft flight-control system and compatibility with good handling qualities; or by active rotor load control, which requires monitoring the rotor state (loads, flapping, etc.) to determine appropriate adjustments to the rotor controls. Advances in automated flight-control technology may eventually eliminate the distinction between these load-control methods, but they are treated separately in the current studies.

Tiltrotors require a high collective range, which constrains control-system kinematics, which in turn strongly affects control-coupling dynamics. Coaxial rotors require dual controls within a small package to minimize hub drag. These issues complicate the application of active loads control to tiltrotors and coaxial rotors.

Concept development and demonstration. Because of its criticality to safety, a demonstration test of aeroelastic stability is mandatory for any candidate rotor concept and should be done early in the program. A small-scale wind tunnel test of a representative system is adequate. (However, "small-scale" is a relative term; a 1/5-scale model of the LCTR would easily dwarf any existing tiltrotor model.) This requires early identification of design concepts that address stability issues (whirl flutter for LCTR, high advance ratio for LCTC and LABC).

Large-scale wind tunnel tests of dynamically scaled rotors and hubs will be needed to fully evaluate downselected concepts. Test metrics include performance, loads, vibration, control, and noise. Useful tests can overlap stability demonstrations if the flight envelope is restricted or, in the case of LCTR, the rotor system is tested in isolation.

Active load-control and automatic load-limiting are essential for the hingeless rotor concepts herein proposed. The heavy lift rotorcraft program must define the approach — flight condition limiting or active load controland develop the associated control concepts, including hub moment control and rotor state feedback that are all compatible with stability, handling qualities, and maneuver requirements. Active-control technology will require small-scale wind tunnel tests to demonstrate viability and refine concepts appropriate for heavy lift rotorcraft, followed by medium or large scale tests to demonstrate capability and stability. Flight tests will be required to fully demonstrate load control, including gusts response and maneuvers.

\section{Active Control: Noise and Vibration Reduction}

Noise and vibration requirements cannot be met solely by design parameter selection or passive techniques. Active control will be required.

Types of active control. Application of active controls to rotorcraft may be divided by frequency domain and by risk/payoff considerations. Loads and flapping control require low-frequency inputs, typically less than $1 / \mathrm{rev}$, whereas noise and vibration reduction, performance improvements, and stability augmentation require higher frequencies, sometimes at several harmonics of $1 /$ rev.

Active control (including 2/rev IBC) promises to improve cruise performance for slowed rotors by reducing drag in reverse flow further than can be achieved by traditional, sinusoidal cyclic controls.

Stability augmentation entails high risk, in that the consequence of failure is immediately catastrophic, as do some applications of flapping control (rotor/rotor separation for coaxials, and rotor/wing clearance for 
tiltrotors). None of the concepts considered here depend upon active stability augmentation or separation control. A failure of loads control may lead to rapid consumption of fatigue life, but need not endanger the aircraft, and can permit large increases in structural design allowables. Therefore, loads control should be strongly considered where it enables significant improvements in the design (a good example is hingeless rotors). Failures of active noise or vibration reduction, or of active performance improvement, have little direct impact on safety, and can therefore be freely employed. Because noise- and vibration-reduction techniques apply to all rotorcraft concepts considered in this study, they are given emphasis here.

Design of vibration-control and noise-control concepts. Design requirements for active controls vary with rotorcraft concept. Active controls may be applied to any of several areas: noise control, vibration reduction, gust-response limiting, and performance enhancement. An important consideration is the establishment of effective metrics for performance, loads, vibration, gust response, and noise, in order to perform effective design tradeoffs and rigorously evaluate competing designs.

Several means of implementing active controls have been proposed, roughly divided into rotor or airframe controls. Individual blade control (IBC) and active swash plate concepts (higher harmonic control, HHC) apply high-frequency control inputs at the blade root. A rapidly-growing technology is on-blade controls via flaperons or local active twist, which promises both lighter systems and more highly optimized (spanwisedistributed) control of the rotor. On the airframe side, active-isolation systems are already in production, but their weight penalty is high. Active noise control (anti-noise) has also been demonstrated. Active aerodynamic control, principally high-frequency flaperon inputs on tiltrotors and compounds, is yet another candidate. All of these methods face challenges when scaled to the size of heavy-lift rotorcraft.

Development and demonstration. Detailed, mutually-compatible requirements must be established to guide and evaluate active-control developments, including integration of noise and vibration control with load alleviation, flapping control, gust response control, and performance improvement, which are all consistent with handling qualities and stability requirements. A comprehensive series of wind-tunnel tests will be required, first at small scale to develop concepts, then at larger scale to demonstrate successful integration with down-selected rotor concepts. This effort includes selection of the control method(s) (IBC, on-blade, or airframe).

Large-scale wind-tunnel and flight tests of active controls are already planned and should be assiduously pursued; they include UH60-IBC and SMART rotor tests. As advanced concepts mature, flight tests on existing aircraft will demonstrate control of noise, vibration, gust response, and possibly performance, and will evaluate handling qualities. Full demonstration of loads control and stability will require integration with new rotor concepts, including rotor dynamics, which will probably dictate a dedicated demonstrator aircraft.

\section{Wing Design for Large Tiltrotors}

Because whirl flutter and wing download present technology challenges for tiltrotors (and to a lesser extent, compounds), the wing design requires careful attention. Compounds can use pusher props, so whirl flutter is not an issue; coaxial concepts do not need a wing. For these and other reasons discussed below, the technology effort is focused on tiltrotor wings.

Design constraints. A tiltrotor wing must accommodate a transmission cross-shaft, and preferably include a nacelle-tilt shaft. For download reduction, the wing must also have full-span, large-chord flaps with very large deflections (up to $90 \mathrm{deg}$ ). The wing is tip-loaded in beam bending for hover and low-speed maneuvers, and the concentrated tip masses (engines and transmissions) drive the wing structural dynamics. Moreover, large in-plane forces generated by the rotors at high-speeds can couple with the wing modes to cause whirl flutter; high torsional stiffness is required for stability. The wing should also accommodate emerging 
download-reduction technology (e.g., active aerodynamics). Fixed-wing design practices are inappropriate to meet these collective requirements.

The large beam and torsional stiffnesses required for tiltrotors result in wings with unusually thick cross sections, compared with fixed-wing aircraft. Thinner wings have lower drag, but higher weight. Purposedesigned airfoils are needed to simultaneously maximize aerodynamic and structural efficiency.

The LCTR baseline design is a low-mounted wing, in contrast to current practice (e.g., V-22). The advantages over a high wing are a lighter, simpler structure to carry landing gear loads between fuselage and wing; no sponsons are needed for landing gear, hence lower drag; and a potential reduction in download (no fountain over the fuselage). Design constraints include fixed engines with tilting shafts, longer rotor shafts or extreme dihedral for fuselage clearance in hover (for cabin noise), and hingeless rotors for adequate pitch control power in hover. A serendipitous fallout of the low-wing configuration is that a hingeless rotor tends to be less susceptible to whirl flutter, so the wing need not be as torsionally stiff as would be required for a gimbaled or articulated rotor. However, a hingeless rotor will require load alleviation. For these reasons, the wing and rotor cannot be designed independently of each other.

The LCTR wing structural design is driven by a 2-g jump takeoff and VSTOL pullout requirements. Combined with low cruise rpm, the lowest wing/nacelle frequency is greater than $2 / \mathrm{rev}$. This is a very different design constraint than applies to any existing tiltrotor, so the wing structure cannot be extrapolated from current (V-22, BA-609) design practice.

Although a strength-designed wing, combined with a hingeless rotor, has no whirl-flutter issues, an advanced wing design could evolve into a low-drag, low-weight structure with inadequate torsional stiffness for stability. Therefore, flutter-alleviation measures should be considered as potential research areas. Demonstration of whirl-mode stability is required in any event. Stability-enhancement technology includes aeroelastic tailoring of the wing (bending/torsion coupling), active flutter suppression via high-frequency rotor control inputs, and possibly passive rotor design measures (aeroelastic tailoring, planform optimization, or mass distribution).

Tests and demonstrations. Test requirements include demonstration of combined rotor/wing aeroelastic stability. Small-scale, semi-span wind-tunnel tests are adequate. Also required are download measurements (covered above in the context of aerodynamic interference).

The wing airfoil(s) will be unique and must be designed and tested independently of rotor airfoils.

Flutter-suppression concepts, if employed, must be rigorously tested. It should be possible to develop the technology at small scale, relative to heavy lift rotorcraft (1/10-scale or even smaller), but a larger scale (at least 1/5) demonstration would eventually be necessary. Any flutter-suppression technology should be flighttested on a demonstrator before commitment to a full-up design.

\section{Acoustics}

\section{External Acoustics - Rotor Noise Sources}

The heavy lift rotorcraft concepts that are being proposed under the NASA Rotorcraft Sector will need to address both interior and external noise issues through design and operational procedures. The acoustic goals set by NASA are very ambitious, given that there is currently no data available for the proposed heavy lift rotorcraft concepts or for any rotorcraft vehicles of that size and class. Existing rotorcraft which are currently considered to be "heavy lift" vehicles are still significantly (20 to 50\%) lighter and smaller than the proposed 
NASA heavy lift rotorcraft concepts. Currently, of vehicles considered to be "heavy lift" rotorcraft, all are of military origin and include the $\mathrm{CH}-53 \mathrm{E}, \mathrm{CH}-47$, and V-22. These vehicles, being of military origin, are not designed, nor are they required, to meet the strict FAA/ICAO noise certification standards. For a successful design, it is necessary for the heavy lift rotorcraft vehicles, at a minimum, to meet current noise certification standards.

Current noise certification regulations and community noise requirements are based on noise metrics designed to emphasize human audible responses to noise. For example, FAA noise certification requirements place a limit on the allowable Effective Perceived Noise Level (EPNLdB) that a helicopter may produce under given flight conditions. These metrics, being based solely on human aural response, do not capture effects of large levels of noise below approximately $50 \mathrm{~Hz}$. Due to the large diameter rotors which are required to operate at low rotational frequencies, fundamental and blade passage frequencies potentially will be below approximately $20 \mathrm{~Hz}$. As such, while there will be significant acoustic energy in the audible range for these heavy lift rotorcraft vehicles, there will also be significant acoustic energy in the infrasonic (below approximately $20 \mathrm{~Hz}$ ) frequencies. It will be critical to determine and understand the physiological and psychological effects of these repetitive very low frequency and infrasonic stimuli on the human body and community before these concepts will be acceptable.

Some of the noise sources known to be very annoying to the community when they occur are blade-vortex interaction (BVI) noise, high-speed shock (HSI) noise, blade-wake interaction (BWI) noise, and blade selfnoise. BVI noise can be one of the most annoying sources when it occurs. BVI noise typically occurs when the vehicle is in a mild descent, which would likely occur as the vehicle approaches an airport, flying over populated areas. When BVI noise occurs, it dominates the frequency range from 6 to 40 times the blade passage frequency (BPF). For typical helicopters flying today, this frequency range is generally in the most sensitive frequency range of human hearing. For the heavy lift rotorcraft vehicles, this frequency range spans from about $60 \mathrm{~Hz}$ to several hundred Hertz. Active control has shown promise as a tool to mitigate BVI noise.

Broadband noise sources, such as BWI and blade self-noise, typically dominate during level and mild ascent conditions. These conditions generally occur when the vehicle is departing an airport, which in most cases requires flight over populated areas. These broadband sources typically occur in a frequency range from 20 to 100 times the blade passage frequency. For conventional sized vehicles of today, this frequency range is in the mid- to upper range of human hearing, and can be of levels that dominate the spectrum in the absence of other noise sources. Because of the very low BPF associated with the heavy lift rotorcraft vehicles, these broadband noise sources will be shifted to lower frequencies and hence in the most sensitive part of human hearing.

Depending on the particular configuration of the heavy lift rotorcraft vehicle, other rotor and non-rotor noise sources could contribute significantly to the acoustic signature of the vehicle. One example of a non-rotor noise source is engine noise. Heavy lift rotorcraft vehicles will require multiple, large engines. The design, configuration, and placement of these engines could contribute significantly to both exterior and interior noise.

Since no vehicles currently exist in the proposed heavy lift rotorcraft-class of vehicles, acoustic prediction methods will be an important tool to aid in the design of a vehicle which meets noise requirements. Acoustic prediction methods are necessary and becoming more essential in assessing acoustic characteristics of designs, computationally testing the effects of design changes, and optimizing flight operations to minimize noise. In order to understand the limitations and improve prediction, the methods must be comprehensively validated with measured data for configurations which are as similar as possible to the heavy lift rotorcraft concept vehicles. 
Validation of prediction methods requires that a comprehensive flight test and wind tunnel test database be available. Currently, such a database does not exist. Acquisition of such a database is a critical step which must be developed in the initial years of a heavy lift rotorcraft effort. Current "heavy lift" rotorcraft vehicles that could be used to meet these criteria are the $\mathrm{CH}-53 \mathrm{E}$, the $\mathrm{CH}-47$, the $\mathrm{V}-22$, and the Mi-26. For a complete flight test program, a full range of flight conditions would include level flight, hover, climb, descent, and low speed mild-maneuver conditions (e.g., steady turns, mild accelerations, and mild decelerations). To adequately capture major acoustic characteristics, a full "U-shaped" microphone array is needed. This type of array consists of a linear ground array and vertically placed microphones at the two ends of the linear ground array. Such an array allows the vehicle to fly through the center of the array, capturing the noise directivity. In addition to data from the microphone arrays, human "sound jury" data is an essential component of a complete database. A human sound jury consists of volunteers who listen to vehicle sounds, whether located at a flight test site or in a sound booth. While listening to the sounds, the sound jury provides various types of feedback on how the sounds affect them. These responses can then be used to develop noise metrics to categorize human responses and to determine which noises provide the highest levels of annoyance.

With a prediction method that has been validated against adequate and applicable measured data, and with metrics that adequately mimic human responses, heavy lift rotorcraft concept vehicles can be evaluated, candidate low noise designs and controls can be computationally examined and down-selected for testing, and flight operations can be optimized to minimize noise in conjunction with other design requirements.

\section{Psycho-acoustics}

Heavy lift rotorcraft will generate extremely high levels of noise in a variety of ways. Large diameter rotors require operation at very low rotational rates to keep the compressibility effects at the rotor blade tips to a minimum. Periodic loading on these blades operating at low rotational rates will generate high levels of very low frequency noise-a significant part of the sound energy will be in the infrasonic range below $20 \mathrm{~Hz}$. Though this is not in the audible range, research in other areas has shown that exposure to repetitive low frequency noise is a concern for humans. The low-frequency sound energy can also cause secondary results such as building vibration. Current Federal Aviation Administration (FAA) regulations for certification of helicopters do not adequately address these issues because of the use of certain noise metrics (e.g., EPNL) that have weightings or tone corrections which are focused on the audible range. Quantification of low frequency noise effects requires definition and development of noise metrics that take into account physiological and psychoacoustic effects. Effects such as the noise impacts on the community and the long term exposure to high levels of low-frequency noise on humans (flight attendants, crew, etc.) must also be quantified in order to assess noise reduction or noise mitigation technologies. Quantification of physiologic and psychoacoustic effects will require development and construction of ground testing facilities with new capabilities to synthesize and accurately reproduce representative acoustic environments. New computational tools and advanced models of human response to such environments will need to be developed for incorporation into system noise prediction tools.

\section{Interior Acoustics}

As with exterior noise, interior noise goals for heavy lift rotorcraft concept vehicles are very aggressive. These aggressive interior noise goals are necessary to make the vehicle cabin environment acceptable to passengers and crew. The two major paths for interior noise transmission to the cabin are the airborne path and structural path. Which paths contribute to the interior noise levels is configuration dependent.

Noise transmitted along airborne paths is typically dominated by noise from the rotor(s). For example, rotor noise impacts the fuselage and is then transmitted through the walls of the fuselage. The fuselage structure provides some measure of acoustic damping to the incoming noise; however, this damping is frequency dependent and typically very small for very low frequencies. In this case, the structure is nearly "acoustically 
transparent", providing almost no inherent noise mitigation. Fortunately, the airborne noise mechanisms are configuration dependent. For example, edgewise rotors could have less noise impacting the fuselage than a tilting prop-rotor in propeller mode. Substantial research is needed to examine combinations of fuselage structure and airborne excitation and how to minimize the noise transmission through these structures. The nature of this type of interior noise is such that it requires near-full-scale testing of hardware. Active noise mitigation of low frequency airborne noise is expected to be a challenging research area and will require innovation. This is because conventional active noise reduction techniques would require very large (undesirable) amplitude structural deflections; conventional passive techniques would require placement of significant quantities of noise dampening material (heavy). Prediction of interior noise from airborne excitation will require significant integration between external noise prediction methods and interior noise analyses.

Noise transmitted along structural paths can contain noise from transmission shafts, bearings, gears, gear boxes, engines, etc. These noise sources originate in structural vibrations, which excite the air near the structure, resulting in acoustic radiation into the cabin. These noise sources are also configuration dependent. For example, interior noise is expected to be higher if cross-shafting or gear boxes are placed in or near the fuselage cabin. Component testing to analyze these various noise sources can be conducted initially at small scale. Analysis of vibro-acoustics of these components also requires further development of prediction tools which include both structural vibration and structural acoustic analyses. To be successful and applicable, the interior noise research effort must be done in conjunction and in coordination with both exterior noise analyses and psychoacoustic analyses.

\section{Noise Reduction/Mitigation}

There are numerous strategies that could be employed to reduce or mitigate the effects of exterior and interior noise from rotorcraft. Most strategies fall into one of two categories: reduction of source noise or mitigation of noise using flight operations.

Source noise reduction typically may come in the form of passive blade design or active control, both of which are designed to minimize some aspect of noise generation. Many of the recent noise reduction efforts have focused on reduction of BVI noise. Passive designs aimed at reducing noise typically have an unconventional planform (e.g., non-rectangular planform, non-square tip region, non-linear twist, sweep, etc.), which is tailored to minimize or mitigate a particular noise mechanism. Active controls have been applied at the blade root in the form of Higher Harmonic Control (HHC) and Individual Blade Control (IBC). Both methods have been successful in demonstrating reductions in BVI noise and vibrations under certain controlled conditions; however, there is typically a penalty of increased low frequency noise associated with these methods. Distributed active controls have been applied in the form of active twist, which has been shown to reduce BVI noise and vibration under controlled conditions. Other on-blade controls such as active flaps show promise in controlling BVI noise sources. While methods of this class have shown promise in controlling BVI noise and/or vibration within certain frequency ranges for conventional sized vehicles and models, application of these techniques to heavy lift rotorcraft class vehicles must be explored to determine their ability to be cost-effective in controlling BVI noise.

Currently, there are no known effective and efficient methods of actively or passively controlling very low frequency noise without significant performance penalties. The heavy lift rotorcraft concept vehicles are expected to generate significant low frequency noise due to rotor size, low rotor rotational rates, thrust required, etc. Mitigation of the low frequency noise will require identification of innovative and revolutionary active noise control concepts. For example, since rotorcraft noise tends to be very directional in nature, using an innovative active control strategy may be possible for canceling or re-directing regions of high noise radiation away from populated areas. 
Noise generation and mitigation can also be affected by flight operational procedures. For example, under NASA's Short Haul Civil Tiltrotor (SHCT) Program, a noise reduction of $6 \mathrm{dBA}$ in the BVI noise component was demonstrated by changing the descent flight profile of an $\mathrm{XV}-15$ aircraft. This was necessary in order to reduce noise while maintaining safe and flyable vehicle handling qualities. Recently, many vehicle manufacturers have begun providing guidance on low noise operations for their vehicles for various flight scenarios. A similar approach must be taken with the heavy lift rotorcraft concept vehicles. However, since heavy lift rotorcraft vehicles will have very different handling qualities than those of existing vehicles, development of safe flight procedures that also mitigate noise impact on the community need to be developed. These efforts must at a minimum encompass vehicle dynamics, handling qualities, and acoustics.

\section{Handling Qualities}

Configurations designed for a conceptual civil heavy-lift vertical flight transport must meet the primary mission requirements of range, speed, and payload while also satisfying regulatory and operational requirements of civil operations. Historically, most production Vertical Take-Off and Landing (VTOL) designs have been derived from military aircraft or requirements, but civil airworthiness and operations regulators have imposed requirements unique to civil operations. This section outlines some of the design considerations important to civil operations, beginning with reference to the FAA's Rotorcraft Airworthiness Criteria. Considerations for aircraft stability and control will be noted as well as one engine inoperative criteria and instrument operations. Noise abatement considerations will be discussed. Finally, aircraft configuration control and the use of secondary surfaces will be discussed.

\section{Civil Certification and Operation}

Transport Category Rotorcraft are certified for airworthiness according to FAR Part 29. The focus of Part 29 is on transport category aircraft as opposed to utility types certified under Part 27. An important distinction is the assumption that transport category aircraft will carry passengers or cargo for hire, requiring a higher degree of safety. The military never quite makes this distinction, although different handling qualities design standards have been developed for attack and scout, utility, and medium lift helicopters. Ultimately, though concerned with safety, the military is most concerned with mission accomplishment. Civil transport aircraft designs and operations must meet a safety standard first, the mission comes second. The design and operations considerations of this distinction can become significant.

Although FAR Part 29 is designated for rotorcraft, it provides the regulatory underpinnings for other VTOL designs. The FAA definition of rotorcraft includes helicopters and autogyros. Tiltrotor aircraft are considered "powered lift." A draft airworthiness criterion, Part XX, was developed for powered lift, but it uses much of the same criteria as rotorcraft for operations near hover. The Bell-Agusta 609 will be certified to criteria largely drawn from Part 29, augmented by appropriate fixed wing criteria (Part 25) for airplane mode operations and selected powered-lift criteria for tilt-mode conversion operations. The criteria and philosophy behind Part 29, based on decades of helicopter operation, will continue to provide the underpinnings of civil VTOL certification criteria for the foreseeable future.

Most of the civil airworthiness criteria for handling qualities and operations are contained in Part 29, Subpart B-Flight. This subpart has criteria for weight and center of gravity limits, performance (including engine out performance), flight characteristics (including static and dynamic stability), ground and water handling characteristics, and vibration. Other subparts deal with strength requirements $(\mathrm{C})$, design and construction (D), the power plant (E), equipment (F), and operating limitations and information (G). Requirements for one engine inoperative performance and operation, and for aircraft stability, will be discussed further below. 


\section{One Engine Inoperative}

Transport category aircraft must be designed and operated such that they can sustain a major system failure and continue a safe operation to either a landing or continued flight. An important failure is that of an engine, as specified in "Category A" operations. The operation and aircraft performance must be designed such that the aircraft, upon failing one engine (one engine inoperative, OEI) can either return to and stop safely on the takeoff surface or continue the takeoff and climb-out at a specified minimum rate, speed and configuration. Given the typical rotorcraft power-required curve and installed power, this usually means the aircraft has a substantial region of height and velocity conditions (close to the ground and at low speed) that must be avoided.

Meeting the Category A OEI requirements typically requires either long clearways (including runways) or special operations. As an example of long runways, the commercial Chinook required a clearway and landing surface on the order of 2400 feet at the design gross weight to satisfy the land-back requirement of a balked takeoff. Some Category A helicopter operations satisfy the OEI requirement by backing up from the middle of a small landing zone, always keeping the land-back point in sight until they reach a safe height where altitude can be traded for airspeed for a continued takeoff and climb-out. Such operations typically use an alternate weight, lower than that certified for use with a long clearway (runway).

The Category A OEI requirements tend to drive commercial operations toward short takeoff techniques when flying with high payloads. Lower payloads are carried when pure vertical operations are required. This provides landing zone flexibility where the allowable payload is matched to the space available for takeoff and landing. The implication for conceptual design is that at least two mission alternative weights should be considered: a maximum gross weight for a defined cruise mission that will use a STOL technique and a lower mission weight that accounts for hovering operations for takeoff or landing.

\section{Aircraft Stability}

The aircraft stability requirements of FAR Part 29 tend to be looser than military design standards. The FAA must set minimum required flight dynamics and stability, while the military, as a customer, can define a desired result. An aircraft that marginally meets the FAA's minimum criteria in one area, often falls short elsewhere, so prudent design comes in from the boundaries a bit. In contrast to the FAR Part 29 requirements, the military Aeronautical Design Standard for Handling Qualities, ADS-33, has a well-constructed, modern mathematical basis, backed up by extensive simulation and flight test. The mathematical basis of ADS-33 provides for mathematical evaluation at a much earlier stage in the design process-essentially when a linear flight dynamics model first becomes available. ADS-33 can serve as a flight dynamics benchmark to at least point to areas needing further control design work or analysis for a civil design.

\section{Inner Loop Control Dynamics}

An issue for large rotorcraft is the frequency overlap that can occur between aeroelastic modes, drive train modes and/or flight dynamics and control modes. While civil certification criteria does not explicitly address this (except for the prohibition of "excessive vibration under each appropriate speed and power condition"), any resonance or confluence of dynamic frequencies could have serious consequences. Most recent large/medium rotorcraft projects have encountered some form of this. Dynamic analysis during the conceptual design stage should help identify the potential for such dynamic issues. Further, the frequency overlap issue is expected to place limitations on tolerable aeroelastic modes and on advanced blade control concepts. Flight control implications will have to be dealt with as that design matures, but early identification of potential interactions might lead to alternative design solutions. 


\section{Transport Category Instrument Operations}

A large civil transport VTOL is expected to operate in near all-weather conditions. The NASA concept for a Runway Independent Aircraft (RIA) envisions commercial airline use of these transports. To achieve the desired airport capacity augmentation, these RIA must operate in the same weather and visibility conditions as the long haul conventional airliner fleet. Low visibility and icing are the primary challenges.

Icing protection will be needed equivalent to that employed by conventional airliners. In addition, the mission cruise altitude for the conceptual design needs to be above 22,000 feet to establish cruise flight above the icing altitude band. The consequence of a lower cruise altitude is an aircraft that cannot fly during some atmospheric conditions that conventional airplane transports are flying or that must carry extra deicing equipment which is usually complex, heavy, and has high power demands.

Operations in low visibility and turbulent winds tend to drive control designs to significant stability augmentation. Typical low visibility operations use gentle maneuvers and low acceleration to maintain a stable operating point. Without visual references for attitude and speed, the aircrew and flight control system must rely upon instrumentation to provide control around the desired operating condition and flightpath. The need for aircraft stability drives control designs to tighter control of body attitude, driving the response frequencies higher, potentially driving into the overlapping frequency issues cited above.

Although instrument flight operations are conducted without visual reference, eventually a visual reference is required, at least for the final landing touchdown. A concern to FAA operations certifiers is the maintenance of a visual sight line to the intended landing spot throughout the approach, should visual conditions permit. High body pitch attitudes that raise the nose and instrument panel into this line of sight are frowned upon. Passenger comfort may also produce a similar pitch attitude constraint. Helicopters, with their rotor shafts fixed relative to the body, can encounter blanking of the critical line of sight as they pitch nose-up to decelerate along the approach path. While yawing to provide a side view of the landing sight-line may be acceptable to military and some commercial operators, this is not expected to be acceptable to the envisioned RIA VTOL operation.

The design implications of this line of sight design standard may affect allowable operations with a given payload (the need for a slower approach than otherwise required), require the use of additional tail deflection, flaps or other pitch moment producers, or limit other desired operations such as noise abatement approach profiles.

Ironically, the approach sight-line design goal may not be satisfied even by use of full-aft nacelle angle in a tiltrotor aircraft. Use of full aft nacelle angle probably places the aircraft in an undesirable flight configuration for recovery from an engine failure. As seen during the studies of the NASA SHCT Program, use of aft nacelle had to be limited until after a commitment to landing was made, very late in the approach. A corollary to this is that nacelle angle movement becomes a primary longitudinal acceleration control. As such, nominal flight operations must be planned to not use the full range of the control movement, leaving some margin to pilot discretion.

The implication to aircraft designers is that not all of the static performance of an aircraft may be used to satisfy nominal requirements. Margins beyond the nominal are required. 


\section{Noise Abatement}

The aerophysics of rotorcraft flight produce the potential for blade vortex interaction (BVI) at positive angles of attack of the rotor disk plane. BVI has been identified as a major noise source for rotorcraft. Positive rotor angles of attack typically occur during descent and deceleration, both of which occur on approach to landing. The rotorcraft noise problem begins with approach. Careful tailoring of the approach profile-airspeed, rate of descent, deceleration, and rotor shaft angle for variable configurations has been demonstrated to impact the production of BVI and resultant noise footprint on the ground.

The state of the art for noise abatement operations design and analysis assumes quasi-static flight conditions. This tends to drive these operations into the same slowly changing operations needed for instrument flight operations. Some of the flight conditions desired for reduced noise can lead to unacceptably high body pitch attitudes. In general, noise abatement operations must use the same nominal range of body pitch attitudes that satisfy the approach line-of-sight goal cited with instrument operations.

\section{Additional Aircraft Features}

Prompted by both noise abatement operations and control issues during approach, secondary surfaces or devices may be useful and important on a new heavy-lift VTOL. High flap angles were used during the SHCT XV-15 noise abatement flight tests to increase the drag on the aircraft, lower the body pitch attitude and increase the power setting required for descending flight. While lowering the pitch attitude should be understandable from both line of sight and comfort considerations, the increased drag and required torque may be counter-intuitive. Increased engine torque places a turbine engine in a more linear response range, good for flight control where power is being used to control flightpath angle and height. In addition, a turbine engine operating more toward its mid-range can respond better to a sudden demand for full power such as might occur in the event of an engine failure.

Additional devices to increase drag during approach may be desirable. A rapidly cleaned-up device could be valuable to rapid recovery from an engine failure during approach. Designers should look for opportunities to provide such devices, especially if they might serve a performance goal such as download reduction during hovering flight.

\section{Summary}

Flight operations, performance, and handling quality considerations impact civil rotorcraft design with design constraints not immediately apparent from basic mission requirements of range, speed and payload. One engine inoperative operations requirements may define alternative mission weights. Flight stability, dynamics and controls considerations may limit allowable aeroelastic mode frequencies. Noise abatement and instrument operations may place even greater constraints on stability requirements and blade control concepts. While handling qualities and operations issues may not drive the initial design, these considerations properly belong in the design iteration loop once a basic configuration has been defined. 


\title{
Risk Reduction Tasks For High Torque, Lightweight Drive System (Propulsion, Figure B3)
}

\author{
PROPUlSION: INNOVATIVE CONCEPTS For LIGHT-WEIGHT, High-TORQUE, LOW MAINTENANCE AND COST
}

Justification: Heavy lift rotorcraft design requires an innovative configuration to handle high torque at low weight, with variable speed operation capability. Propulsion system weight, cost, and efficiency depend on technology gains from advanced components. Advanced materials, processing and design can result in substantial cost reduction and improved reliability.

Design-Transmission and Engine System Configuration Study

Variable speed drive system concept definition (Y1)

Define mechanism components, weight penalties, operational characteristics, location for mechanism, fail-safe operation

Variable speed engine capability defined (Y1)

Define speed range capability, SFC penalties, identify risk reduction issues for implementation in Heavy Lift RC

Choose drive system or engine speed or a combination to meet heavy lift rotorcraft requirements (Y1)

Component Development and Concept Validation

Choose component development/advanced concepts that provide increased capabilities for power to weight, lower cost, and increased reliability (Y1-4)

Choose concept(s) to achieve variable/multi-speed operation of the propulsion system (Y2)

Analyze, design, and fabricate variable speed concepts (Y2-3)

Conduct sufficient parametric tests to ensure scale effects are understood (Y3-4)

TRANSMission: ScAle Sub-System VALIDATION, Full SCALE TECHNOLOGY DEMONSTRATION

Justification: Advanced configurations necessary for heavy lift rotorcraft propulsion will require scaled subsystem development and validation followed by full system testing of the advanced variable/multi-speed propulsion system.

Small Scale Demonstration/Transmission Arrangements

Choose scale demonstration concept arrangement(s) (Y3-4)

Develop scale demonstration system configuration test arrangement (Y4)

Design and fabricate scaled variable speed concept(s) (Y4-5)

Validate speed change propulsion system operation using scaled loading to correctly represent vehicle characteristics (Y5-6)

Full Scale Propulsion Demonstration

Choose full scale demonstration configuration (Y5)

Using concept validated in scale test-develop design of full scale proof-of-concept propulsion system (Y5-6) 
Design and fabricate current or new system to test the heavy lift rotorcraft propulsion system (Y6-7)

Conduct life cycle, over-load, and loss-of-lube testing for drive system qualification (Y7-9)

\section{Risk Reduction Tasks For High Performance, Structurally Efficient Rotor/Wing System (Structures, Figure B4)}

MATERIALS CHARACTERIZATION AND INSERTION: IMPROVED STIFFNESS, STRENGTH, DuRABILITY, DAMAGE TOLERANCE

Justification: Material characterization data are prerequisite to advances in damage tolerance and durability.

Material Characterization

Composite delamination

Delamination in composite components, and debonding in bonded joints, for materials used in validation of analytical tools and TRL benchmark demonstrations (Y1)

Delamination fracture toughness and fatigue resistance of the embedded sensor-to-composite bond for composite materials with embedded sensors (Y2)

Delamination in composites with through-thickness reinforcement under mode I, mode II and mixed-mode I and II loading conditions, both static and fatigue (Y2-3)

Material and failure mode for fiber-metal laminates (Y3), for selectively reinforced metals (Y4-5)

Non-structural properties of multifunctional materials (such as damping, EM shielding, energy attenuation, $\mathrm{RF}$ radiance/attenuation) (Y6-7)

Material Screening

Identify advanced fiber metal laminates that have improved stiffness, strength, durability, damage tolerance and lower density (Y2)

Identify multifunctional materials (structural plus electrical, damping, sensing, etc.) (Y2)

Identify advanced in-situ selectively reinforced metals that have improved stiffness, strength, durability, damage tolerance and lower density (Y4-5)

Manufacturing Process Development

Very large, complex, integrated rotating components (blades \& hubs) and non-rotating structure (such as bulkheads, frames, roof structure) (Y2)

Develop methods for enhancing delamination resistance for all three fracture modes using throughthickness reinforcement concepts (Y2)

Laminated metals (Y3)

Highly anisotropic tailored components (Y3-5)

Prepreg from fiber reinforced materials with self-healing matrices cured at autoclave temperatures (Y4-5)

In-situ selectively reinforced metals (Y4-5) 


\section{DURABILITY AND DAMAGE TOLERANCE (D\&DT)}

Justification: Certification requirements for damage tolerance must be satisfied to achieve a viable lightweight rotor system and airframe. Improvements in durability and damage tolerance key to effective utilization of advanced materials.

Low Velocity Impact

Evaluate impact damage resistance and identify unique impact damage modes of new structural/construction concepts and joints (Y1-2)

Conduct composite post-impact static and fatigue testing to determine critical damage modes that affect strength and life (Y2)

Evaluate effects of panel size and curvature on the impact response of new structural/construction concepts and joints (Y4-5)

Continue evaluation of impact damage resistance and identify unique impact damage modes of new structural/construction concepts, joints, stiffeners, cutouts, and large attachments (Y4-5)

Improve and verify the analytical models for impact damage resistance and damage tolerance (Y6-7)

Fatigue

Investigate spectrum loading effects on typical flexible structures for rotorcraft (flexbeams, blades, wing components, etc.) (Y2)

Manufacture coupon-size flexible components with embedded sensors and conduct fatigue tests to determine durability of the component and sensor (Y2)

Manufacture and test composite stringer pull-off specimens with self-healing matrices and z-pin reinforcement (Y2)

Fabricate and test rotor and wing components with implanted flaws to determine the effect of typical manufacturing flaws on fatigue life (Y4-5)

Develop probabilistic methods for structural certification (Y4-5)

Develop fatigue life methodology to establish accept/reject criteria for manufacturing flaws in rotor and wing components (Y6-7)

Demonstrate enhanced damage tolerance and durability provided by through-thickness reinforced, self-healing, polymeric matrix composites via test and analysis of heavy lift rotorcraft structural components (Y6-7)

Structural EFFiciency: InNOvative Concepts For Light-Weight, Durable, Reliable, Low MAINTENANCE STRUCTURES

Justification: Heavy lift rotorcraft will require significant weight reductions in rotor system, airframe, and wing to be feasible. Structural design concepts are required that make use of the advances in damage tolerance and durability.

Design Concepts

Develop structural concepts (wing/fuselage skins, joints, cutouts, concentrated load points, frame skin interface discontinuities) 
For components made with fiber-metal laminates (Y2)

Utilizing multifunctional structures (Y2)

Utilizing smart/adaptive structures (Y3)

For joining (bonded \& bolted) anisotropic \& isotropic composites and metals for tailored structure (Y2)

For components made with selectively reinforced metals (Y4-5)

Analytical investigation of buckling (and post buckling) strength of anisotropic panels for tailored structure (Y3)

Design, fabricate, and test

Anisotropic panels for tailored structure (Y4-5)

Tailored box beam with anisotropic top and bottom panels and balanced laminated in the other panels (Y4-5)

Structural elements and small components using selectively reinforced laminated metals (Y6-7)

Tailored rotor blade spar section (Y6-7)

Tailored wing box beam and rotor blade spar (Y6-7)

\section{Risk Reduction Tasks For High Performance, Structurally Efficient Rotor/Wing System (Aeromechanics, Figure B5)}

\section{AERODYNAMIC EFFICIENCY: EFFICIENT ROTOR AND AIRCRAFT}

Justification: Aerodynamic efficiency is key to economically-competitive heavy lift rotorcraft. Aerodynamic database and analysis tools are inadequate for design of heavy lift rotorcraft. Airframe drag levels required have not yet been achieved by rotorcraft industry. Edgewise rotor hub drag at level of current helicopters would not be acceptable.

\section{Optimized Efficient Rotors}

Rotor system optimized for aerodynamic efficiency in hover and cruise (Y2-3)

Airfoils (appropriate LCTR/LCTC/LABC hover and cruise environment; maneuver capability in edgewise flight; high Reynolds number; high advance ratio for LCTC/LABC)

Geometry (including planform and twist, integrated with dynamics; for hover and cruise environment)

Minimize aerodynamic interference (including rotor/wing for LCTR/LCTC, rotor/rotor, rotor/tail, rotor/engine, rotor/prop interference for LCTC/LABC)

Minimize download

Aerodynamic performance tests and validated design/analysis tools

Medium to large scale wind tunnel tests, with representative blade and control system dynamics; define and confirm aerodynamic behavior and predictive capability (Y3-5) 
Medium to large scale wind tunnel tests, define and confirm aerodynamic behavior and predictive capability utilizing advanced technology (Y6-7)

LABC: Active control (including 2/rev IBC) to improve cruise performance

LCTC/LABC Hub Drag Reduction

Identify candidate passive (fairings) and active flow control methods (Y1)

Analysis and component tests to develop low drag concepts (Y2-3)

Large scale tests to demonstrate concepts (Y3-4)

Efficient Airframe

Analysis and optimization, including interference (Y2)

LCTR spinner drag reduction (Y2-3)

Small scale and component tests (Y2-3)

Complete airframe wind tunnel test (Y4)

LCTC/LABC auxiliary propulsion

Efficient, low noise propellers for cruise propulsion (Y2-5)

\section{Risk Reduction Tasks For High Performance, Structurally Efficient Rotor/Wing System, and For Super-Integrated Vehicle Management System (Aeromechanics, Figure B5)}

DynAmics AND LOADS: Light-WeIght, StRONG, StABLE, LOW MAINTENANCE Rotor System

Justification: Low weight-fraction for rotor system crucial to economically-competitive design. Consequence of substantially reduced weight and low disk loading is large, lighter rotors with novel hub and control concepts. Such rotors will have radically altered dynamic characteristics compared to current rotors. Objective is design that is inherently stable and takes advantage of active load control to minimize loads and hence weight.

Design: Blade and hub concept (Y1)

Solution to stability issues (LCTR whirl flutter, LCTC high advance ratio)

Solution for strength and weight

LABC: Structural coupling concept to maximize transient blade tip clearance

Design: Load control (Y1)

Requirement for active control of loads; approach (flight condition limit, active load control, other)

Aeroelastic stability demonstration

Small scale wind tunnel test of representative system (Y2-3)

Load active control and automatic limiting

Develop control concepts (Y1-2) 
Including hub moment control and rotor state feedback

Compatible with handling qualities and maneuver requirements

Small scale tests

Medium or large scale wind tunnel tests to demonstrate capability and stability (Y3-7)

Flight tests to demonstrate load control, including maneuvers (Y4)

ACTIVE CONTROL: NOISE AND VIBRATION CONTROL

Justification: Noise and vibration requirements can not be met by design parameter selection or passive techniques. Active control will be required.

Design: Vibration and Noise Control (Y1)

Requirement (noise, vibration, gust, performance control)

Control method (IBC or on-blade or airframe)

Develop and Demonstrate Active Control

Control development for selected approach (Y1-2)

Including integration with flight control system

Wind tunnel tests (Y2-7)

Including integration of noise and vibration control with load alleviation, flapping control, gust response control, performance improvement

Flight tests to demonstrate effectiveness and reliability

UH60-IBC and/or SMART (Y1)

Advanced control method (Y4)

\section{Risk Reduction Tasks For Low Noise Aircraft (Acoustics, Figure B6)}

\section{NOISE CHARACTERIZATION OF LARGE ROTORCRAFT}

Justification: Low external and internal noise are essential for a truly market responsive vehicle. Heavy lift rotorcraft will have unique acoustic characteristics, and the goals are very aggressive.

Flight test measurements of noise of existing heavy lift vehicles (Y1-3)

Exterior noise and interior noise

Low frequency, long range propagation effects

Identify dominant noise sources

Psychoacoustic effects for low frequency noise (Y1-3)

Low frequency noise simulator tests to develop human response database

Assess/develop metrics to model response to low frequency noise exposure

Demonstrate initial noise prediction capability (Y2-4) 
Exterior noise and interior noise

Models of human response

Conducted with aeromechanics and handling qualities tasks

Advanced noise prediction capability (Y2-8)

Wind tunnel tests of aeroacoustics unique to heavy lift

Low noise procedure prediction/optimization methods

Low frequency propagation modeling for community noise impact

Interior noise prediction methods, including effects of passive/active models

\section{NOISE REDUCTION CONCEPTS FOR LARGE ROTORCRAFT}

Justification: Low external and internal noise are essential for a truly market responsive vehicle. Combination of noise reduction technology and safe flight operations is required to achieve community acceptance.

Design: noise reduction (Y1)

Approach (design features, active control); certification and community impact

Design: vibration and noise control (Y1)

Requirement (noise, vibration, gust, performance control); control method (IBC or on-blade or airframe)

Low noise operation procedures (Y2-6)

Identify viable low noise flight operations (includes procedures) / maneuvers (coordinated with handling qualities)

Flight test of initial low noise operations using existing vehicles (Y4)

Interior noise reduction strategies (Y2-6)

Develop viable active/passive interior noise reduction strategies

Small to medium scale component testing of active/passive interior noise reduction (coordinated with structures and propulsion)

Develop and demonstrate active control

Control development for selected approach (Y1-2)

Wind tunnel tests (Y2-7)

Including integration of noise and vibration control with load alleviation, flapping control, gust response control, performance improvement

Flight tests to demonstrate effectiveness and reliability

UH60-IBC and/or SMART (Y1)

Advanced control method (Y4)

Low noise rotor (Y2-8)

Active/passive low noise model rotor concepts and wind tunnel testing 
Refined and optimized active/passive low noise rotor design and wind tunnel testing

Down select for full scale rotor design development and fabrication (Y4)

Flight test demonstration of low noise design approach and operating procedures

Large scale demonstration of interior noise reduction

\section{Risk Reduction Tasks For Super-Integrated Vehicle Management System (Handling Qualities, Figure B7)}

HANDLING QUALITIES AND FLIGHT CONTROLS FOR VTOL OPERATIONS IN CAT IIIC CONDITIONS

Justification: Airframe structural frequencies of large rotorcraft will impact flight control and maneuver frequencies, necessitating an integrated design. Near all-weather operations (Category IIIC) capability needed for commercial schedule reliability, safety, and competition with fixed wing airliners.

Adaptive/robust fully augmented control system, including handling qualities with low rotor and airframe structural frequencies and load limiting or control

Develop and refine certification requirements (Y1)

Flight control system analysis and design (Y2)

Moving-base simulation to explore concepts (Y2-4)

In-flight simulator tests to prove concepts (Y2-6)

Cockpit automation for pilot supervision of complex RIA operations flight tasks in congested airspace

System analysis, design, and simulation (Y2-3)

Flight tests to prove concepts (Y3-6)

OEI/AEI OPERATIONS

Justification: Transport category safety required for certifiable operations.

Develop and demonstrate OEI/AEI requirements and procedures

Analysis, design, and simulation (Y1-2)

Development and demonstration of certification requirements (Y2-4) 


\section{Strategic Direction}

The strategic direction provides guidance for selecting highest priority activities, aimed at the four highest risk areas of heavy lift rotorcraft development. Note that there are some important and difficult tasks that are not yet high risk, including rotor aerodynamic design and optimization, airfoil design, airframe aerodynamics, and airframe structures.

\section{HIGH TORQUE, Light WEIGHT DRIVE SYSTEM}

Innovative design is required for low drive system weight. Large size implies high torque and high weight fraction, hence drive system weight reduction is essential for an efficient and economical aircraft. The focus must be on design concept, advanced-technology components, and materials.

Low maintenance is required for low operating cost. Low maintenance must be a primary design requirement, even ahead of weight and performance.

High flight speed requires, or at least benefits from, a variable speed propulsion system design. First it is necessary to establish the speed range available from advanced engine technology, and to define the engine required for the heavy lift rotorcraft concept.

\section{HIGH PERFORMANCE, STRUCTURALLY EFFICIENT ROTOR/WING SYSTEM}

Innovative rotor and wing design is required, probably with unconventional dynamics. Large size implies high weight fraction, high speed introduces stability issues, and good rotor system performance is essential for an efficient and economical aircraft. The focus must be on integrated rotor/wing performance and dynamic behavior.

Structural efficiency is required for low rotor and hub and wing weight. The focus must be on design concepts for durability and damage tolerance.

Low maintenance is required for low operating cost. Low maintenance must be a primary design requirement, even ahead of weight and performance.

\section{LOW NOISE AIRCRAFT}

New approaches are required to meet the challenge of low noise. Large size implies low frequency noise and expanded acoustic footprint. An understanding of heavy lift vehicle acoustic phenomena (low frequency and relative distance to community) is required, including psychoacoustics for low frequency. New rotor design guidelines and annoyance metrics must be developed. The focus must be on a combination of rotor design, active control, and flight operations.

\section{SUPER-INTEGRATED VEHICLE MANAGEMENT SYSTEM}

Broad spectrum active control is required for an effective heavy lift rotorcraft. Large size implies a significant influence of low frequency airframe elastic modes on flight dynamics. Active control is required to achieve the goals of low rotor-induced vibration and noise. Safe operation in one-engine inoperative conditions is essential for civil rotorcraft. Rotor load limiting and active control are needed for full utilization of the structural capability in the rotor and airframe. Hence an expanded integration of the vehicle management system is required: a flight control system for good handling qualities and gust response, active control of vibration and noise, and rotor load limiting and active control. The focus must be on load limiting and system integration. 


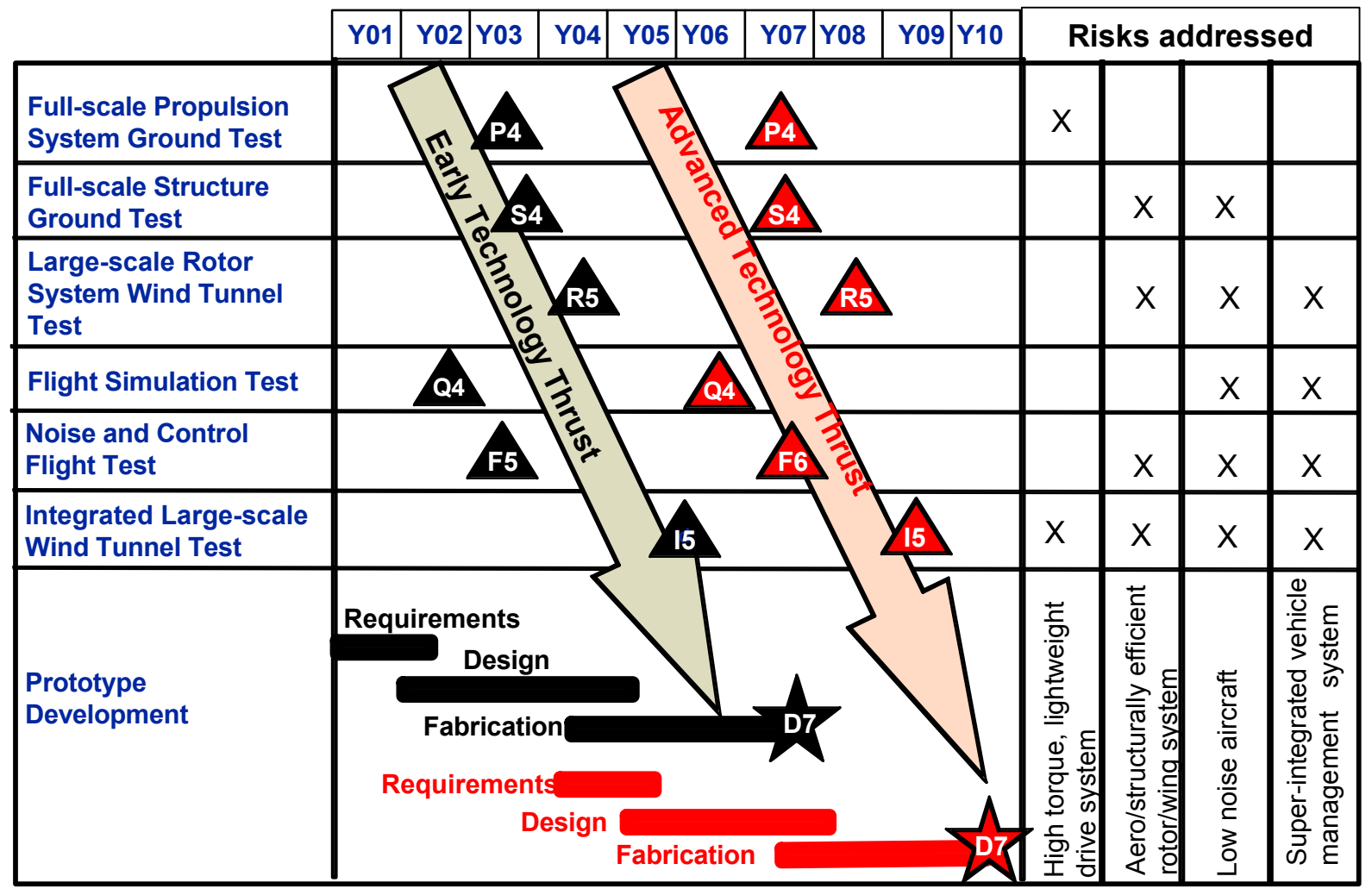

BLACK represents Early Technology; RED represents Advanced Technology; Numbers = TRL

Figure B1. LCTR Technology Readiness Level Benchmarks. 


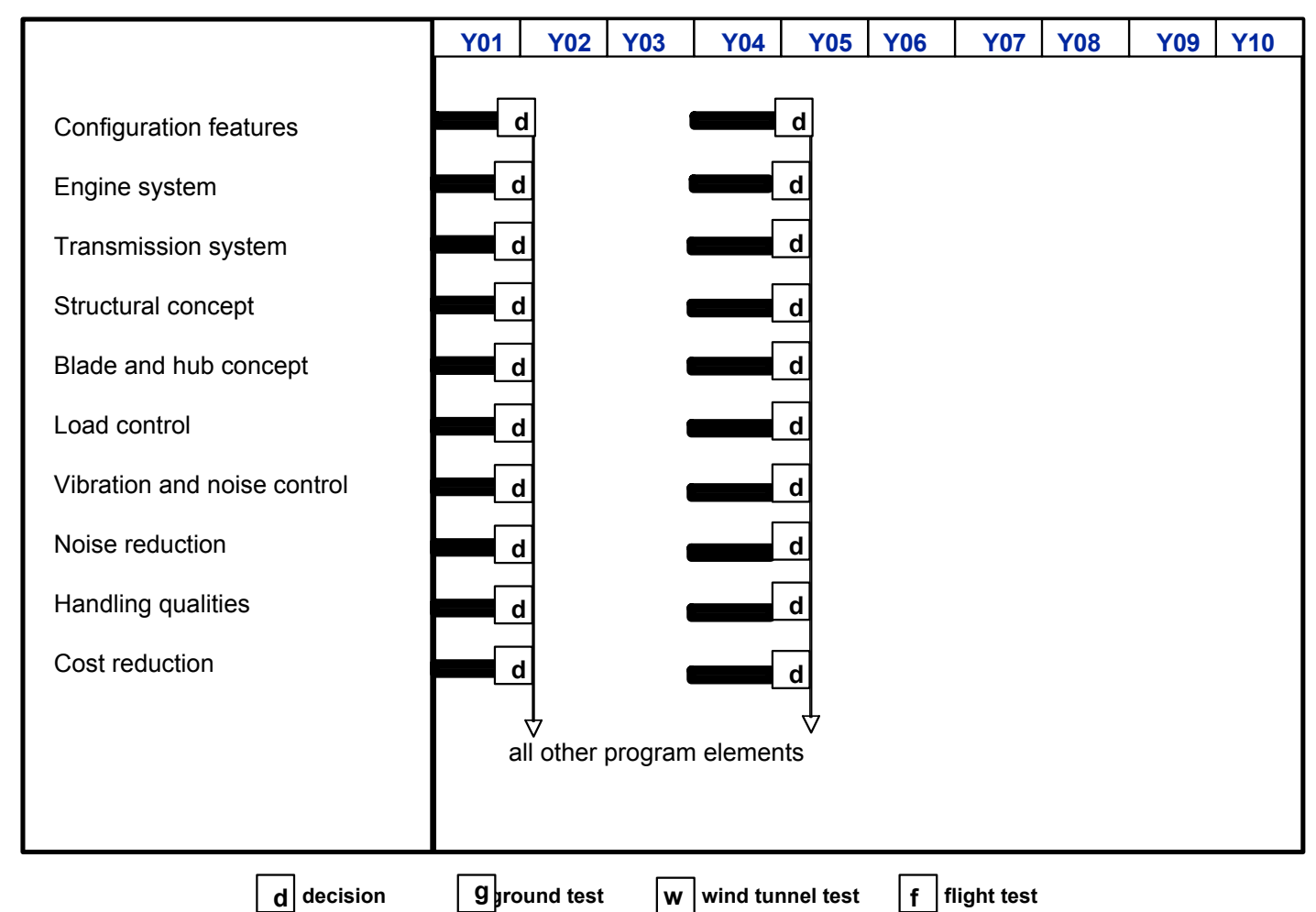

Figure B2. Concept development.

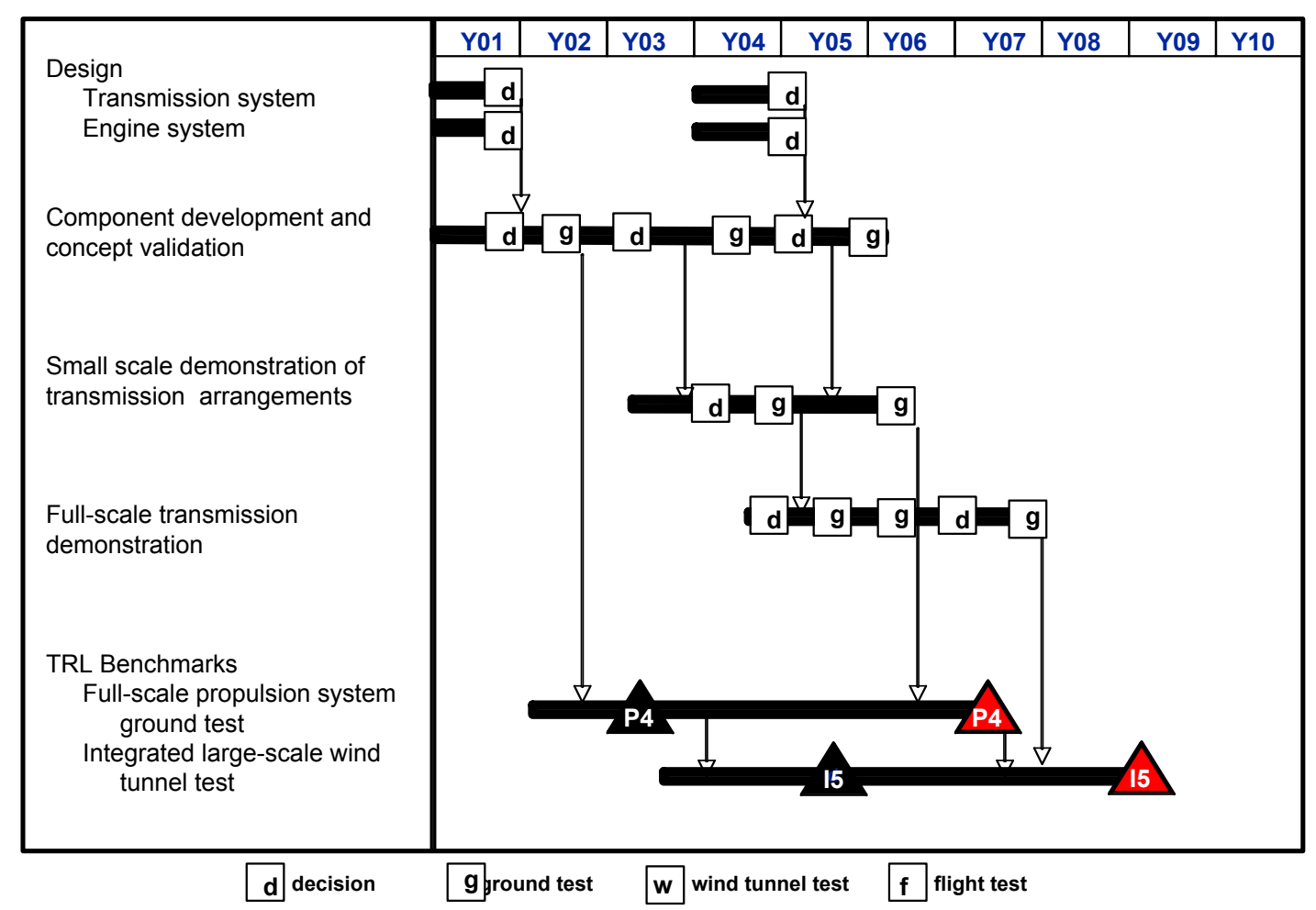

Figure B3. Risk reduction tasks for high torque, lightweight drive system (propulsion). 


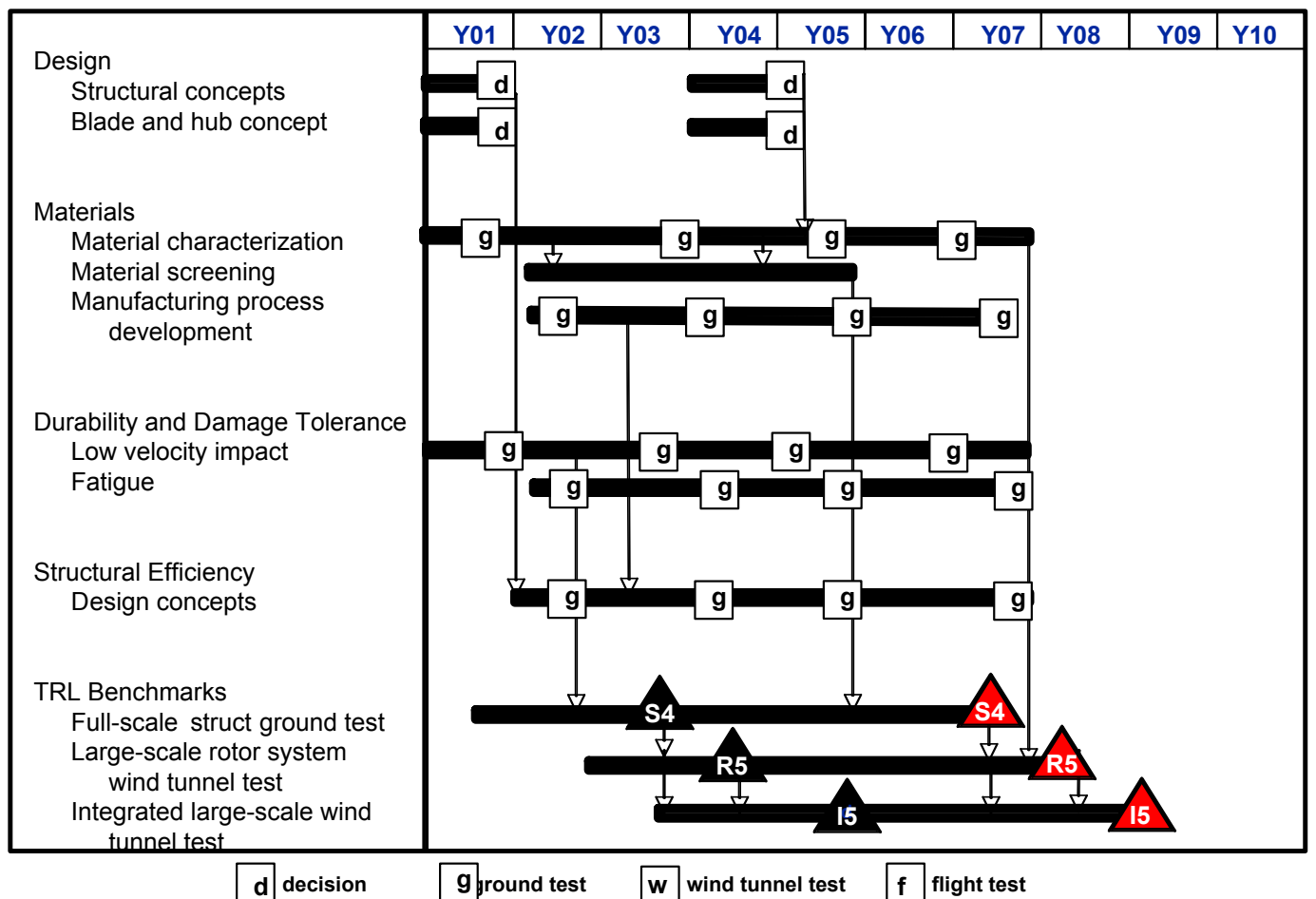

Figure B4. Risk reduction tasks for high performance, structurally efficient rotor system (structures).

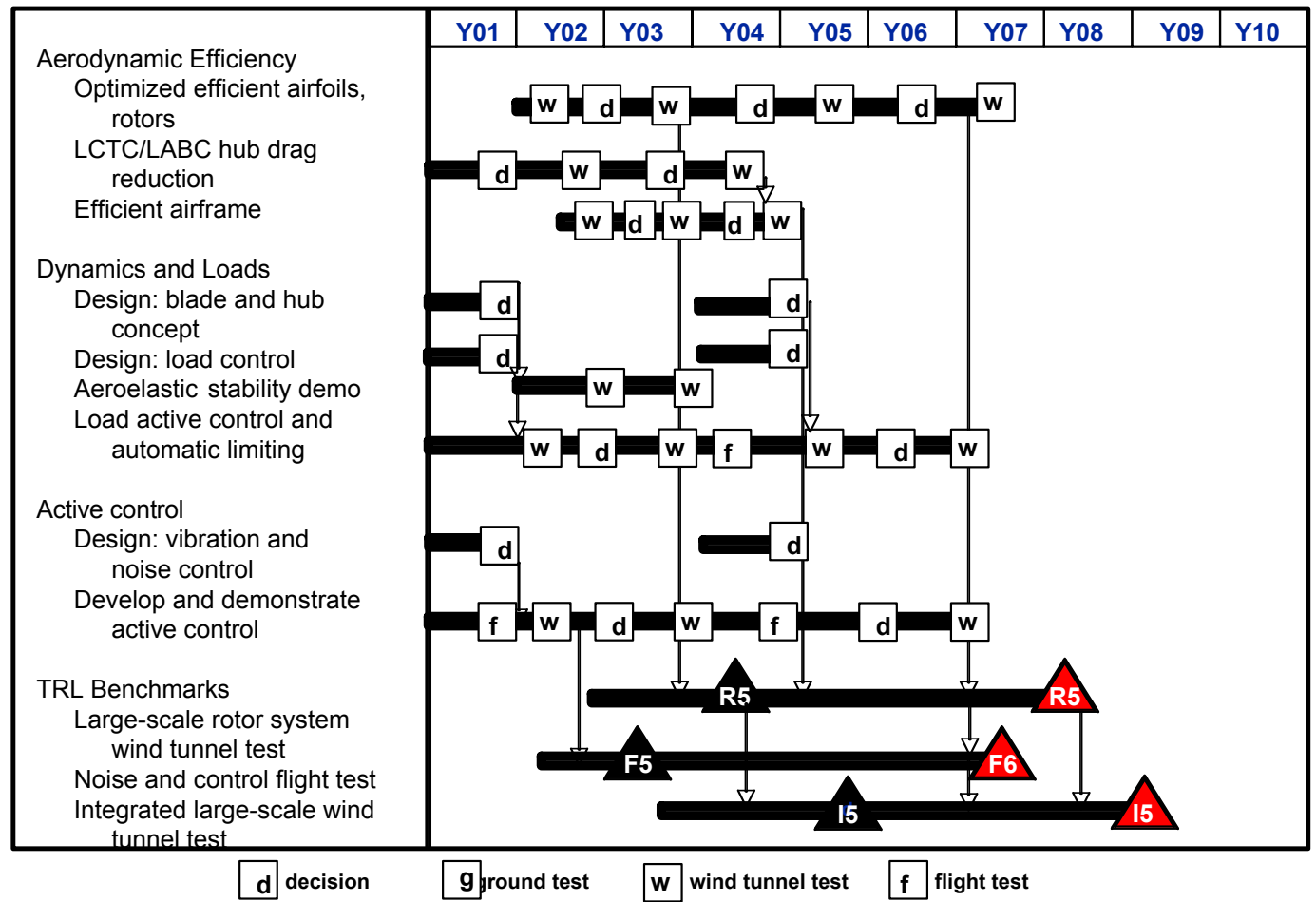

Figure B5. Risk reduction tasks for high performance, structurally efficient rotor system, and for superintegrated vehicle management system (aeromechanics). 


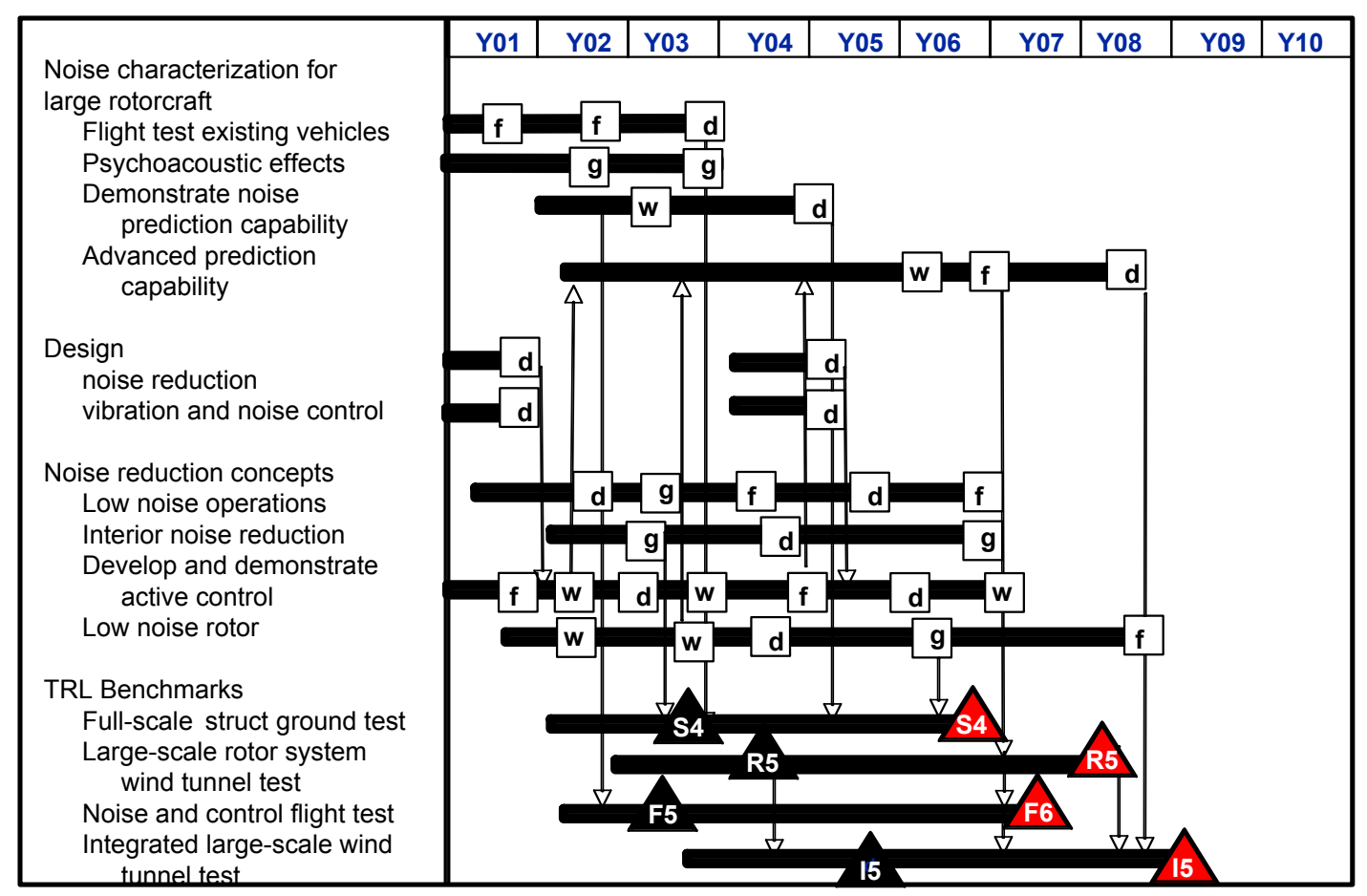

\begin{tabular}{lll}
\hline d decision & g ground test $\quad \mathrm{w}$ wind tunnel test $\quad \mathrm{f}$ flight test
\end{tabular}

Figure B6. Risk reduction tasks for low noise aircraft (acoustics).

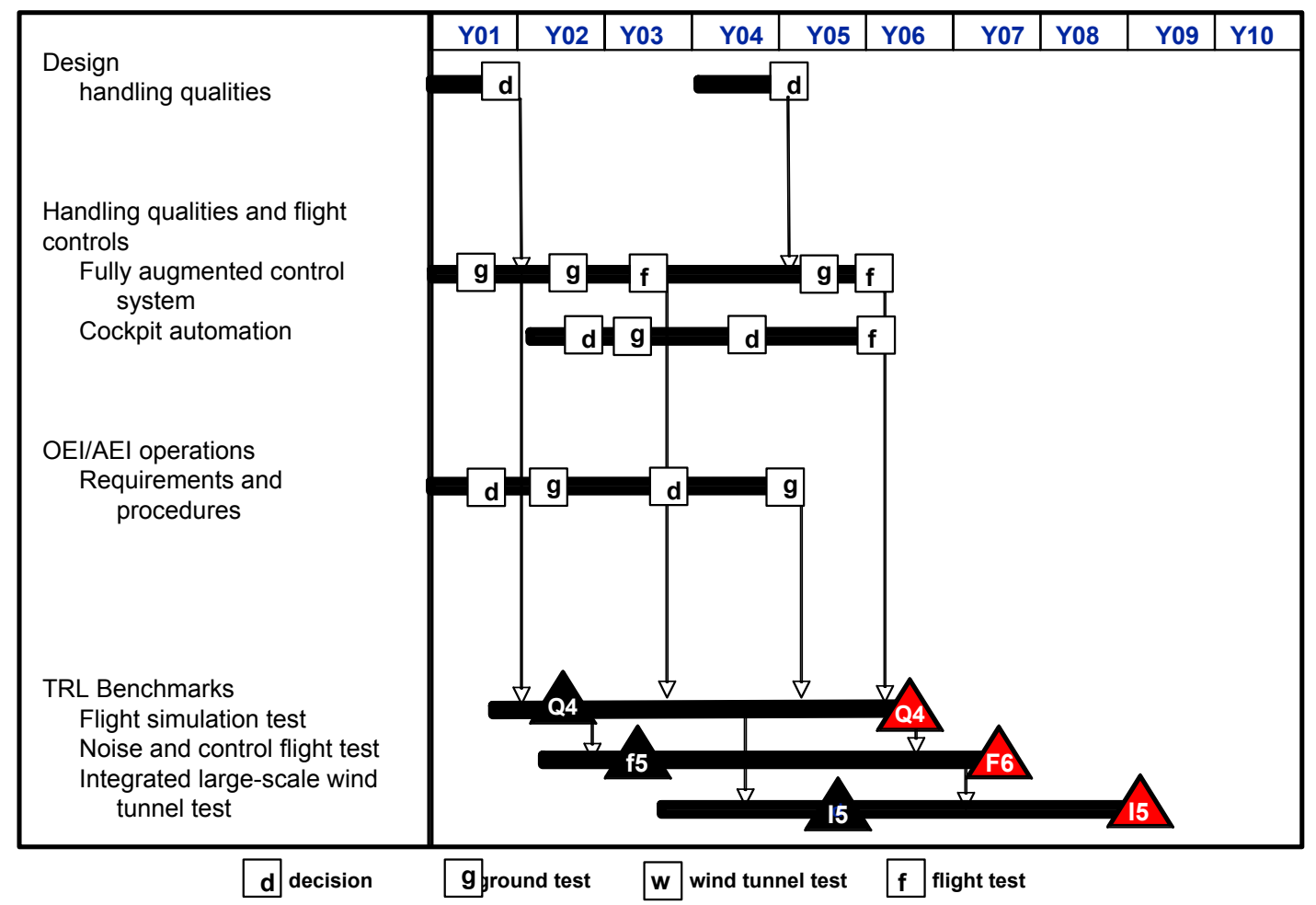

Figure B7. Risk reduction tasks for super-integrated vehicle management system (handling qualities). 
The public reporting burden for this collection of information is estimated to average 1 hour per response, including the time for reviewing instructions, searching existing data sources, gathering and maintaining the data needed, and completing and reviewing the collection of information. Send comments regarding this burden estimate or any other aspect of this collection of information, including suggestions for reducing this burden, to Department of Defense, Washington Headquarters Services,

Directorate for information Operations and Reports (0704-0188), 1215 Jefferson Davis Highway, Suite 1204, Arlington, VA 22202-4302. Respondents should be aware

that notwithstanding any other provision of law, no person shall be subject to any penalty for failing to comply with a collection of information if it does not display a

currently valid OMB control number.

PLEASE DO NOT RETURN YOUR FORM TO THE ABOVE ADDRESS

\begin{tabular}{l|l} 
1. REPORT DATE $(D D-M M-Y Y Y Y)$ & 2. REPORT TYPE
\end{tabular} $12 / 2005$

Technical Publication

3. DATES COVERED (From - To)

\section{TITLE AND SUBTITLE}

NASA Heavy Lift Rotorcraft Systems Investigation

5a. CONTRACT NUMBER

5b. GRANT NUMBER

5c. PROGRAM ELEMENT NUMBER

6. AUTHOR(S)

Wayne Johnson ${ }^{1}$, Gloria K. Yamauchi ${ }^{1}$, and Michael E. Watts ${ }^{2}$

5d. PROJECT NUMBER

5e. TASK NUMBER

5f. WORK UNIT NUMBER

21-065-40-10

7. PERFORMING ORGANIZATION NAME(S) AND ADDRESS(ES)

${ }^{1}$ Ames Research Center

8. PERFORMING ORGANIZATION

REPORT NUMBER

Moffett Field, CA 94035-1000 and

${ }^{2}$ Langley Research Center

A-0514419

1000 NASA Road, Hampton, VA 23681-2199

9. SPONSORING/MONITORING AGENCY NAME(S) AND ADDRESS(ES)

National Aeronautics and Space Administration

Washington, D.C. 20546-0001

10. SPONSORING/MONITOR'S ACRONYM(S)

NASA

11. SPONSORING/MONITORING REPORT NUMBER

NASA/TP-2005-213467

12. DISTRIBUTION/AVAILABILITY STATEMENT

Unclassified — Unlimited

Subject Category 05

Availability: CASI (301) 604-5642

13. SUPPLEMENTARY NOTES

Point of Contact: Wayne Johnson, Ames Research Center, MS243-12, Moffett Field, CA 94035-1000 (650) 604-2242

14. ABSTRACT

The NASA Heavy Lift Rotorcraft Systems Investigation examined in depth several rotorcraft configurations for large civil transport, designed to meet the technology goals of the NASA Vehicle Systems Program. The investigation identified the Large Civil Tiltrotor as the configuration with the best potential to meet the technology goals. The design presented was economically competitive, with the potential for substantial impact on the air transportation system. The keys to achieving a competitive aircraft were low drag airframe and low disk loading rotors; structural weight reduction, for both airframe and rotors; drive system weight reduction; improved engine efficiency; low maintenance design; and manufacturing cost comparable to fixed-wing aircraft. Risk reduction plans were developed to provide the strategic direction to support a heavy-lift rotorcraft development. The following high risk areas were identified for heavy lift rotorcraft: high torque, light weight drive system; high performance, structurally efficient rotor/wing system; low noise aircraft; and super-integrated vehicle management system.

15. SUBJECT TERMS

Heavylift rotorcraft, Design, Tiltrotor, Compound helicopter, Advancing blade concept

\begin{tabular}{|l|l|l|}
\hline \multicolumn{2}{|l|}{ 16. SECURITY CLASSIFICATION OF: } \\
\hline a. REPORT & b. ABSTRACT & c. THIS PAGE \\
Unclassified & Unclassified & Unclassified \\
\hline
\end{tabular}

17. LIMITATION OF
ABSTRACT

Unclassified

\begin{tabular}{|l|l|}
$\begin{array}{l}\text { 18. } \begin{array}{l}\text { NUMBER } \\
\text { OF } \\
\text { PAGES }\end{array} \\
106\end{array}$ & $\begin{array}{l}\text { 19a. NAME OF RESPONSIBLE PERSON } \\
\text { Wayne Johnson }\end{array}$ \\
\cline { 2 - 2 } & $\begin{array}{l}\text { 19b. TELEPHONE (Include area code) } \\
(650) 604-2242\end{array}$
\end{tabular}

Standard Form 298 (Rev. 8-98)

Prescribed by ANSI Std. Z39-18 